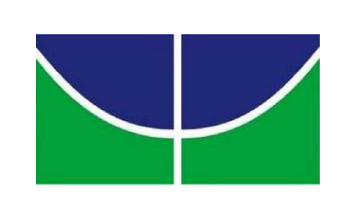

\author{
Universidade de Brasília \\ Instituto de Física
}

\title{
Estudo das Anomalias da Água Utilizando Dois Modelos em Rede Unidimensional
}

\section{Fernando Barbosa V. da Silva}

Orientador: Dr. Fernando Albuquerque de Oliveira Co-orientador: Dr. Marco Aurelio Alves Barbosa.

Tese de Doutorado apresentado ao Instituto de Física da Universidade de Brasília (UnB).

Brasília

2016 
Dedicado a pequena Sarah detentora da mente mais fantástica que já conheci. 


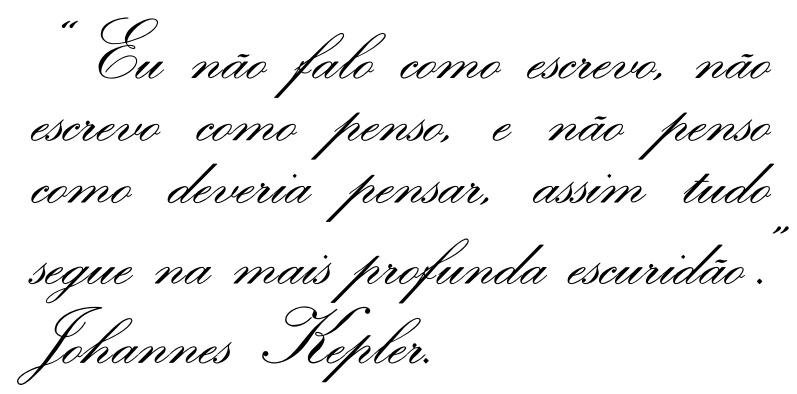

\section{AGRADECIMENTOS}

Há tantas pessoas que merecem meus mais sinceros agradecimentos por ter conseguido concluir mais esta etapa da minha vida.

Minha família, que é meu porto seguro e sei que nas horas difíceis sempre estão ao meu lado. Minha mãe que batalhou muito para que hoje pudesse estar aqui escrevendo esta tese. Meu irmão e minhas irmas obrigado por todos os ensinamentos de vida.

Obrigado todos da confraria dos físicos malditos (CFM) que sempre estão a disposição para compartilhar o conhecimento.

Meus Orientadores, Fernando, Marco e Andre, obrigado por ter tanta paciência com esse pobre rapaz, sei do grande desafio que foi tentar fazer com que um pouco de conhecimento entrasse nessa cabeça dura.

Obrigado a todos que passaram por minha vida, pois cada um deixa sempre um pouco de si e assim contribui com o que nos tornamos hoje.

Agradeço ao CNPQ pelo apoio financeiro durante todo Doutorado. 


\section{RESUMO}

Desenvolvemos nesta tese dois modelos de fluido em rede com intuito de estudar as anomalias termodinâmicas e dinâmicas da água. Os modelos foram propostos com vista à simplificação de modelos já existentes, portanto, nosso trabalho principal foi demonstrar que um modelo com potencial que apresenta somente uma interação repulsiva entre primeiros vizinhos pode reproduzir as anomalias conhecidas da água.

Realizamos simulações computacionais, utilizando o Método de Monte Carlo, com código do programa escrito em linguagem C, para estudarmos a dinâmica do modelo. Com isso fomos capazes de ver o comportamento anômalo na difusão, onde temos um aumento da difusão quando aumentamos a densidade do sistema. Esse tipo de comportamento é semelhante ao encontrado em outros modelos com outras formas de interação mais complexas.

A termodinâmica foi estudada através de cálculos analíticos e, para tal, fizemos uso da técnica da matriz de transferência, que nos possibilitou encontrarmos as soluções exatas das funções de resposta, da densidade e da entropia do sistema. As funções respostas estudadas foram: a compressibilidade isotérmica e o coeficiente de expansão térmica, pois elas são as de maior interesse no estudo de fluidos. Todas as propriedades termodinâmicas apresentaram comportamento típico de água, tal comportamento é considerado anômalo quando comparado à de outros fluidos considerados normais. 


\section{ABSTRACT}

We developed this thesis two models of fluid network aiming to study the thermodynamic and dynamic anomalies of water. The models have been proposed to simplify the existing models, therefore our main work was to demonstrate that with a potential model that only has a repulsive interaction between first neighbors can reproduce the known anomalies of water.

We performed computer simulations using the Monte Carlo method, with program code written in $\mathrm{C}$ language, to study the dynamics of the model. Thus we were able to see the anomalous behavior in broadcasting, where we have increased the spread when we increase system density. This type of behavior is similar to that found in other models of other more complex forms of interaction.

Thermodynamics was studied by analytical calculations and for that, we use the technique of the transfer matrix, which enabled us to find the exact solutions of the response functions, density and system entropy. The functions responses were: the isothermal compressibility and the thermal expansion coefficient, as they are the most interested in the fluid study. All thermodynamic properties exhibited behavior typical of water, such behavior is considered anomalous when compared to other fluids considered normal. 


\section{Sumário}

\begin{tabular}{lll}
\hline & INTRODUÇÃO & 1
\end{tabular}

2 TÓPICOS DE TERMODINÂMICA E MECÂNICA ESTATÍSTICA 13

2.1 Relações Termodinâmicas . . . . . . . . . . . . . . . . . . . . . . . . 13

2.1 .1 Potenciais Termodinâmicos . . . . . . . . . . . . . . . . . . . 15

2.1 .2 Funções Resposta . . . . . . . . . . . . . . . . . . . . . . . . . . . 16

2.2 Ensemble Grande Canônico ． . . . . . . . . . . . . . . . . . . . . . 17

2.3 Técnica da Matriz de Transferência. . . . . . . . . . . . . . . . . . . . . . 18

3 MODELO DE GÁS DE REDE 20

3.1 Gás de Rede com "Caroço Duro" . . . . . . . . . . . . . . . . . . . . . . 20

3.1 .1 Gás de Rede Atrativo . . . . . . . . . . . . . . . . . . . . . . . . . 22

3.2 Modelos de Água em Rede . . . . . . . . . . . . . . . . . . . . . . . . . 23

4 MODELOS DE ÁGUA EM REDE UNIDIMENSIONAL 25

4.1 Motivação . . . . . . . . . . . . . . . . . . . . . 25

4.2 Modelo com duas interações atrativas . . . . . . . . . . . . . . . . . . 25

$4.2 .1 \quad$ Pressão crítica e Densidade . . . . . . . . . . . . . . . . . . . 29

4.2 .2 Coeficiente de Expansão Térmica e Compressibilidade Isotérmica 31

4.2 .3 Dinâmica . . . . . . . . . . . . . . . . . . . . . . . . . . . . . . . 33

4.2 .4 Conclusões . . . . . . . . . . . . . . . . . . . . . . . . . . . 36

$4.3 \quad$ Modelo com interação repulsiva entre primeiros vizinho $\ldots$. . . . . . . . . 37

$4.3 .1 \quad$ Pressão crítica e Densidade . . . . . . . . . . . . . . . . . . . . . 40

4.3 .2 Cálculo da Entropia $\ldots$. . . . . . . . . . . . . . . . . . . . . . . 42

4.3 .3 Coeficiente de Expansão Térmica e Compressibilidade Isotérmica 45

$4.3 .4 \quad$ Estrutura líquida . . . . . . . . . . . . . . . . . . . . . . . . 48

4.3 .5 Dinâmica . . . . . . . . . . . . . . . . . . . . . . . . . . . . . . . 49

4.3 .6 Conclusões . . . . . . . . . . . . . . . . . . . . . . . . . . . . . . . 54 
$\begin{array}{lll}5 & \text { CONCLUSÕES } & 56\end{array}$

\begin{tabular}{|ll}
\hline A Método de Monte Carlo & 59
\end{tabular}

A.1 Algoritmo de Metropolis . . . . . . . . . . . . . . . . . . . . . . 61 


\section{Lista de Figuras}

1.1 Diagrama de fases P vs T da água. Retirado da referência |1] . . . . . . . 2

1.2 Molécula de água. . . . . . . . . . . . . . . . . . . . . . . . 2

1.3 Estrutura tetraédrica da molécula de água. Formação de pontes de hidro-

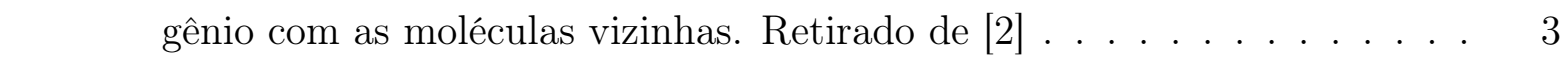

1.4 Dependência da densidade em função da temperatura a pressão ambiente. Figura retirada da referência $\mid 3]$. . . . . . . . . . . . . . . 4

1.5 Coeficiente de difusão pela pressão obtido de dados experimentais por Angell at al. $[4 \mid \ldots \ldots \ldots \ldots$. . . . . . . . . . . . . . 5

1.6 Dependência do coeficiente difusão com a densidade, oito isotérmicas são mostradas. De cima para baixo as temperaturas T (K) são, 400, 350, 320, 300, 280, 260, 240 and 220. Retirado de [5] . . . . . . . . . . . . . 6

1.7 Compara o comportamento da densidade, do coeficiente de expansão térmica, da compressibilidade isotérmica, e da capacidade térmica a pressão constante, de um fluido simples com a água. Extraído de $|3|$. . . . . . . 7

1.8 Diagrama de fase P-T (unidades reduzidas). Hipótese do segundo ponto crítico, $\epsilon>0$ é a energia caracteristica. Retirado da referência $\mid 6 \square$. . . 8

1.9 Conjectura da estabilidade limite. Retirado de |7] . . . . . . . . . . . . 9

1.10 Anomalia na estrutura. Retirado de $[8]$. . . . . . . . . . . . . . . . 10

1.11 Relação entre as anomalias no plano T vs $\rho$ no modelo SPC/E. Anomolia estrutural é localizada por uma região entre o parâmetro de ordem orientacional máximo $q_{\max }$ (triângulos para cima) e parâmetro de ordem trânslacional minimo $t_{\min }$ (triângulo para baixo). Na água dentro dessa região encotra-se a região de anomalia da difusão, localizada entre a difusão máxima $D_{\max }$ (quadrados pequenos) e mínima $D_{\min }$ (circulos). Logo abaixo vemos a região de anomalia na densidade, localizada pela linha de Temperatura de Máximo de Densidadde (TMD) (quadrados). Modificado da referência [5] . . . . . . . . . . . . . . . . . . . 10 
1.12 Hierarquia de Anomalias no modelo TIP5P. Observamos a região de anomalia estrutural envolvendo a região de anomalia na difusão, que por sua vez envolve a região de anomalia na densidade. Retirado de $\mid 9]$. . . . . . 11

4.1 rede linear. As partículas são representadas por círculos pretos . . . . . . 26

4.2 Potencial em função da distância . . . . . . . . . . . . . . . . . . 26

4.3 Densidade em função da temperatura para três pressões distintas. $p=$

\begin{tabular}{|c|}
\hline 0.45 (ponto e linha), $p=p_{c}=0.50$ (linha tracejada), $p=0.55$ (linha \\
\hline cheia). Para $p=0.5$, observamos um comportamento de um fluido normal, \\
\hline
\end{tabular}
com a densidade diminuindo com aumento da temperatura. . . . . . . . . 30

$4.4 \quad$ Densidade em função da pressão para três temperaturas distintas. $t=0.3$

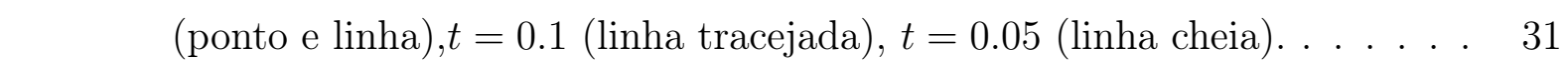

4.5 Coeficiente de expansão térmica em função da pressão com temperatura

\begin{tabular}{|cc|}
\hline fixa. $\mathrm{t}=0.02$ (linha cheia), $\mathrm{t}=0.05$ (linha tracejada), $\mathrm{t}=0.1$ (linha ponto- \\
\hline
\end{tabular}

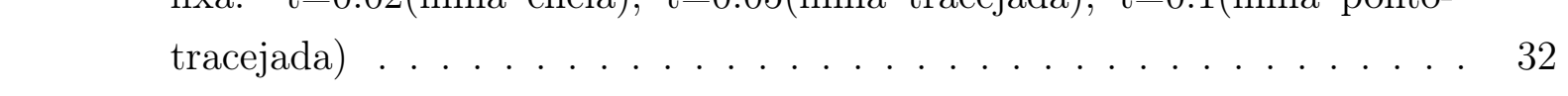

4.6 Compressibilidade isotérmica em função da temperatura mantendo a pres-

\begin{tabular}{|c|c|}
\hline são fixa. $p=0.45$ (ponto e linha), $p=0.50$ (linha tracejada), $p=0.55$ \\
\hline
\end{tabular}
(linha cheia) $\ldots \ldots \ldots \ldots \ldots . \ldots \ldots 33$

4.7 Difusão em função da densidade . . . . . . . . . . . . . . . . . . . . . . . . . . . 35

4.8 hierarquia de anomalias no diagrama de fase $\mathrm{t} v \mathrm{vs}$. . . . . . . . . . . 36

4.9 rede linear. As partículas são representadas por círculos pretos . . . . . . 37

4.10 Representação do potencial de interação entre as moléculas da rede no

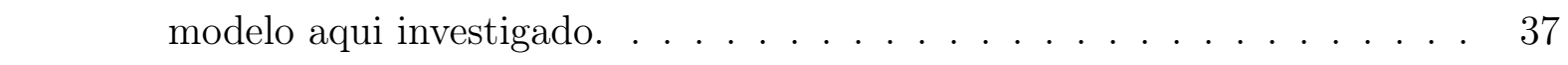

4.11 Densidade em função da temperatura para três pressões distintas. Para

\begin{tabular}{|c|}
\hline $\mathrm{P}=1.1$, observamos um comportamento de um fluido normal, com a den- \\
\hline
\end{tabular} sidade diminuindo com aumento da temperatura. . . . . . . . . . . . . . 41

4.12 Entropia em função da pressão, com temperatura fixa, soluções exatas

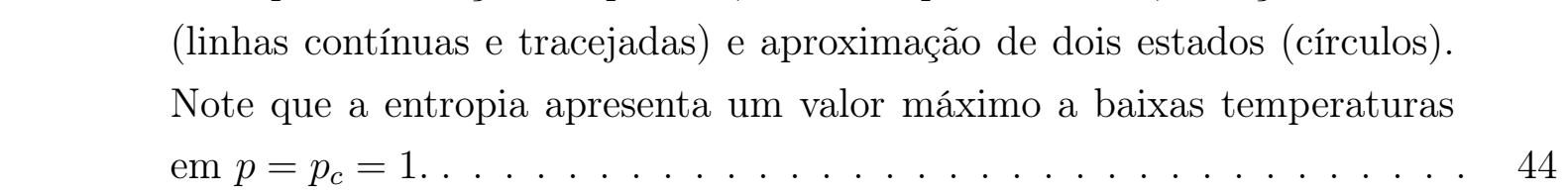

4.13 Coeficiente de expansão térmica em função da pressão com temperatura

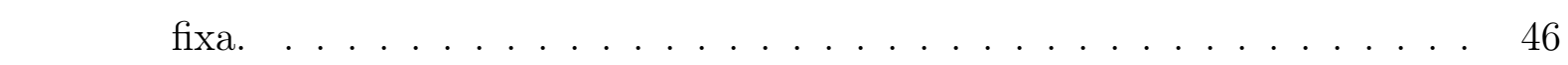

4.14 Compressibilidade isotérmica em função da temperatura . . . . . . . . . 47

4.15 Temperatura de máximo de densidade TMD . . . . . . . . . . . . . . . . 48

4.16 Potencial de Gibs em uma dimensão em função da distância entre as

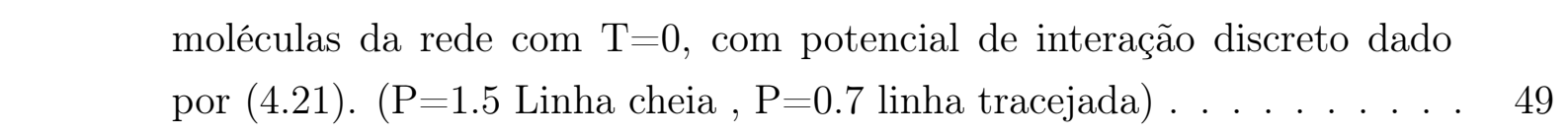


4.17 Deslocamento quadrado médio em função do tempo (passos de monte carlo) na escala logarítmica. Do lado direito a temperatura é igual 0.3, do lado esquerdo a temperatura é igual a $0.8 \ldots \ldots$. . . . . . . . . . . 51

4.18 Difusão pela densidade, para modelo unidimensional com interação repulsiva entre primeiros vizinhos . . . . . . . . . . . . . . . . . . 52

4.19 Hierarquia de anomalias no diagrama temperatura vs densidade. Máximo (círculos) e mínimo (quadrados) de difusão comparado com a TMD (linha contínua) . . . . . . . . . . . . . . . . . 53 


\section{Capítulo 1}

\section{INTRODUÇÃO}

A água uma das substâncias mais comuns da terra, tem sua importância reconhecida desde a antiguidade, sendo um dos quatro elementos aristotélicos, juntamente com fogo, terra e ar, a água é um elemento essencial para sobrevivência de todas as formas conhecidas de vida. Sua distribuição pelo planeta terra, que tem aproximadamente $70 \%$ da superfície coberta por água [10] nos faz entender uma preocupação constante sobre uma possível falta para o consumo. A grande maioria da água liquída esta localizada nos oceanos, que concentram aproximadamente $97 \%$ do total, as calotas polares e glaciais armazenam 1,74\% na forma de gelo, restando então apenas 1\% de água doce, sendo que estima-se somente $0,02 \%$ do total, de fácil acesso para consumo. Ela pode ser encontrada no meio ambiente em três fases, quais sejam, na forma líquida (rios, lagos), sólida (calotas polares, lagos congelados) e gasosa (nuves, atmosfera terrestre). O diagrama de fase da água é bastante complexo, principalmente na sua fase sólida onde a água apresenta diversas estruturas diferentes para o gelo [3], marcadas com algarismos romanos, como pode ser visto na figura 1.1. Podemos observar nessa figura duas fases marcadas com Ic (ice cubic) gelo cúbico e Ih (ice hexagonal) gelo hexagonal. A existência destas configurações para o gelo é uma pista que indica haver alguma competição entre formas de interação molecular.

A água também é uma das menores moléculas, formada por somente um oxigênio e dois hidrogênios, figura 1.2 , resultando na fórmula molecular $\mathrm{H}_{2} \mathrm{O}$. O ângulo HÔH da molécula de água é de $104.5^{\circ}$, (figura 1.2 e a distância entre o oxigênio e o hidrogênio é de $0,957 \AA[3]$. Na formação da molécula o átomo de hidrogênio compartilha seu elétron com um elétron do átomo de oxigênio afim de torna-se mais estável, então os eletrons ficam numa região próxima a ambos os núcleos, caracterizando uma ligação covalente. Como o oxigênio é mais eletronegativo que o hidrogênio temos uma distribuição eletrônica não homogênea na molécula, sendo formada uma densidade de carga positiva sobre o átomo 


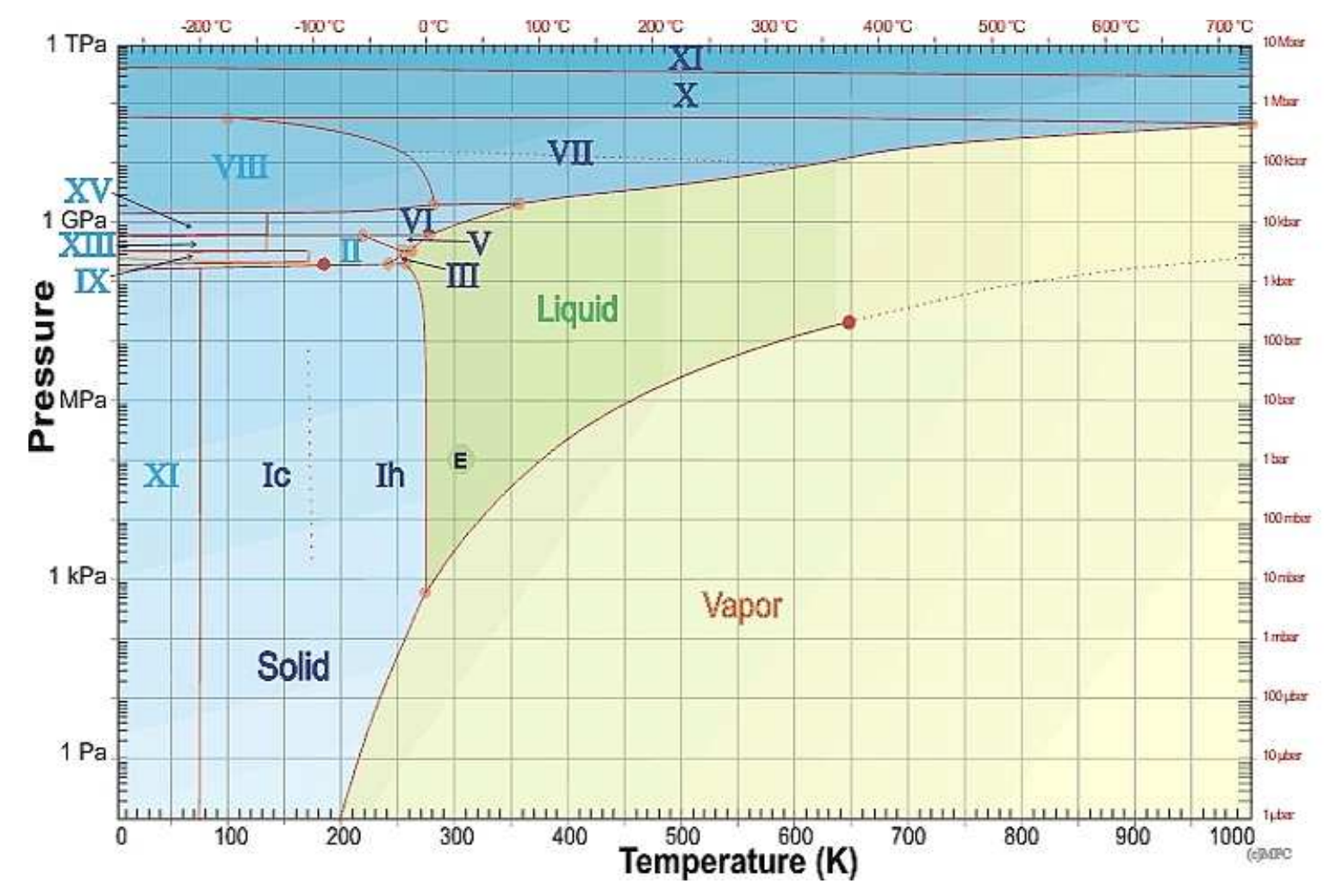

Figura 1.1: Diagrama de fases $\mathrm{P}$ vs T da água. Retirado da referência 1]

de hidrogênio e negativa no átomo de oxigênio. Devido a essa distribuição assimétrica das cargas e o tamanho do ângulo de ligação HÔH, a molécula de água torna-se uma molécula polar, ou seja ela pode ser orientada com a aplicação de um campo elétrico [11.

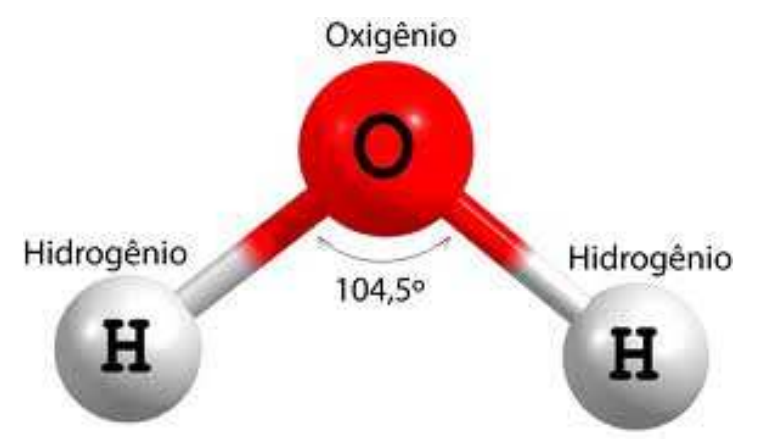

Figura 1.2: Molécula de água.

Porém, apesar da simplicidade aparente a água é uma substância que apresenta uma gama de propriedades que desperta o interesse de vários cientistas pelo mundo, sendo catalogadas mais de 60 anomalias [1] em suas propriedades físico-química. São consideradas propriedades anômalas da água aqueles que apresentam um comportamento 
bem diferente dos outros líquidos considerados normais.

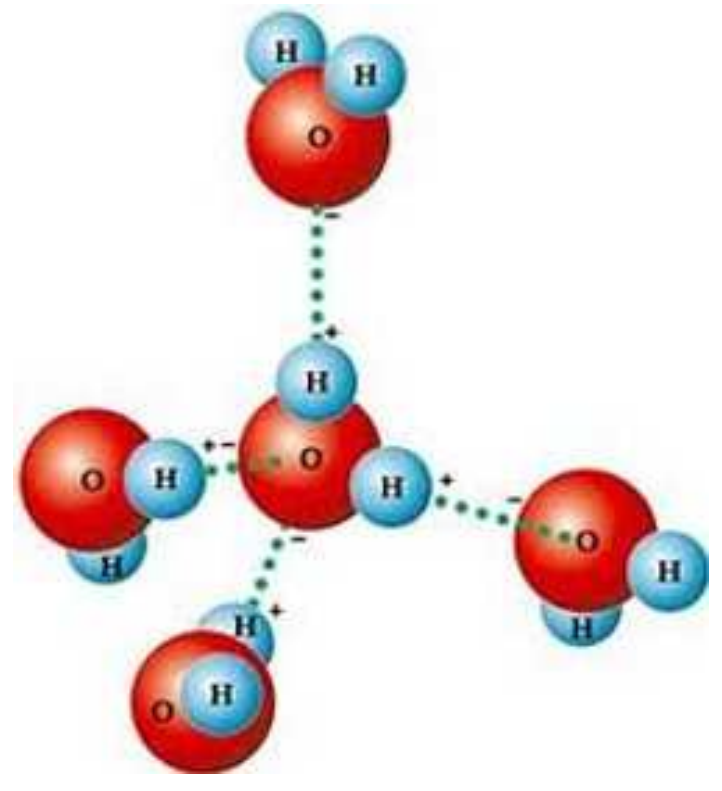

Figura 1.3: Estrutura tetraédrica da molécula de água. Formação de pontes de hidrogênio com as moléculas vizinhas. Retirado de [2]

Na estrutura molecular da água o átomo de oxigênio possui dois orbitais eletrônicos fora do plano de ligação $\mathrm{HOH}$, apontando na direção oposta aos átomos de hidrogênio, como a densidade de carga do hidrogênio é positiva e no oxigênio negativa, temos a formação de um dipolo, isso da resultado a uma forte ligação direcional que é formada entre os átomos de oxigênio e o átomo de hidrogênio, a qual chamamos de ligações de hidrogênio essa configuração forma uma distribuição tetraédrica nas moléculas de água, como mostrado na figura 1.3

Entre as anomalias da água, a mais fácil de se perceber é a anomalia na densidade. Enquanto usualmente a densidade aumenta, nos líquidos considerados "simples", quando diminuímos a temperatura, a água apresenta um máximo de densidade na temperatura em torno de $4{ }^{\circ} \mathrm{C}$, na pressão ambiente, passando então a diminuir com a redução da temperatura $[12]$. O ponto onde a água apresenta seu máximo de densidade em função da temperatura, para uma dada pressão, é conhecido como a temperatura de máximo de densidade (TMD). Em um gráfico de temperatura vs. pressão a TMD apresenta uma inclinação negativa, e entra numa região de líquido metaestável em altas pressões [13]. Um gráfico da densidade em função da temperatura é mostrado na figura 1.4. Podemos perceber na figura que a variação na densidade é muito pequena, o que não deixa de ser importante. Como consequência desse comportamento anômalo, eventualmente encontramos em nosso refrigerador uma garrafa de água estourada, isso pode ser explicado pelo aumento do volume causado pela diminuição da densidade, visto que 
a densidade é inversamente proporcional ao volume. Outra consequência importante é o congelamento da superfície dos lagos, rios e mares. Como o gelo é menos denso que a água líquida, ele fica flutuando por cima desta, então o congelamento acontece primeiro na superfície, garantido a existência de vida na camada abaixo, formada por água com temperatura entre 0 e $4^{\circ} \mathrm{C}$.

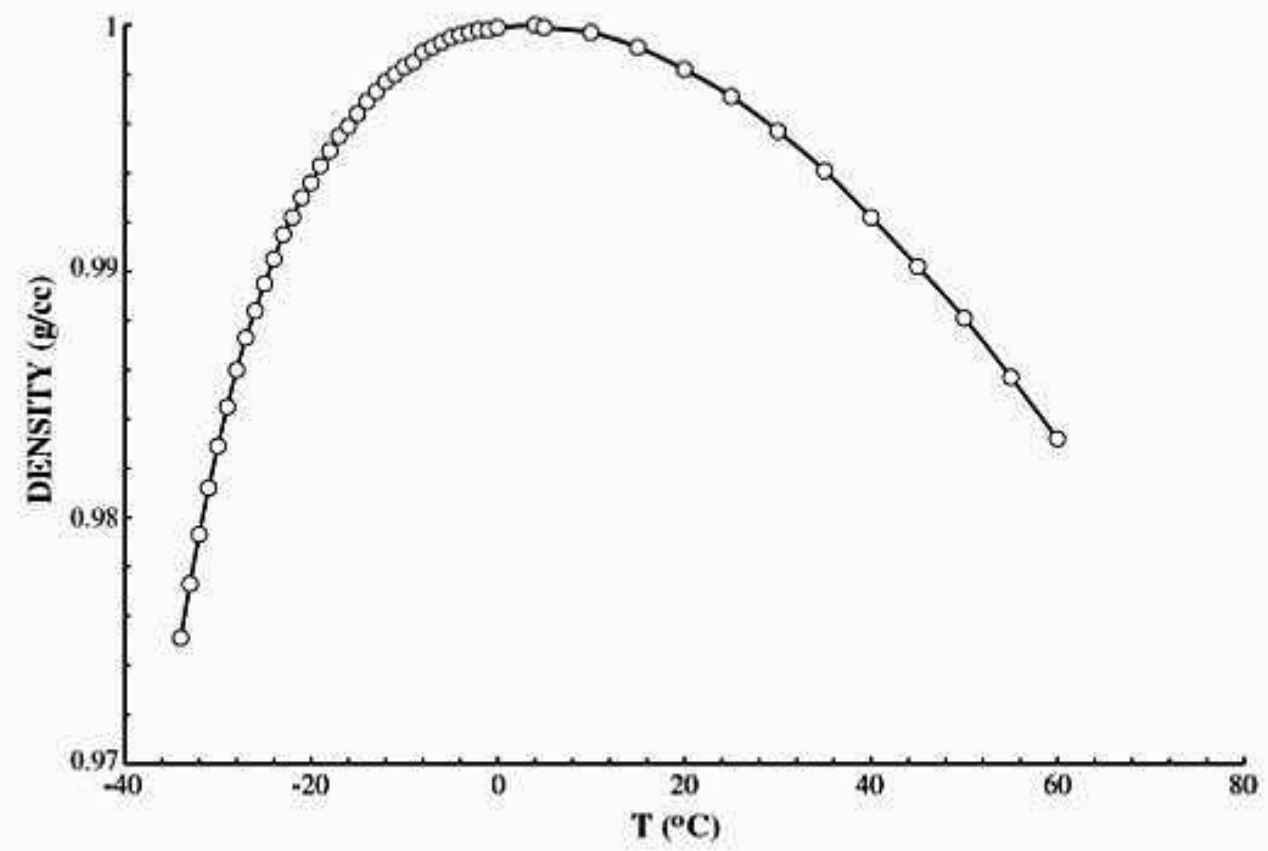

Figura 1.4: Dependência da densidade em função da temperatura a pressão ambiente. Figura retirada da referência $[3$

A água também apresenta um comportamento anômalo na difusão [14 17]. Estranhamente o coeficiente de difusão, quando em baixas temperaturas, aumenta com o aumento da densidade, apresentando um máximo $D_{\max }$, como podemos ver na figura 4.7. (dados de Angell [4]). Diversos modelos em rede [18, 19], apresentam essa propriedade característica da água. Na figura 1.6 além de um máximo também podemos ver um mínimo $D_{\min }$ de difusão, esse mínimo é encontrado somente em simulações.

Outra característica importante da água é seu elevado calor específico, o segundo maior valor dentre os compostos químicos conhecidos, ficando atrás apenas da amônia [2]. Esta propriedade faz com que a água possa absorver grandes quantidades de calor variando pouco sua temperatura, graças a essa capacidade o clima da terra se torna mais estável, pois a absorção de calor pela a água diminui as flutuações de temperatura. O calor específico da água apresenta um crescimento elevado para temperaturas abaixo de 4 ${ }^{\circ} \mathrm{C}$, que tem influência direta na anomalia na densidade [20]. Na figura 1.7 Debenedetti compara algumas propriedades da água com as mesmas propriedades de um líquido 


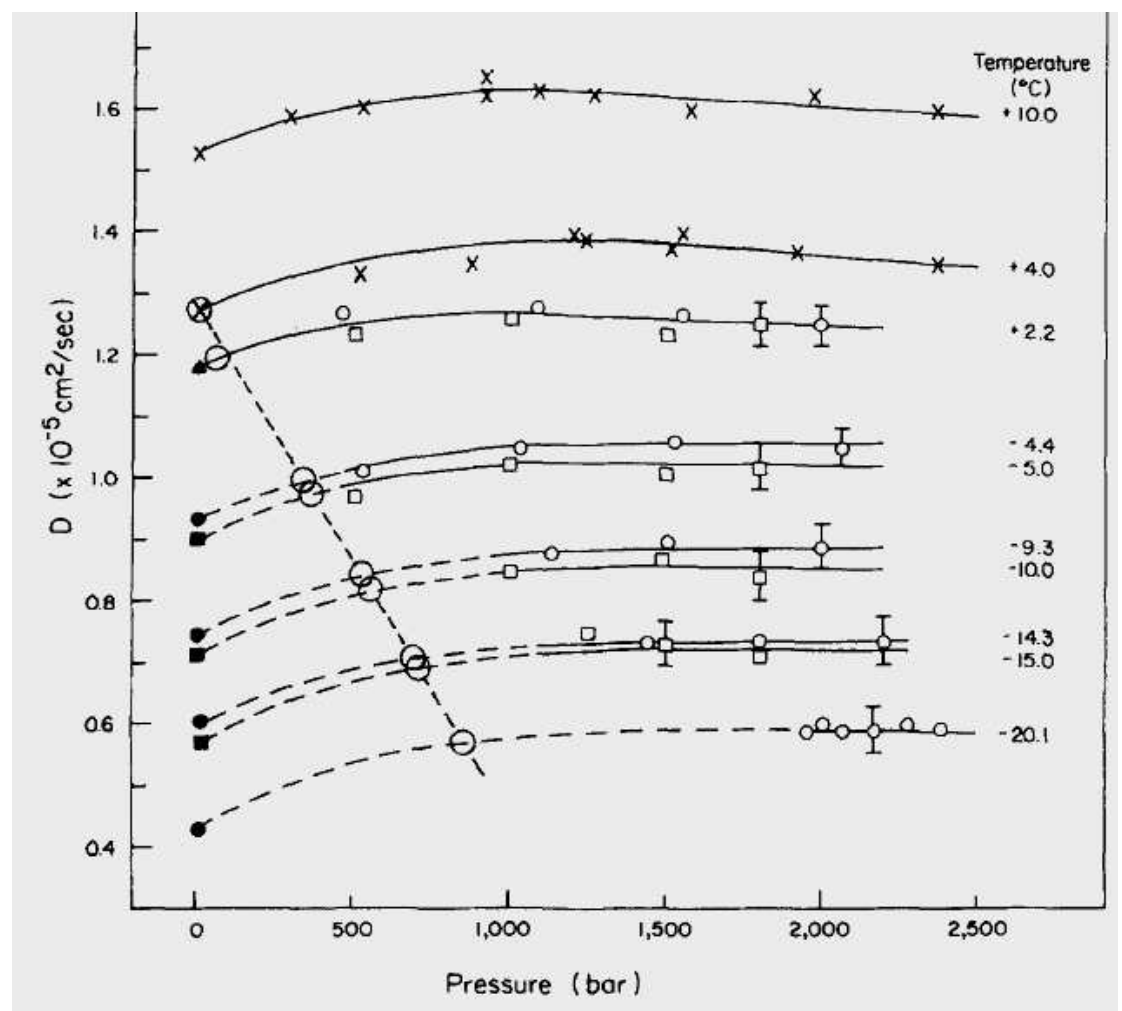

Figura 1.5: Coeficiente de difusão pela pressão obtido de dados experimentais por Angell at al. [4]

comum. Podemos observar que enquanto para um líquido simples a compressibilidade isotérmica, o coeficiente de expansão térmica e o calor específico a pressão constante apresentam um comportamento praticamente linear, a água apresenta, na mesma região pontos de mínimo para a compressibilidade isotérmica e o calor específico e uma inversão de sinal para o coeficiente de expansão térmica, que passa a ser negativo.

Quando se diminui a temperatura da água abaixo do ponto de congelamento, adentrando no estado de líquido super resfriado, as anomalias desse líquido metaestável tem seu comportamento mais acentuado. Nessa região a compressibilidade isotérmica e o calor específico a pressão constante aumentam quando a temperatura diminui, já o coeficiente de expansão térmica diminui, tornando-se cada vez mais negativo, indicando que pode existir uma relação entre alguma criticalidade na região metaestável e as anomalias apresentadas na água.

Devido a sua importância fundamental, entender todas as propriedades da água tem sido um grande desafio para a ciência. Diversos trabalhos, tanto experimentais 21 23 como teóricos 4, 13, 16, 24, foram publicados, fazendo o entendimento dessa substância tão singular ser cada vez melhor. Algumas teorias foram propostas para tentar explicar as estranhas propriedades desse fluido, como por exemplo o rápido aumento da 


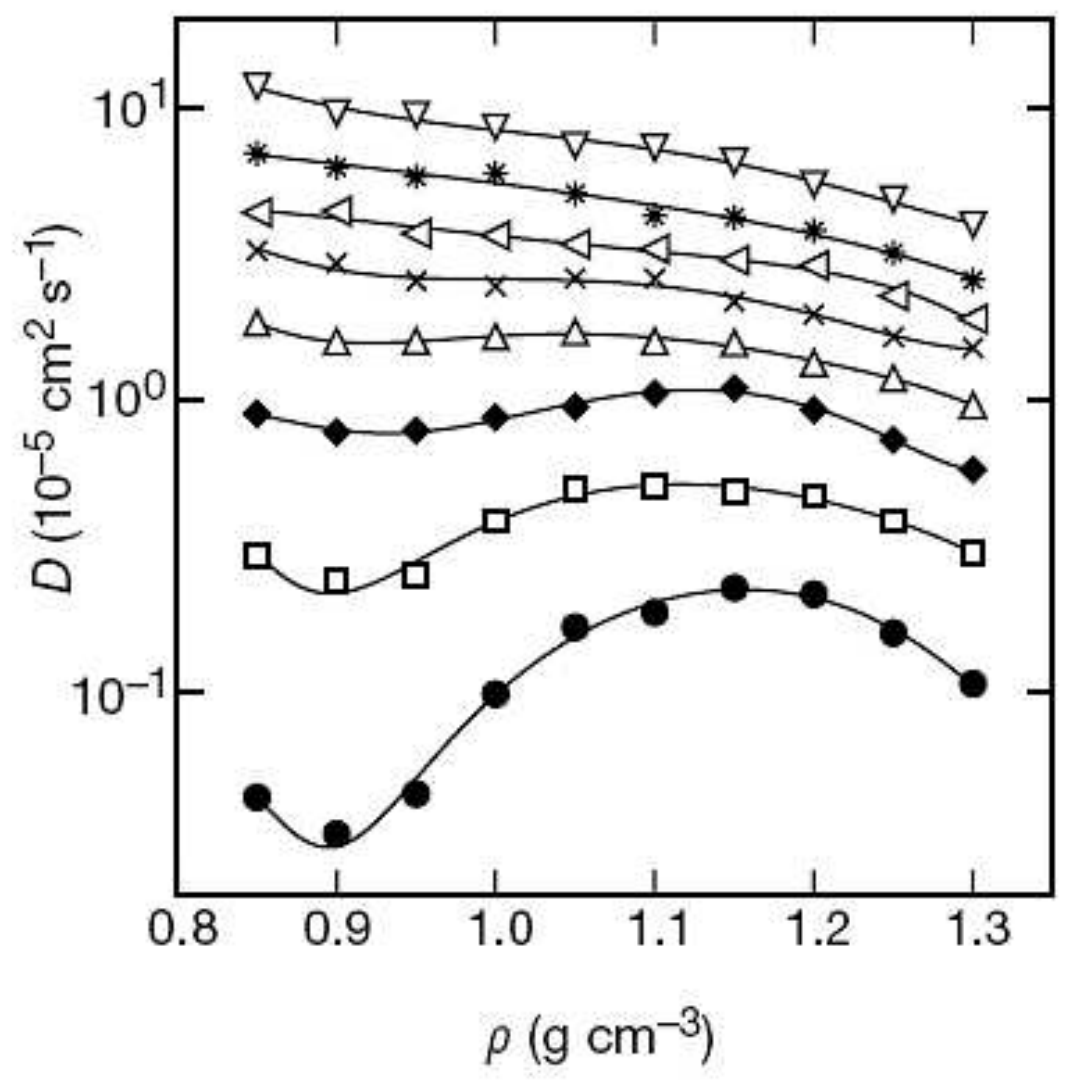

Figura 1.6: Dependência do coeficiente difusão com a densidade, oito isotérmicas são mostradas. De cima para baixo as temperaturas T (K) são, 400, 350, 320, 300, 280, 260, 240 and 220. Retirado de 5

compressibilidade isotérmica e do calor específico, com a diminuição da temperatura [24]. No entanto, ainda que o número de trabalhos publicados seja grande, nenhum deles foi confirmado definitivamente, devido, principalmente, à dificuldade de acessar regiões de baixa temperatura sem que ocorra o congelamento da água. Dessas hipóteses destaca-se, o cenário da singularidade livre 21, 25], e a hipótese do segundo ponto crítico [26 29].

No cenário da singularidade livre as funções respostas não divergem na região anômala, porém, aumentam quando a temperatura diminui, até um valor máximo. Este comportamento pode ser associado a linha de temperatura de máxima densidade (TMD), que aparece no plano pressão vs temperatura.

Na hipótese do segundo ponto crítico, além da transição líquido-gás, um novo ponto crítico aparece no final de uma linha que separa duas estruturas líquidas diferentes, uma de alta densidade e outra de baixa densidade. Este ponto aparece na região de líquido super resfriado, que é de difícil acesso experimental pois está abaixo da tempera- 

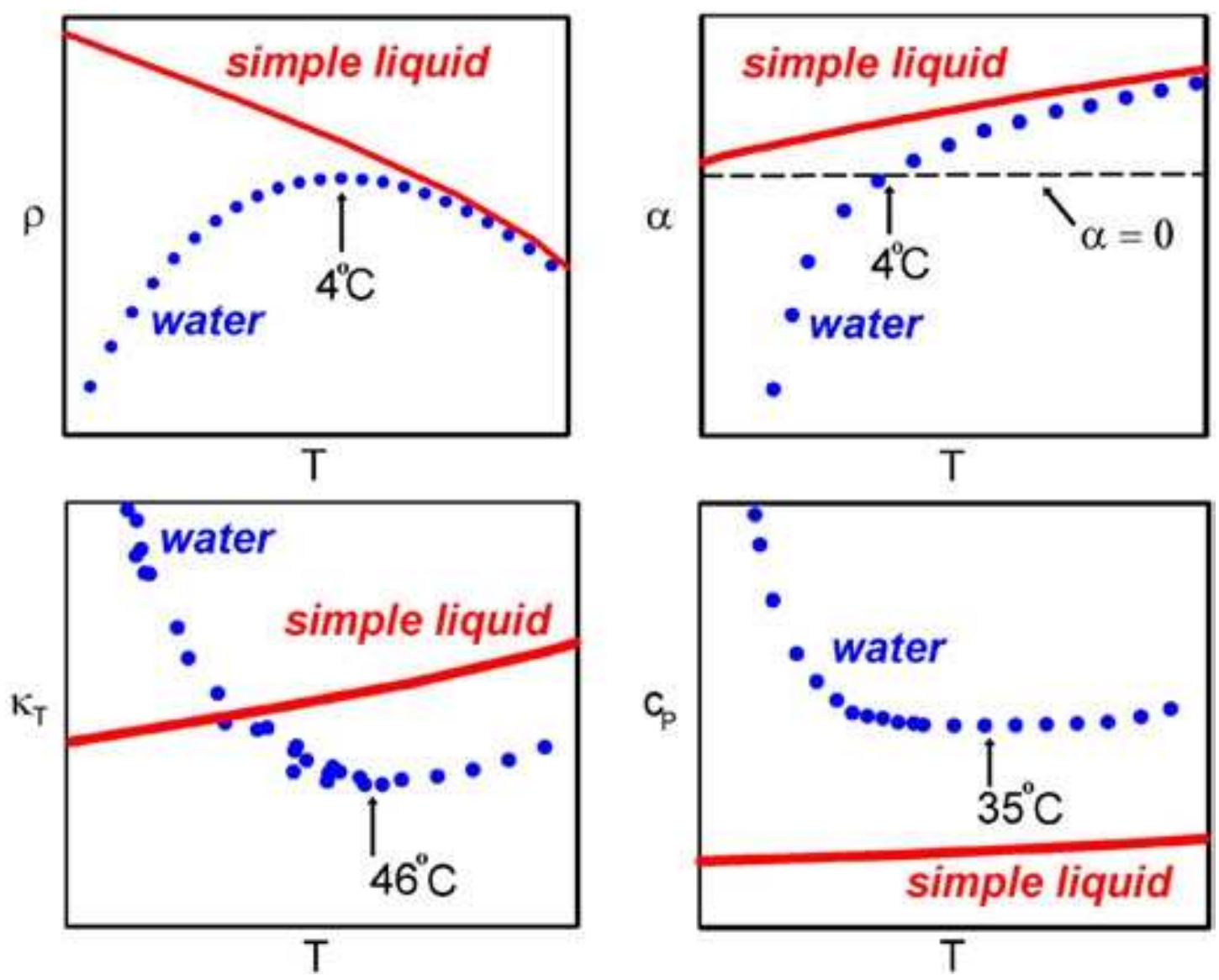

Figura 1.7: Compara o comportamento da densidade, do coeficiente de expansão térmica, da compressibilidade isotérmica, e da capacidade térmica a pressão constante, de um fluido simples com a água. Extraído de $|3|$.

tura de nucleação expontânea. Contudo várias simulações computacionais foram feitas, tanto em modelos com detalhe atômico (TIP4P e TIP5P) 30, 31 como em rede [6, 19, obtendo o segundo ponto crítico. Este cenário é ilustrado na figura 1.8, onde podemos ver o ponto crítico líquido-gás marcado com C', no final da linha de transição líquidogás, e C" que marca o segundo ponto crítico no final da linha de transição entre um líquido de baixa densidade (LDL), estrutura mais aberta em que prevalece as pontes de hidrogênio, e outro de alta densidade (HDL), nesse caso as pontes de hidrogênio são quebradas prevalecendo as ligações de Van der Waals [32]. Esta hipótese é a que possui mais evidências, dentre as apresentadas aqui, porém ainda existem dúvidas sobre o comportamento metaestável da água na sua fase líquida. Nessa dissertação trabalhamos com esse cenário, e as simulações feitas com o modelo proposto apresentam tanto a anomalia na densidade, quanto a criticalidade, o que corrobora à hipótese do segundo ponto crítico.

Defendeu-se ainda em uma terceira hipótese conhecida como conjectura do limite de estabilidade [33]. Nessa conjectura as anomalias termodinâmicas da água estão relaci- 


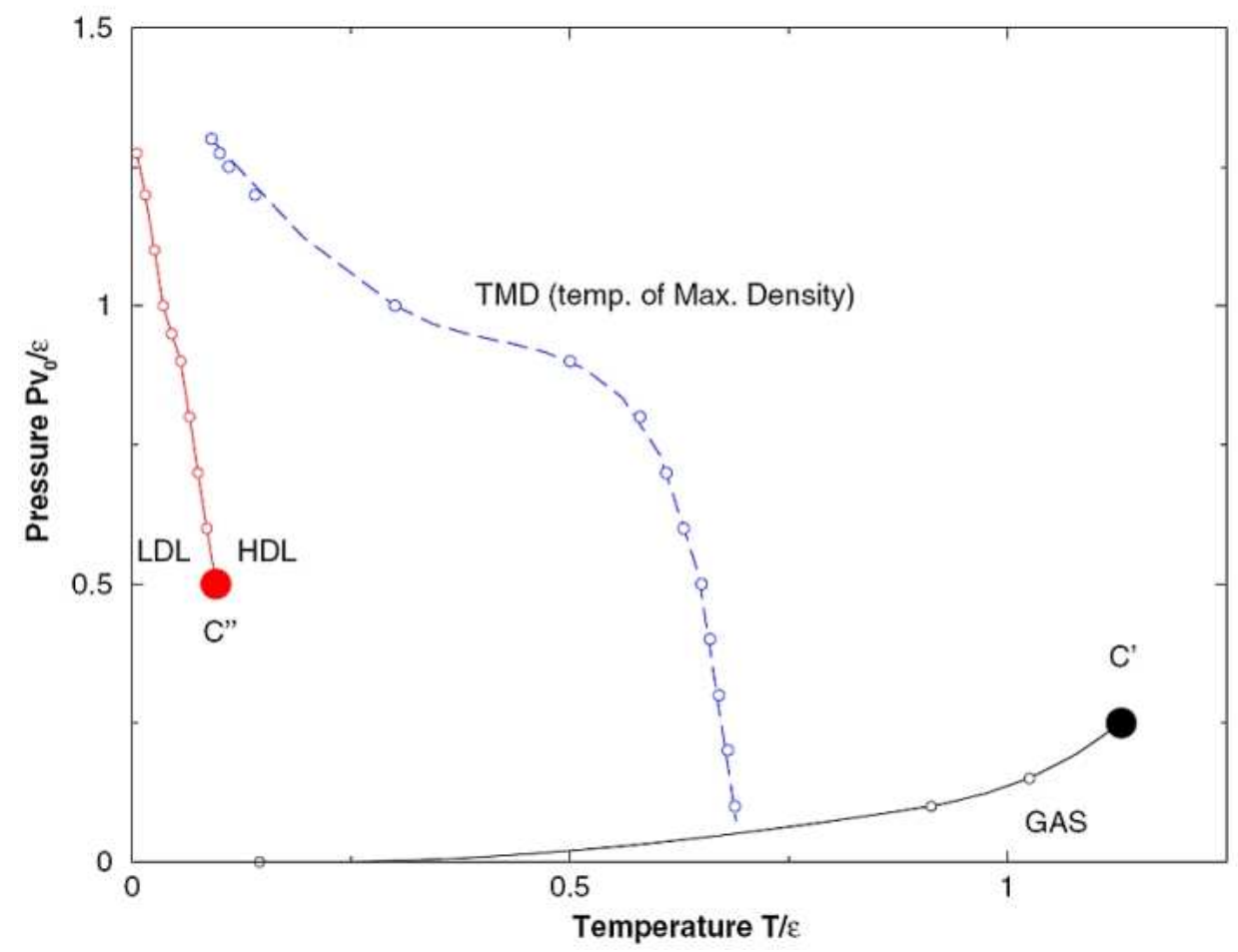

Figura 1.8: Diagrama de fase P-T (unidades reduzidas). Hipótese do segundo ponto crítico, $\epsilon>0$ é a energia caracteristica. Retirado da referência $\mid 6]$

onadas à linha de estabilidade do líquido. Esta linha tem início no ponto de coexistência gás-líquido e envolve as regiões de líquido super aquecido, esticado e super-resfriado (fig. 1.9. . Nessa conjectura há um aumento das funções respostas na região anômala, isso deve acontecer devido a proximidade com uma linha espinodal, onde a compressibilidade diverge como consequência do fim da estabilidade termodinâmica do fluido. A pressão da linha espinodal diminui quando a temperatura abaixa, até alcançar um ponto de mínimo, que esta na região negativa, aumentando em seguida Quando ela entra novamente na região de pressão positiva no diagrama de fases P-T causaria uma linha de singularidades nessa região 34,35 .

Como visto anteriormente, a água líquida apresenta anomalia na termodinâmica, a densidade aumenta quando a temperatura aumenta; anomalia dinâmica, aumento da difusão com aumento da pressão. Além dessas anomalias a água apresenta também anomalia estrutural. A estrutura da água é quantificada utilizando dois parâmetros, um orientacional q e um translacional t, 9, 36. Tanto o parâmetro de ordem orientacional quanto o translacional decrescem com a densidade para água líquida [5], como podemos ver na figura 1.10 .

As anomalias termodinâmica, dinâmica e estrutural da água aparecem relacionadas no diagrama de fases de temperatura pela densidade, essa relação é conhecida 


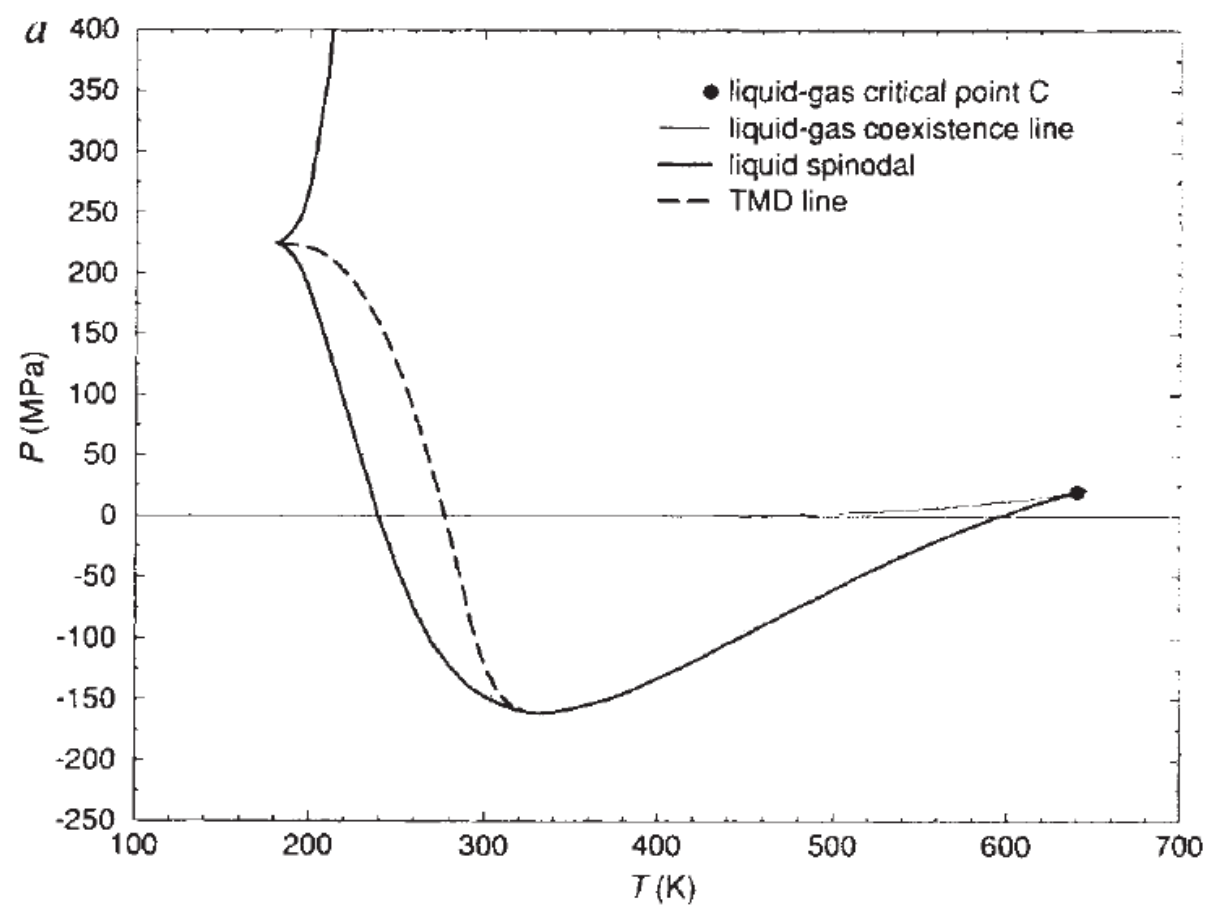

Figura 1.9: Conjectura da estabilidade limite. Retirado de [7]

como hierarquia de anomalias. A região onde ocorre o máximo da difusão engloba a região onde acontece o máximo na densidade. Errington e Debenedetti [5], mostraram utilizando dinâmica molecular e simulações no modelo SPC/E que as anomalias dinâmica e termodinâmica aparecem na forma de uma cascata, em um diagrama de temperatura pela densidadade, como mostrado na figura 1.11. Podemos observar também uma região de anomalia estrutural que envolve externamente as regiões de anomalia termodinâmica e dinâmica. Yan e outros, usando simulações no modelo de água TIP5P [9], também observaram o mesmo comportamento de hierarquia entre as anomalias (figura 1.12). Modelos computacionais usando potenciais efetivos de duas escalas, também apresentaram esse tipo de hierarquia [37,38]. A água não é a única a apresentar este tipo de hierarquia, sendo observado comportamento semelhante para $\mathrm{SiO}_{2}$ 39, 40], $\mathrm{BeF}_{2}$ [40] e silício [41.

Nesta tese vamos investigar a relação existente entre as anomalias dinâmicas e termodinâmicas da água, olhando para dois modelos em rede unidimensional. Modelos desse tipo foram propostos em 1969 por Bell [42] e mais recente por Ben-Naim [43, 44] e outros 45, 46].

Inicialmente Propomos um modelo de água em rede unidimensional com um potencial de interação simples, apresentando, além de uma interação tipo 'caroço duro', duas interações atrativas, uma entre primeiros vizinhos e outra entre segundos vizi- 


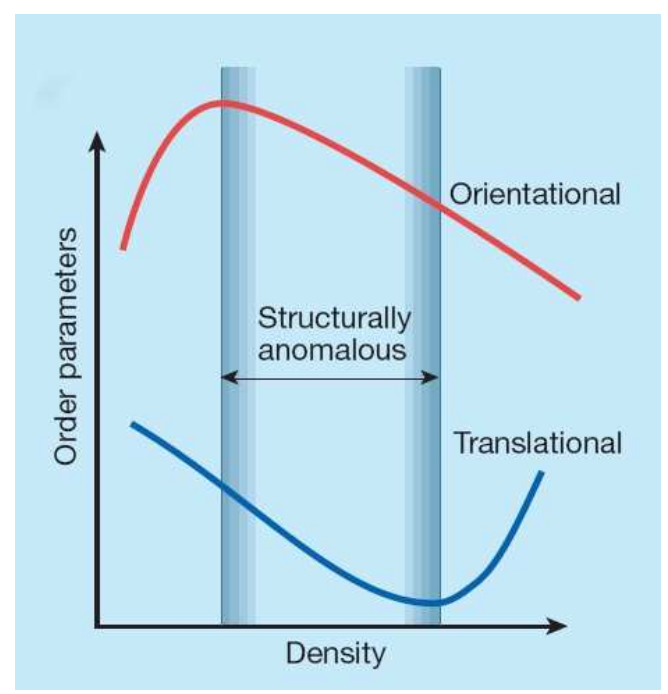

Figura 1.10: Anomalia na estrutura. Retirado de [8]

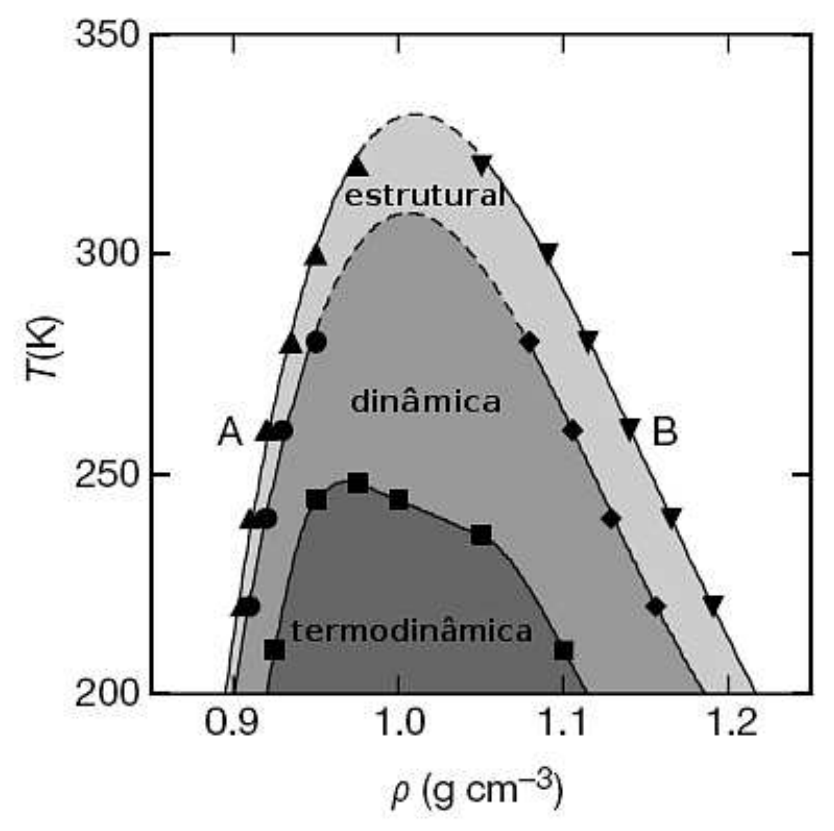

Figura 1.11: Relação entre as anomalias no plano T vs $\rho$ no modelo SPC/E. Anomolia estrutural é localizada por uma região entre o parâmetro de ordem orientacional máximo $q_{\text {max }}$ (triângulos para cima) e parâmetro de ordem trânslacional minimo $t_{\min }$ (triângulo para baixo). Na água dentro dessa região encotra-se a região de anomalia da difusão, localizada entre a difusão máxima $D_{\max }$ (quadrados pequenos) e mínima $D_{\min }$ (circulos). Logo abaixo vemos a região de anomalia na densidade, localizada pela linha de Temperatura de Máximo de Densidadde (TMD) (quadrados). Modificado da referência [5]

nhos com um sitio vazio entre eles. Logo em seguida estudamos um segundo modelo, mais simplificado visto que, apresenta somente uma interação repulsiva entre sítios vi- 


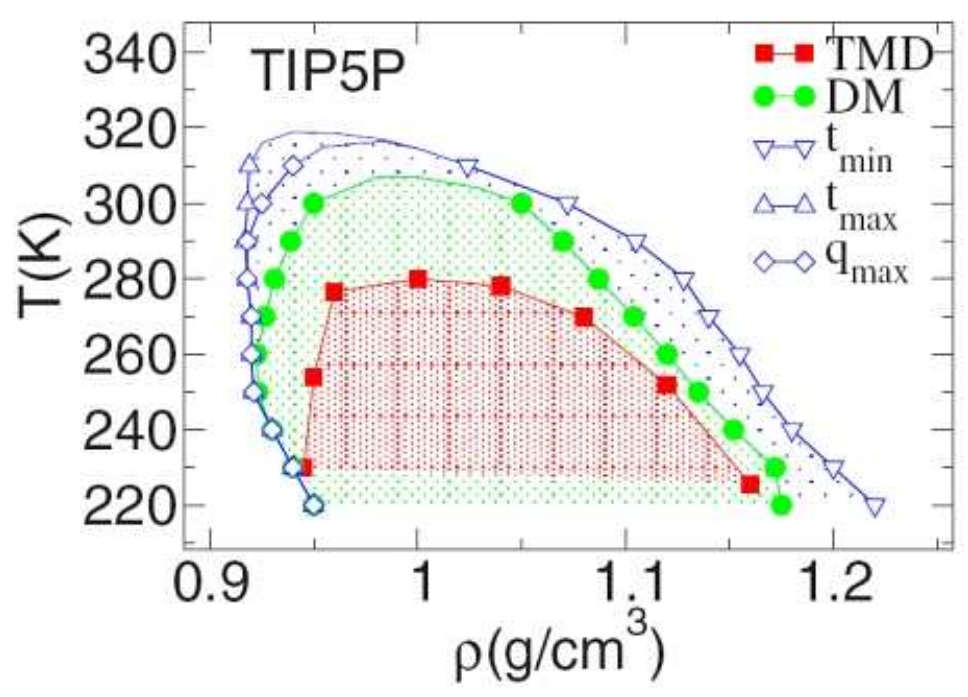

Figura 1.12: Hierarquia de Anomalias no modelo TIP5P. Observamos a região de anomalia estrutural envolvendo a região de anomalia na difusão, que por sua vez envolve a região de anomalia na densidade. Retirado de [9].

zinhos, devido a essa simplicidade pudemos obter soluções analíticas do sistema. Para resolvermos a termodinâmica utilizamos a técnica conhecida como técnica da matriz de transferência, que possibilitou o cálculo das funções de partição. Calculamos então a densidade, que apresentou um aumento com a temperatura, de acordo com o comportamento anômalo apresentado na água [3]. Utilizando simulações de Monte Carlo investigamos a dinâmica dos modelos, que apresentaram o comportamento anômalo na difusão, que tem um ponto de máximo e um ponto de mímimo no diagrama de fases da difusão pela densidade, como esperado para esse fluido [26, 47].

Esta tese está organizada da seguinte forma: No segundo capítulo faremos uma breve revisão dos conceitos termodinâmicos mais relevantes para nosso trabalho, mostramos algumas relações termodinâmicas e funções resposta de maior interesse no estudo de fluidos. Nesse capítulo vamos também mostrar como fazer a ligação entre a mecânica estatística e a termodinâmica, através do ensemble grande canônico. Por fim mostramos a técnica da matriz de transferência, que será utilizada para encontrar a solução analítica do modelo proposto.

No terceiro capítulo descrevemos os modelos de fluido em rede, apresentando o cenário atual dos modelos de água. Começando com uma revisão do gás de rede, mostramos como esse modelo pode ser aplicado para representar as anomalias apresentada pela água. Em seguida mostramos nosso modelo de água em rede unidimensional, descrevemos como é feita a interação entre vizinhos a partir de um potencial simples. Encerramos este capítulo mostrando as anomalias termodinâmicas do modelo com todas 
a soluções de forma analítica.

No quarto capítulo apresentamos nossos dois modelos propostos, descrevendo em detalhes cada um e mostramos a solução analítica da parte termodinâmica completa dos modelos. Em seguida mostramos como foi realizada toda parte de simulação computacional do trabalho, então verificamos que mesmo para modelos simples como os apresentados nesta tese é possível simular a anomalia da difusão, mostrando um gráfico do coeficiente de difusão pela densidade.

No quinto capítulo apresentamos nossas principais conclusões deste trabalho.

No apêndice ilustramos o método de Monte Carlo e o algoritmo de Metropolis, técnica de simulação que foi empregada para resolvermos a dinâmica do nosso modelo. 


\section{Capítulo 2}

\section{TÓPICOS DE TERMODINÂMICA E MECÂNICA ESTATÍSTICA}

Neste capítulo vamos relembrar algumas das propriedades termodinâmicas de interesse, com intuito de fixar os principais conceitos no tocante ao estudo dos fluidos. Mostraremos as equações de estado para sistemas em equilíbrio, relacionadas as variáveis de estado independentes. Em seguida descrevemos o ensemble grande canônico, que será de grande importância na descrição do nosso modelo. No outro tópico apresentamos a técnica da Matriz de Transferência, a qual é muito utilizada para soluções de problemas que envolve o gás de rede. Essa é utilizada para resolvemos nosso modelo, achando a solução exata para função de grande partição.

\subsection{Relações Termodinâmicas}

Para descrevermos o estado macroscópico de um sistema, devemos especificar algumas variáveis de estado, como por exemplo seu volume, $\mathrm{V}$, número de partículas, $\mathrm{N}$ e a entropia, S, que são variáveis extensivas, ou seja, seu valor depende do tamanho do sistema. Outras variáveis como temperatura, T, e o potencial químico, $\mu$, são variáveis intensivas, as quais o valor não dependem do tamanho do sistema.

As variáveis de estado de um sistema em equilíbrio não dependem da forma como esse estado foi alcançado, portanto, o processo termodinâmico que foi seguido pelo sistema fechado não é importante para sua descrição no equilíbrio. Isso pode ser expresso matematicamente por diferenciais exatas como: $d F(x, y)=\left(\frac{\partial F}{\partial x}\right)_{y} d x+\left(\frac{\partial F}{\partial y}\right)_{x} d y$. Então a equação de um fluido puro na representação da energia $U(S, V, N)$ é dado por,

$$
d U=\left(\frac{\partial U}{\partial S}\right)_{V, N} d S+\left(\frac{\partial U}{\partial V}\right)_{S, N} d V+\left(\frac{\partial U}{\partial N}\right)_{S, V} d N
$$


Algumas vezes podemos achar mais conveniente utilizarmos a representação da entropia, $\mathrm{S}(\mathrm{U}, \mathrm{V}, \mathrm{N})$, de tal forma que podemos expressar a equação como:

$$
d S=\left(\frac{\partial S}{\partial U}\right)_{V, N} d U+\left(\frac{\partial S}{\partial V}\right)_{U, N} d V+\left(\frac{\partial S}{\partial N}\right)_{U, V} d N
$$

A primeira lei da termodinâmica para sistemas fechados é expressa da forma,

$$
d U=d Q-P d v+\mu d N
$$

onde $d Q$ é a variação de calor e $P d v$ é o trabalho realizado pelo sistema. Para um processo reversível temos $d Q=T d S$, então podemos reescrever 2.3

$$
d U=T d S-P d v+\mu d N
$$

fazendo uma comparação desta equação com a equação(2.1) podemos ver imediatamente que

$$
\begin{gathered}
T=\left(\frac{\partial U}{\partial S}\right)_{V, N}, \\
P=-\left(\frac{\partial U}{\partial V}\right)_{S, N}, \\
\mu=\left(\frac{\partial U}{\partial N}\right)_{S, V} .
\end{gathered}
$$

Que são as relações de estado na representação da energia. Podemos também fazer a mesma comparação entre as equações (2.4) e (2.2), assim obtemos as seguintes equações de estado na representação da entropia:

$$
\begin{gathered}
\frac{1}{T}=\left(\frac{\partial S}{\partial U}\right)_{V, N}, \\
\frac{P}{T}=\left(\frac{\partial S}{\partial V}\right)_{U, N}, \\
\frac{\mu}{T}=-\left(\frac{\partial S}{\partial N}\right)_{U, V}
\end{gathered}
$$

Temos então um conjunto de variáveis independentes que na representação da energia são S, V, N; e na representação da entropia são U, V, N. 
As vezes é mais útil trabalhar com variáveis independentes que podem ser medidas experimentalmente de forma mais fácil, como a temperatura e a pressão. Esse processo pode ser feito usando as transformadas de Legendre da energia [48]. Essas transformadas dão origem aos potenciais termodinâmicos, os quais vamos apresentar na próxima seção.

\subsubsection{Potenciais Termodinâmicos}

Potenciais termodinâmicos são de grande importância na física estatística, uma vez que através deles podemos montar as equações de estado e consequentemente obter toda a descrição do sistema em estudo. Além disso eles também servem para fazer a ligação entre a física estatística e a termodinâmica.

Para se estudar um sistema com temperatura, volume e número de partículas fixos é conveniente realizar uma transformada de Legendre na equação da energia $U(S, V, N)$, com relação a entropia S. Então usando a expressão para temperatura dada em (2.5), encontra-se:

$$
F(T, V, N)=U-T S
$$

Conhecido como energia livre de Helmhotz.

Para sistemas com pressão, temperatura e potencial químico fixos, realiza-se duas transformadas de Legendre em relação às variáveis $\mathrm{S}$ e V. Obtendo a energia livre de Gibbs,

$$
G(T, P, N)=U-T S+p V
$$

Para sistemas com temperatura, potencial químico e volume fixos, a transformada de Legendre é feita com relação às variáveis $\mathrm{S}$ e $\mathrm{N}$, então:

$$
\Phi(T, V, \mu)=U-T S-\mu N
$$

Conhecido como potencial grande canônico. Podemos diferenciar essa equação que resulta em,

$$
d \Phi=d U-T d S-S d T-\mu d N-N d \mu .
$$

Comparando essa expressão com a equação 2.3 obtem-se:

$$
d \Phi=\left(\frac{\partial \Phi}{\partial V}\right)_{T, \mu} d V+\left(\frac{\partial \Phi}{\partial T}\right)_{V, \mu} d T+\left(\frac{\partial \Phi}{\partial \mu}\right)_{T, V} d \mu
$$

A partir desta expressão pode-se forma as seguintes equações de estado: 


$$
\begin{gathered}
P=-\left(\frac{\partial \Phi}{\partial V}\right)_{T, \mu}, \\
S=-\left(\frac{\partial \Phi}{\partial T}\right)_{V, \mu}, \\
N=\left(\frac{\partial \Phi}{\partial \mu}\right)_{T, V} .
\end{gathered}
$$

Portanto temos a pressão, a entropia e o número de partículas, expressos por meio do potencial grande canônico.

\subsubsection{Funções Resposta}

As funções resposta são derivadas termodinâmicas que estão relacionadas com um procedimento experimental, sendo obtidas de maneira simples. Para um fluido puro, as funções que despertam maior interesse são: o calor específico, a compressibilidade isotérmica e o coeficiente de expansão térmica.

O calor específico mede o quanto a temperatura varia quando uma quantidade de calor é fornecida ao sistema, ou seja, fornecendo uma certa quantidade de calor a uma determinada substancia qual a mudança temos no valor da sua temperatura. O calor específico pode ser medido mantendo a pressão ou o volume fixo, por essa razão tem-se duas definições a saber.

(a) Calor especifico a volume constante $c_{V}$.

$$
c_{V}=\frac{1}{N}\left(\frac{d Q}{d T}\right)_{V, N}=\frac{T}{N}\left(\frac{d S}{d T}\right)_{V, N}
$$

(b) Calor específico a pressão constante $c_{p}$

$$
c_{p}=\frac{1}{N}\left(\frac{d Q}{d T}\right)_{P, N}=\frac{T}{N}\left(\frac{d S}{d T}\right)_{P, N} .
$$

A compressibilidade isotérmica indica quanto o sistema varia seu volume quando é submetido a um pressão, mantendo a temperatura fixa. Ele é definido por:

$$
K_{T}=-\frac{1}{V}\left(\frac{d V}{d P}\right)_{T, N}
$$

O coeficiente de expansão térmica mede quanto varia o volume do sistema 
quando variamos a temperatura, mantendo a pressão constante. Sua definição é,

$$
\alpha=\frac{1}{V}\left(\frac{d V}{d T}\right)_{p, N} .
$$

\subsection{Ensemble Grande Canônico}

O ensemble Grande Canônico é definido na mecânica estatística para modelar sistemas em que a temperatura e potêncial químico são mantidos fixos. Define-se uma função conhecida como: função de grande partição, cuja demostração pode ser encontrada em livros de física estatística, o resultado para um sistema de N particulas será a soma ponderada de todas as funções de partição, logo temos:

$$
\Xi(\mu, V, T)=\sum_{N=0}^{\infty} e^{\beta \mu N} Q_{n}(T, V, N)
$$

o fator de ponderação $e^{\beta \mu}=z$ é conhecido como fugacidade. A conexão com a termodinâmica é feita através do potêncial Grande Canônico, dado por:

$$
\Phi(T, V, \mu)=-\frac{1}{\beta} \ln [\Xi(\mu, V, T)],
$$

lembrando a equação 2.9 para o potencial grande canônico.

$$
\Phi=U-T S-\mu N
$$

Comparando essa expressão com a equação fundamental da Termodinâmica ou equação de Euler.

$$
U=T S-P V+\mu N
$$

Podemos então facilmente identificar o potêncial Grande Canônico com a pressão vezes o volume, ou seja:

$$
\Phi=-P V
$$

Multiplicando por $\beta$ e tirando a exponencial em ambos os lados na equação 2.20, então substituindo $\Phi$ dado pela equação 2.22 , ficamos com:

$$
\Xi(\mu, V, T)=e^{\beta P V}
$$




\subsection{Técnica da Matriz de Transferência.}

Essa técnica, muita utilizada para obter soluções exatas de problemas na física estatística, consiste em obter os autovalores de uma matriz montada a partir de uma função de partição. Para ilustrar, suponha uma função de partição, de um sistema unidimensional, dada por:

$$
Z=\sum_{\{s\}} e^{\beta E\left(s_{1} s_{2}+s_{2} s_{3}+\ldots+s_{N} s_{N+1}\right)+\beta J\left(s_{1}+s_{2}+\ldots+s_{N+1}\right)},
$$

onde $\{\mathrm{s}\}$ indica todos os estados possíveis do sistema, com $s_{k}$ assumindo apenas os valores 0 ou 1 , ou seja

$$
s_{k}=\left\{\begin{array}{l}
1 \\
0
\end{array}\right.
$$

Impomos também uma condição de contorno períodica com, $s_{N+1}=s_{1}$ para que possamos reescrever a eq. 2.24 como:

$$
Z=\sum_{\{s\}} e^{\beta E s_{1} s_{2}+\beta J\left(s_{1}+s_{2}\right) / 2} e^{\beta E s_{2} s_{3}+\beta J\left(s_{2}+s_{3}\right) / 2} \ldots e^{\beta E s_{N} s_{1}+\beta J\left(s_{N}+s_{1}\right) / 2}
$$

Agora, vamos definir uma matriz P como:

$$
P=e^{\beta E s_{i} s_{i+1}+\beta J\left(s_{i}+s_{i+1}\right) / 2}
$$

Para ficar mais claro o entendimento vamos escrever P como sendo um operador atuando no seu autoestado $|s\rangle$, assim a equação (2.25) assume a forma:

$$
Z=\sum_{\{s\}}<s_{1}|P| s_{2}><s_{2}|P| s_{3}>\ldots<s_{N}|P| s_{1}>,
$$

usando então a relação de completeza ou completude

$$
\sum_{i}\left|s_{i}><s_{i}\right|=\hat{1}
$$

ficamos com :

$$
Z=\sum_{i}<s_{i}\left|P^{N}\right| s_{i}>
$$


Agora fica fácil ver que a função de partição $\mathrm{Z}$ é o traço de uma matriz $\mathrm{P}$ definida em 2.26. Portanto:

$$
Z=\operatorname{Tr}\left(P^{N}\right)
$$

Como a matriz é simétrica, por construção, ela pode ser diagonalizada por uma transformação unitária na forma, $U T U^{-1}=D$, onde D é uma matriz diagonal. Então reduzimos o problema de encontrar a solução da soma em (2.25), a um problema de autovalor que, para sistemas simples, pode ser resolvido mais facilmente, bastando para isso encontrar os autovalores $\lambda_{i}$. Logo temos de 2.30 que,

$$
Z=\sum_{i} \lambda_{i}^{N}
$$

Quando N é grande o suficiente, no limite termodinâmico, a equação 2.31 se reduz ao maior autovalor. Para vermos isso, vamos escrever a função de partição colocando o maior autovalor em evidência,

$$
Z=\left(\lambda_{\max }\right)^{N}\left(1+\left(\frac{\lambda_{i}}{\lambda_{\max }}\right)^{N}+\left(\frac{\lambda_{j}}{\lambda_{\max }}\right)^{N}+\ldots\right)
$$

então, quando tomamos o limite para $\mathrm{N}$ muito grande, os termos da divisão torna-se desprezíveis restando somente o maior autovalor. 


\section{Capítulo 3}

\section{MODELO DE GÁS DE REDE}

Neste capítulo vamos descrever o modelo de Gás de Rede simples, suas propriedades e aplicações no estudo de fenômenos físicos.

O modelo de gás de rede é muito utilizado na física da matéria condensada, tendo uma gama de aplicações em simulações de processos físicos e biológicos [49 53, como por exemplo no estudo de absorção e supercondutividade. Em sua forma mais simples é composto por uma rede com $\mathrm{V}$ sítios, cada sítio podendo ter somente uma partícula, ou estar vazio. Uma variável de ocupação $\eta$ é definida para cada sítio assumindo os valores 0 caso o sítio esteja vazio e 1 se estiver ocupado. Para completar a descrição da rede é preciso descrever um potencial de interação entre as partículas.

\subsection{Gás de Rede com "Caroço Duro"}

Para o gás de rede com interação entre as partículas dada somente por uma barreira infinita em uma distância igual ao tamanho do sítio, o potencial tem uma forma conhecida como "caroço duro", ou seja, duas partículas não podem ocupar o mesmo sítio na rede. Este tipo de interação tem sido usado como base para modelar diversos tipos de sistemas, como fluidos e magnetos. Em modelos que utilizam potenciais como esse, onde a interação é somente da forma de caroço duro, a temperatura não é importante na descrição termodinâmica do sistema, que fica conhecido como sistema atérmico. Para esse modelo simples podemos calcular analiticamente sua função de partição e a partir dela todas funções termodinâmicas de interesse. Assumindo uma condição periódica de contorno, o Hamiltoniano é dado por

$$
H=-\mu \sum_{i=1}^{V+1} \eta_{i}
$$


e então temos o peso de Boltzmann de uma configuração:

$$
Q=e^{-\beta H}=\prod_{i} e^{\beta \mu \eta_{i}}
$$

a partir deste peso podemos calcular a função de partição grande canônica, obtendo:

$$
\Xi=\sum_{\left\{\eta_{i}\right\}} \prod_{i} e^{\beta \mu \eta_{i}}=\left(1+e^{\beta \mu}\right)^{V}
$$

onde $\mu$ é o potencial químico, $\beta=\frac{1}{k_{B} T}$ e rede e $k_{B}$ é a constante de Boltzmann. Vamos calcular o potencial grande-canônico, que é dado por:

$$
\Phi=-k_{B} T \ln \Xi
$$

usando a equação (3.3) ficamos com

$$
\Phi=-k_{B} T V \ln \left(1+e^{\beta \mu}\right)
$$

considerando que o sistema tem temperatura, volume e potencial químico fixos, podemos usar a identidade,

$$
\Phi=U-T S-\mu N
$$

assim calculamos a entropia $\mathrm{S}$ e o número de partículas $\mathrm{N}$, através das equações de estado,

$$
\begin{aligned}
& S=-\frac{\partial \Phi}{\partial T}, \\
& N=-\frac{\partial \Phi}{\partial \mu} .
\end{aligned}
$$

Por fim, Calculamos a densidade e a entropia por sítio do sistema:

$$
\begin{gathered}
\rho=\frac{N}{V}=-\frac{1}{V} \frac{\partial \Phi}{\partial \mu}=\frac{e^{\beta \mu}}{1+e^{\beta \mu}}, \\
s=-\frac{1}{V} \frac{\partial \Phi}{\partial T}=-\rho \ln \rho-(1-\rho) \ln (1-\rho) .
\end{gathered}
$$

De acordo com estes cálculos, vemos que a densidade apresenta o comportamento esperado para fluidos simples, diminuindo a densidade quando há um aumento de temperatura. Obviamente, este modelo simples não apresenta transição de fase. Um modelo, em uma dimensão, onde podemos encontrar transição de fase se apresenta quando 
os primeiros vizinhos da rede podem interagir de maneira repulsiva ou atrativa. Com isso podemos encontrar uma transição do tipo líquido-gás como acontece na água.

\subsubsection{Gás de Rede Atrativo}

Modelos de gás de rede com interação atrativa estabelecem uma correspondência direta com as variáveis termodinâmicas de um sistema magnético de spin na rede, podendo então ser utilizados os resultados conhecidos de um sistema para outro. Nesse caso onde temos um gás de rede atrativo podemos mapear o modelo de Ising ferromagnético, que tem soluções analíticas para uma e duas dimensões [48].

No modelo de Ising, tem-se uma rede formada por $N$ sítios, cada sítio é ocupado apenas por um spin que pode ser up ou down, a representação desses estados na rede é feito pela variável $\sigma_{i}$ que pode assumir os valore $\sigma=1$ e $\sigma=-1$, para spin up e spin down respectivamente. O hamiltoniano para esse sistema é dado por:

$$
\mathcal{H}=-J \sum_{i, k} \sigma_{i} \sigma_{k}-H \sum_{i} \sigma_{i}
$$

nesta equação a soma é feita sobre todos sítios vizinhos $(i, k)$ da rede, $\mathrm{J}$ e $\mathrm{H}$ representam a intensidade de interação entre os primeiros vizinhos e entre um sítio e o campo magnético externo, respectivamente. Sendo o volume e o número de partículas bem definidos, podemos trabalhar com ensemble canônico, que melhor se encaixa na solução deste tipo de problema. A probabilidade de equilíbrio nesse ensemble pode ser escrita como:

$$
P_{e q}(\sigma)=\frac{1}{Z(T)} e^{-\beta \mathcal{H}(\sigma)},
$$

onde $Z(T)$ é a função de partição. A solução para esse modelo em uma dimensão foi apresentada por Ising em 1924, e duas dimensões por Onsager em 1944. Para fazermos a correspondência entre o modelo de Ising e o modelo de gás de rede, precisamos somente que se faça uma troca da variável de spin $\sigma$ por uma variável de ocupação $\eta$, definida como:

$$
\eta_{i}=\frac{\sigma_{i}+1}{2}
$$

então $\eta$ assume os valores 0 caso o sítio esteja vazio e 1 caso esteja ocupado. Com isso o hamiltoniano dado pela equação (3.6) pode ser reescrito como,

$$
\mathcal{H}=-4 J \sum_{i, k} \eta_{i} \eta_{k}+8 J \sum_{i} \eta_{i}-2 H \sum_{i} \eta_{i}-N H
$$

podemos fazer $\epsilon=4 J$ e então reescrever a equação (3.9), a menos de uma constante, 
como:

$$
\mathcal{H}=-\epsilon \sum_{i, k} \eta_{i} \eta_{k}-2(H-\epsilon) \sum_{i} \eta_{i}
$$

Assim utilizamos a solução do modelo de Ising para mapear a solução de um modelo de gás de rede, definindo as variáveis

$$
\mu \equiv 2(H-J)
$$

onde $\mu$ é o potencial químico e $\epsilon$ é a interação entre os primeiros vizinhos.

\subsection{Modelos de Água em Rede}

Com intuito de simular o comportamento da água e sua estrutura, diversos modelos computacionais foram implementados, dentre eles temos modelos com detales atômicos, como com exemplo, TIP5P (Five Point Transferable Intermolecular Potential) [54], SPC (Simple Point Change) [31] e SPC/E ( Extended Simple Point Change) [9]. Estes modelos são capazes de reproduzir a maioria das propriedades anômalas da água, contudo, eles são bastante complicados o que dificulta a compreensão física das anomalias apresentadas e outra grande dificuldade enfrentada por esses modelos é a falta de soluções exatas. Neste sentido, modelos em rede surgem como alternativa para estudar algumas das anomalias presentes na água líquida, no entanto, mesmo os modelos de água em rede em duas e três dimensões ainda não possuem soluções exatas.

Um modelo em rede unidimensional que apresentou anomalia na densidade foi proposto por Bell [42]. Nesse modelo as ligações de hidrogênio podem ou não ocorrer entre segundos vizinhos, quando o sitio entre eles estiver vazio. Em baixa temperatura e pressão esse modelo apresentava uma competição entre duas estruturas, uma configuração local aberta e outra mais fechada de alta energia. Cho et al. propuseram um modelo 55 que pode ser considerado uma generalização do modelo de Bell. Foram estudados a relação entre as anomalias termodinâmicas e o segundo ponto crítico que aparece no final da linha de transição líquido-líquido. Nesse modelo as pontes de hidrogênio tem sua energia reduzida com a aproximação de uma terceira molécula na ligação, e um conjunto q de estados foram adicionados as moléculas.

Em um trabalho pioneiro, Stell e Hemmer introduzem um potencial para o gás de rede formado por um "caroço duro" mais uma parte negativa, a qual suavisa seu caroço duro [56,57. Este potencial, que ficou conhecido como core-softened, é capaz de reproduzir duas transições de fase de primeira ordem, uma transição líquido-gás e outra líquido-líquido. Frank Stillinger e Teresa Head-Gordon mostraram que o core-softened 
pode ser considerado uma aproximação realística de primeira ordem da interação real entre as moléculas de água [58,59]. Debenedetti e colaboradores usando argumentos termodinâmicos, demostraram que potenciais core-softened podem apresentar uma região onde há instabilidade do fluido e confimaram a existência de um coeficiente de expansão térmica negativo $\alpha_{T}<0$ [60]. 


\section{Capítulo 4}

\section{MODELOS DE ÁGUA EM REDE UNIDIMENSIONAL}

Neste capítulo vamos apresentar nossos dois modelos de fluido em rede e obter as soluções analíticas dos sistemas. Então mostramos que apesar da simplicidade dos modelos ambos apresentam em suas propriedades termodinâmicas comportamento anômalo típico de água.

\subsection{Motivação}

Atualmente existem na literatura vários modelos de água que apresentam tanto as anomalias dinâmicas quanto as termodinâmicas. Porém a maioria desses modelos são muito complexos implicando na falta de soluções analíticas. Então resolvemos procurar por um modelo que seja ao mesmo tempo simples e apresente características similares à água. Acredita-se que essas anomalias estejam associadas à ligações de hidrogênio, que geram uma competição entre duas estruturas, uma de alta densidade e outra de baixa densidade. Com esta visão em mente passamos a investigar um potencial de interação entre as moléculas que fosse simples e que apresentasse uma transição de fase, gerado por essa competição, mesmo em um modelo unidimensional. $\}^{1}$

\subsection{Modelo com duas interações atrativas}

Estudamos através de simulação computacional e cálculos analíticos, as anomalias dinâmica e termodinâmica da água em um modelo de gás de rede unidimensional

\footnotetext{
${ }^{1}$ Note que a transição de fase ocorre em $\mathrm{T}=0$.
} 
com duas interações atrativas 61. Esse modelo é formado por uma rede linear de comprimento $L$ e dividida em $N$ sítios, que podem estar vazios ou ocupados por moléculas, como representado na figura 4.1. As moléculas são distribuídas aleatoriamente na rede e podem se mover entres os sítios, saltando um ou dois sítios. Distribuindo um número $n$ de moléculas nos $N$ sítios da rede vemos que a densidade dada por $\rho=\frac{n}{L}$.

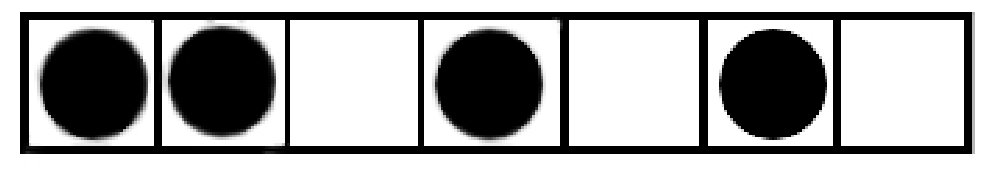

Figura 4.1: rede linear. As partículas são representadas por círculos pretos

Definimos um potencial com duas interações atrativas entre as partículas, além do "caroço duro", uma interação entre primeiros vizinhos $\epsilon_{v d w}$, a qual associamos com a atração de Van der Waals, e outra entre segundos vizinhos, com sítio intermediário vazio, $\epsilon_{h b}$, que associamos com a ligação de hidrogênio. Sendo ambos positivos e $\epsilon_{v d w}<\epsilon_{h b}$. Dessa forma nosso potencial tem a seguinte forma,

$$
U(x)=\left\{\begin{array}{ll}
\infty, & x \leq r_{1} \\
\epsilon_{v d w}, & r_{1}<x \leq r_{2} \\
\epsilon_{h b}, & r_{2}<x \leq r_{3} \\
0, & x>r_{3}
\end{array} .\right.
$$

Onde $r_{1}, r_{2}$ e $r_{3}$ são as distâncias de primeiro, segundo e terceiro vizinhos respectiva-

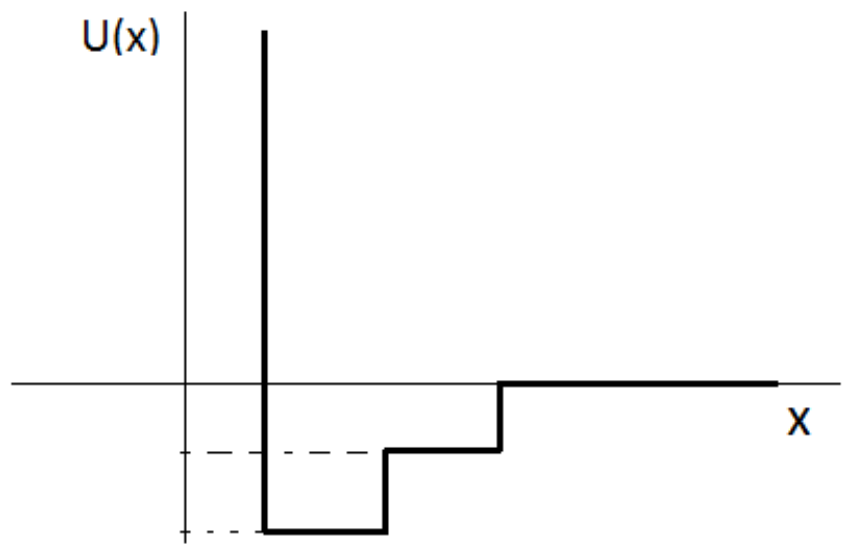

Figura 4.2: Potencial em função da distância. 
mente.

No que se segue a pressão e a temperatura serão definidas como variáveis reduzidas adimensionais da seguinte maneira:

$$
\begin{aligned}
& t=\frac{k_{B} T}{\epsilon}, \\
& p=\frac{P L}{\epsilon_{v d w}} .
\end{aligned}
$$

Onde $k_{B}$ é a constante de Boltzmann.

Neste modelo podemos distinguir a existência de três fases distintas, Gás, Fluido de Baixa Densidade e Fluido de Alta Densidade, definidas da seguinte maneira;

Gás(G) quando as partículas da rede não interagem ou seja estão afastadas por mais de dois sítios; Fluido de Baixa Densidade(BF) quando temos uma dominância de ligações de hidrogênio, as partículas estão interagindo com segundos vizinhos, e Fluido de Alta Densidade ou Fluido Denso(DF), quando se tem dominância de interação de Van der Waals, ou seja, quando a interação de primeiros vizinhos.

Outros modelos de água, como o TIP4P/2015, ST2 e TIP5P, também evidenciam a existência de um ponto crítico no fim da linha de transição líquido-líquido na região do líquido superesfriado 62 64].

O Hamiltoniano efetivo no ensemble grande canônico para esse modelo é escrito como

$$
\mathcal{H}=-\sum_{i=1}^{N+1}\left[\epsilon_{v d w} \eta_{i} \eta_{i+1}+\epsilon_{h b} \eta_{i}\left(1-\eta_{i+1}\right) \eta_{i+2}\right]-\mu \sum_{i=1}^{N+1} \eta_{i}
$$

Partimos deste Hamiltoniano para encontramos a propriedades termodinâmicas deste modelo analiticamente. Primeiro temos que encontrar nossa função de partição grande canônica para o Hamiltoniano dado pela eq. 4.2. Para isso vamos usar a técnica da matriz de transferência, descrita anteriormente. Levando em conta que nosso modelo apresenta interação somente entre os três primeiros vizinhos, podemos olhar para um pedaço da rede somente com três sítios e escrever o Hamiltoniano como:

$$
h\left(\eta_{i-1}, \eta_{i}, \eta_{i+1}\right)=-\frac{1}{2} \epsilon_{v d w}\left(\eta_{i-1} \eta_{i}+\eta_{i} \eta_{i+1}\right)-\epsilon_{h b} \eta_{i-1}\left(1-\eta_{i}\right) \eta_{i+1}-\mu \eta_{i}
$$

Podemos ver que $\mathcal{H}=\sum h$. Com esse Hamiltoniano podemos calcular o peso de Boltz- 
mann, escrito da seguinte forma,

$$
Q_{n}=e^{-\beta \mathcal{H}}=\prod_{i} e^{-\beta h}
$$

e então calculamos a função de grande partição que é dada por

$$
\Xi(\mu, L, T)=\sum_{\{\eta\}} Q_{n}
$$

Substituindo (4.4) em 4.5 temos:

$$
\Xi(\mu, L, T)=\sum_{\{\eta\}} \prod_{i} e^{-\beta h}
$$

Para obtermos a solução exata desta função, vamos usar à Técnica da Matriz de Transferência (TMT), apresentada anteriormente na seção (2.3). Em nosso modelo temos a função de Grande Partição dada pela equação (4.6), onde assumimos uma condição períodica de contorno. Definimos uma matriz $P\left(\eta_{i-1}, \eta_{i}, \eta_{i}^{\prime}, \eta_{i+1}\right)$, tal que,

$$
P\left(\eta_{i-1}, \eta_{i}, \eta_{i}^{\prime}, \eta_{i+1}\right)=\left\{\begin{array}{cc}
Q\left(\eta_{i-1}, \eta_{i}, \eta_{i+1}\right), & \eta_{i}=\eta_{i}^{\prime} \\
0, & \eta_{i} \neq \eta_{i}^{\prime}
\end{array} .\right.
$$

Como visto anteriormente, podemos escrever a equação (4.6) como o traço da matriz $P^{N}, \log \mathrm{O}$

$$
\Xi(\mu, L, T)=\operatorname{Tr}\left(P^{N}\right)
$$

lembrando que a variável de ocupação $\eta$ assume os valores 0 ou 1, substituindo esse valores em 4.7) calculando o peso de Boltzmann (4.4) usando a função 4.3, podemos montar nossa matriz. Vamos usar a seguinte notação $a=e^{-\beta \epsilon_{e v w}}, b=e^{-\beta \epsilon_{h b}}$ e $z=e^{\beta \mu}$, assim a matriz fica com a seguinte forma:

$$
P=\left(\begin{array}{cccc}
1 & 1 & 0 & 0 \\
0 & 0 & z & a^{1 / 2} z \\
1 & b & 0 & 0 \\
0 & 0 & a^{1 / 2} z & a z
\end{array}\right)
$$

Para encontrarmos uma solução do autovalor não trivial é necessário que:

$$
\operatorname{Det}(P-I \lambda)=0,
$$

então temos 


$$
\operatorname{Det}\left(\begin{array}{cccc}
1-\lambda & 1 & 0 & 0 \\
0 & -\lambda & z & a^{1 / 2} z \\
1 & b & -\lambda & 0 \\
0 & 0 & a^{1 / 2} z & a z-\lambda
\end{array}\right)=0
$$

Com isso encontramos o polinômio característico do problema, dado por

$$
\lambda^{3}-(1+a z) \lambda^{2}+z(a-b) \lambda+z(b-1)=0 .
$$

Colocando $z$ em função de $\lambda$ temos:

$$
z=\frac{\lambda^{2}(1-\lambda)}{a \lambda(1-\lambda)+b(1-\lambda)-1} .
$$

Como no limite termodinâmico somente o maior autovalor tem uma contribuição significativa para a função de grande partição, a equação 4.8 resulta em

$$
\Xi(\mu, L, T)=\lambda^{L}=e^{\beta P L} .
$$

Portanto, obtemos $\lambda=e^{\beta P}$. Com isso podemos encontrar a solução exata de todas as funções termodinâmicas indicadas na seção anterior.

\subsubsection{Pressão crítica e Densidade}

A pressão critíca para o modelo proposto pode ser calculado a partir da minimização da energia livre de Gibbs (eq. 2.8), como feito anteriormente por Sadr-Lahijany et al. em um modelo similar 45. Tomando o limite $T \rightarrow 0$, temos

$$
P_{c}=-\frac{\left(U_{a}-U_{d}\right)}{\left(r_{a}-r_{d}\right)}
$$

onde $U_{a}$ e $U_{d}$ são os valores da energia para uma estrutura aberta (baixa densidade) e outra fechada (alta densidade), respectivamente. Fazendo as substituições $U_{a}=\epsilon_{h b}$, $U_{d}=\epsilon_{v d w}, r_{a}=l$ e $r_{b}=2 l$, ficamos com

$$
P_{c}=\frac{\epsilon_{h b}-\epsilon_{v d w}}{l}
$$

que é a pressão critica.

A densidade do modelo pode ser calculada em função de $\lambda$, partindo da equação 2.14 e realizando alguns cálculos chegamos a seguinte expressão: 


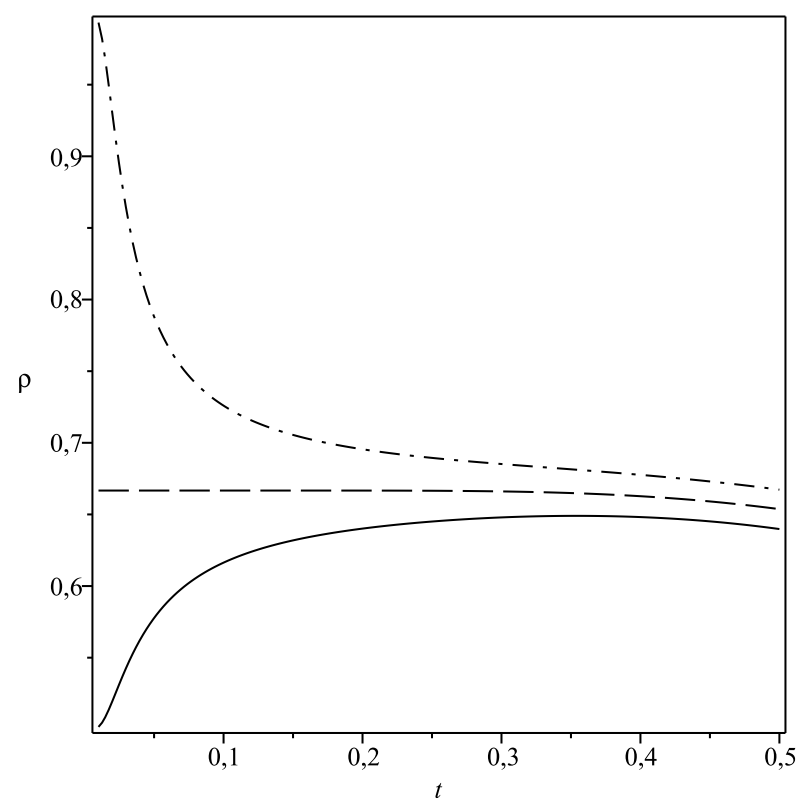

Figura 4.3: Densidade em função da temperatura para três pressões distintas. $p=0.45$ (ponto e linha), $p=p_{c}=0.50$ (linha tracejada), $p=0.55$ (linha cheia). Para $p=0.5$, observamos um comportamento de um fluido normal, com a densidade diminuindo com aumento da temperatura.

$$
\rho=\frac{z}{L}\left(\frac{\partial \ln \Xi}{\partial z}\right)=\frac{z}{\lambda}\left[\left(\frac{\partial z}{\partial \lambda}\right)\right]^{-1},
$$

então substituindo o valor de $z$ dado pela equação (4.11), temos:

$$
\rho=\frac{(\lambda-1)[(a \lambda+b)(\lambda-1)+1]}{(\lambda-1)^{2}(a \lambda+2 b)+3 \lambda-2} .
$$

Um gráfico da densidade pela temperatura, com pressão constante, é mostrado na figura 4.3. Podemos observar um aumento na densidade com a temperatura, com $p<p_{c}$ sendo $p_{c}=0.5$, até que seja alcançado um ponto de máximo, reproduzindo um comportamento anômalo da água. Nessa região temos um coeficiente de expansão térmica negativo $(\alpha<0)$. Após o ponto máximo da densidade, esta começa a diminuir quando temperatura aumenta, como esperado para fluidos considerados "normais". Para esse caso temos, portanto, uma inversão no sinal do coeficiente de expansão térmica $\alpha$, que passa a ser positivo.

Quando $p>p_{c}$ não observamos a anomalia na densidade, assim independente da temperatura $\alpha$ é sempre positivo, visto que a pressão está fora da região onde ocorre o comportamento não usual das propriedades termodinâmicas da água. 


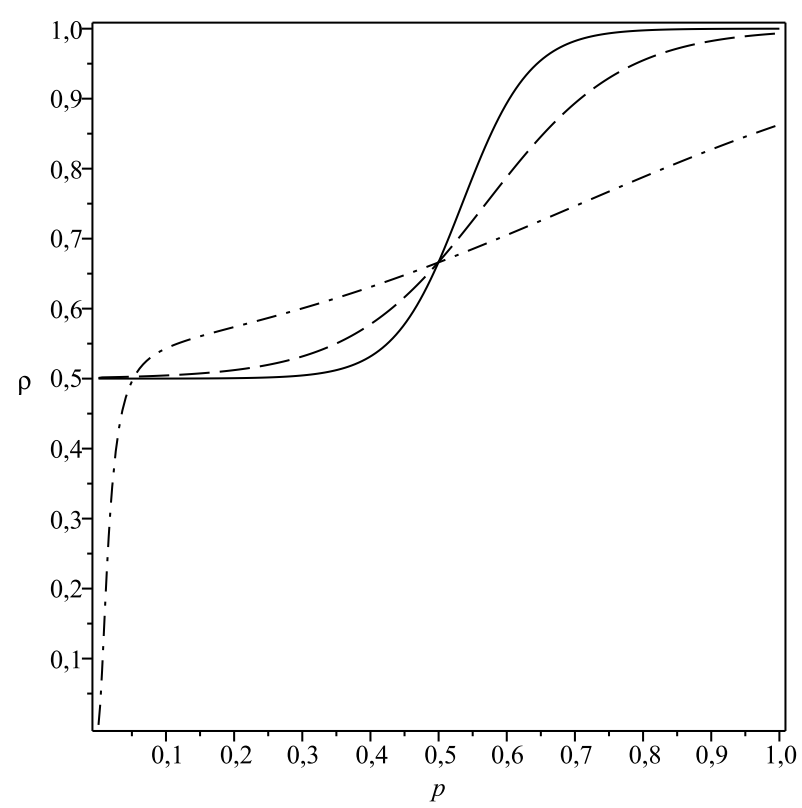

Figura 4.4: Densidade em função da pressão para três temperaturas distintas. $t=0.3$ (ponto e linha), $t=0.1$ (linha tracejada), $t=0.05$ (linha cheia).

Na figura 4.4 é apresentado a densidade em função da pressão, mantendo a temperatura constante. Podemos observar uma transição suave entre as fases de fluido de baixa densidade e fluido denso, essa transição se torna mais abrupta a medida que vamos aumentando a temperatura [61].

\subsubsection{Coeficiente de Expansão Térmica e Compressibilidade Iso- térmica}

O coeficiente de expansão térmica, $\alpha$, a pressão constante, pode ser expresso em termos da densidade por

$$
\alpha=-\frac{1}{\rho}\left(\frac{\partial \rho}{\partial T}\right)_{p} .
$$

Ele mede a capacidade de um corpo aumentar o diminuir suas dimensões com a variação da temperatura, por isso também é conhecido como coeficiente de dilatação térmica. A sua unidade é o inverso da temperatura, no sistema internacional $\left(K^{-1}\right)$. Quanto maior for $\alpha$ maior será a variação do tamanho do sistema com a flutuação na temperatura. Para a maioria dos materiais, que são considerados "normais", o volume aumenta com aumento da temperatura, isso ocorre pois, ao ser aquecido os materiais absorvem energia na forma de calor, que resulta em um aumento da energia cinética dos átomos e consequentemente 
um maior afastamento entre eles. No caso da água essa propriedade apresenta um comportamento diferente do usual, pois na região de 0 a $4{ }^{\circ} \mathrm{C}$ o volume da água diminui com aumento da temperatura, o que caracteriza um coeficiente de expansão negativo.

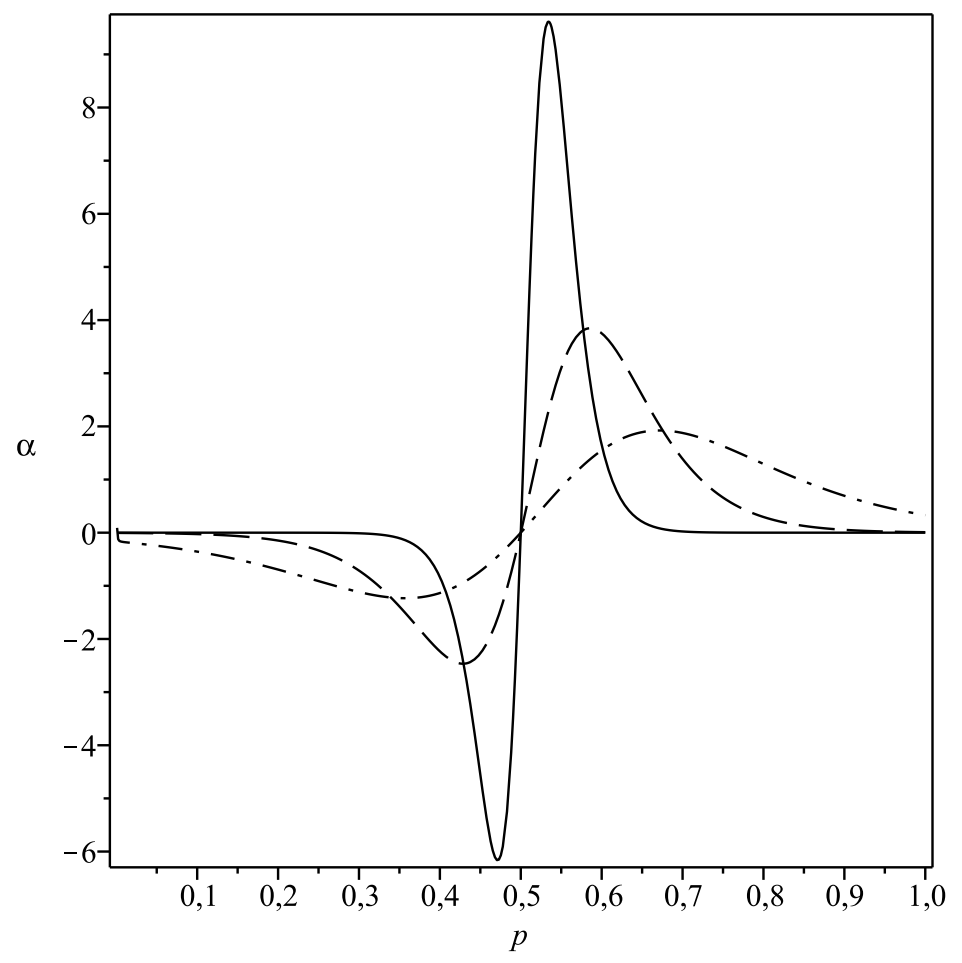

Figura 4.5: Coeficiente de expansão térmica em função da pressão com temperatura fixa. $\mathrm{t}=0.02$ (linha cheia) $\mathrm{t}=0.05$ (linha tracejada), $\mathrm{t}=0.1$ (linha ponto-tracejada)

Na figura 4.5, plotamos o coeficiente de expansão térmica em função da pressão, mantendo a temperatura fixa. Podemos observar nesse gráfico um comportamento divergente de $\alpha$ quando nos aproximamos da região de transição entre baixa densidade e alta densidade. Tomando o limite de aproximação de ponto de transição pela esquerda, baixa densidade, o coeficiente de dilatação tende a $\alpha \rightarrow+\infty$, se aproximamos pela direita, alta densidade, $\alpha \rightarrow-\infty$. Este comportamento fica mais acentuado a medida que a temperatura vai se aproximando de 0 . Repare que a divergência acontece no ponto onde temos $p=p_{c}$, ou seja, na pressão crítica.

A compressibilidade isotérmica $\left(K_{T}\right)$, é a medida da variação do volume em resposta a uma variação na pressão, mantendo a temperatura constante. Em termos da densidade podemos expressar $K_{T}$ como,

$$
K_{T}=\frac{1}{\rho}\left(\frac{\partial \rho}{\partial P}\right)_{T} .
$$

O comportamento esperado para a compressibilidade é a diminuição do vo- 
lume com o aumento da pressão. Em todos os sistemas termodinâmicos estáveis temos $\left(\partial K_{T} / \partial T\right)_{P}>0$. Visto que, $K_{T} \propto<(\Delta V)^{2}>$, então, para esses sistemas temos uma diminuição da flutuação volumétrica quando abaixamos a temperatura.

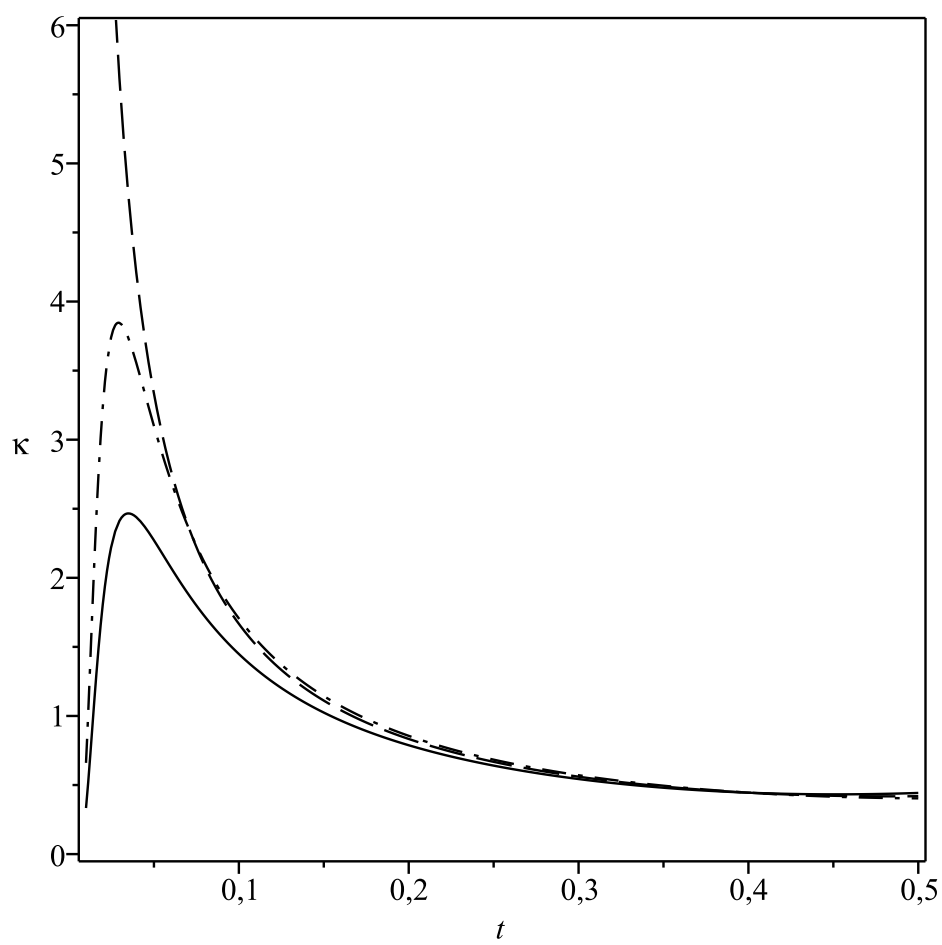

Figura 4.6: Compressibilidade isotérmica em função da temperatura mantendo a pressão fixa. $p=0.45$ (ponto e linha), $p=0.50$ (linha tracejada), $p=0.55$ (linha cheia))

No caso da água, existe uma região onde a compressibilidade diminui com o aumento da temperatura, apresentando um ponto de mínimo. Para pressão $P=1 \mathrm{~atm}$, o mínimo acontece em torno de $T=46^{\circ} \mathrm{C} 65$.

Podemos observar na figura $4.6 \mathrm{um}$ aumento do valor de $K_{T}$ enquanto diminuímos a temperatura. Quando a pressão se aproxima da pressão crítica, $p=p_{c}$, e a temperatura se aproxima de zero, ponto de transição entre DF-BF, vemos o valor da compressibilidade divergir para o infinito.

\subsubsection{Dinâmica}

Utilizando o Método de Monte Carlo obtemos a dinâmica do nosso modelo, descrito anteriormente. Todas as simulações foram feitas no ensemble canônico, considerando uma configuração inicial gerada distribuindo-se N partículas aleatoriamente nos $\mathrm{V}$ sítios da rede, sendo nossa rede montada com $\mathrm{V}=1000$ sítios e condições de contorno periódicas. 
A cinética das partículas do fluido é definida da seguinte maneira: uma partícula é escolhida aleatoriamente e em seguida ela realiza um salto que pode ser de um ou dois sítios à direita ou à esquerda em relação à posição atualmente ocupada. Quando o salto for de dois sítios ela não olha para o sítio intermediário, que pode estar ocupado ou vazio. Esta condição foi aplicada para que pudéssemos obter a difusão, visto que, para uma rede unidimensional as partículas ficariam sempre na mesma ordem inicialmente arranjadas se não houvesse a possibilidade de saltos através de outra partícula.

Após a montagem da rede com uma configuração inicial aleatória, atribuímos um vetor $\vec{X}(a)$ a posição de cada uma das partículas. Em seguida escolhemos uma delas para realizar um salto, então olhamos a posição para qual a partícula irá ser deslocada, caso esse sítio esteja ocupado ela não pode realizar o salto permanecendo na posição que ocupava originalmente, em seguida escolhemos outra partícula e testamos novamente a possibilidade de que seja realizado o salto. Quando uma partícula salta para um sítio vazio, usamos o algorítimo de Metropolis para testarmos se a nova configuração é aceita. Ao repetirmos esse procedimento $\mathrm{N}$ vezes obtemos um passo de Monte Carlo (PMC) 66 e ao final de cada PMC calculamos o deslocamento médio das partículas.

Quando é atingido um tempo de equilíbrio $\tau_{e q}$ estipulado inicialmente, passamos a calcular o deslocamento quadrado médio, que é salvo em um arquivo a cada $10^{3}$ PMC. Terminada a simulação, obtemos a constante de difusão interpolando a relação de Einstein, dado por:

$$
D(t, \rho)=\left\langle\frac{1}{2 N \tau} \sum_{j=1}^{N}\left[X_{j}(\tau)-X_{j}(0)\right]^{2}\right\rangle .
$$

onde t é a temperatura reduzida, $\rho$ é a densidade, $\mathrm{N}$ é o número de partículas e $\tau$ é o tempo de simulação.

Com o intuito de descobrir se nosso modelo apresentava também anomalia na difusão $D$, analisamos o comportamento da variação de $D$ em função da densidade $\rho$, com temperatura fixa. Para cada temperatura realizamos dez simulações, partindo de configurações iniciais diferentes, sobre as quais tomamos a média. Com isso obtemos a média expressa na equação 4.49. Foram obtidos dados para temperaturas reduzidas entre 0.3 a 0.7 e densidades de 0.15 até 0.90. Em todos os casos o tempo para cada simulação, dado em passos de Monte Carlo, foi de $10^{6} \mathrm{PMC}$.

Na figura 4.7 é mostrado o comportamento da constante de difusão $D$ em função da densidade para cinco temperaturas diferentes. Podemos observar uma região onde claramente acontece um aumento da difusão com a densidade, especialmente para temperaturas abaixo de $t=0.56$. Nesta região podemos localizar os pontos de mínimo na difusão $\left(D_{\min }\right)$ e máximo $\left(D_{\max }\right)$, este comportamento de aumento de difusão com 


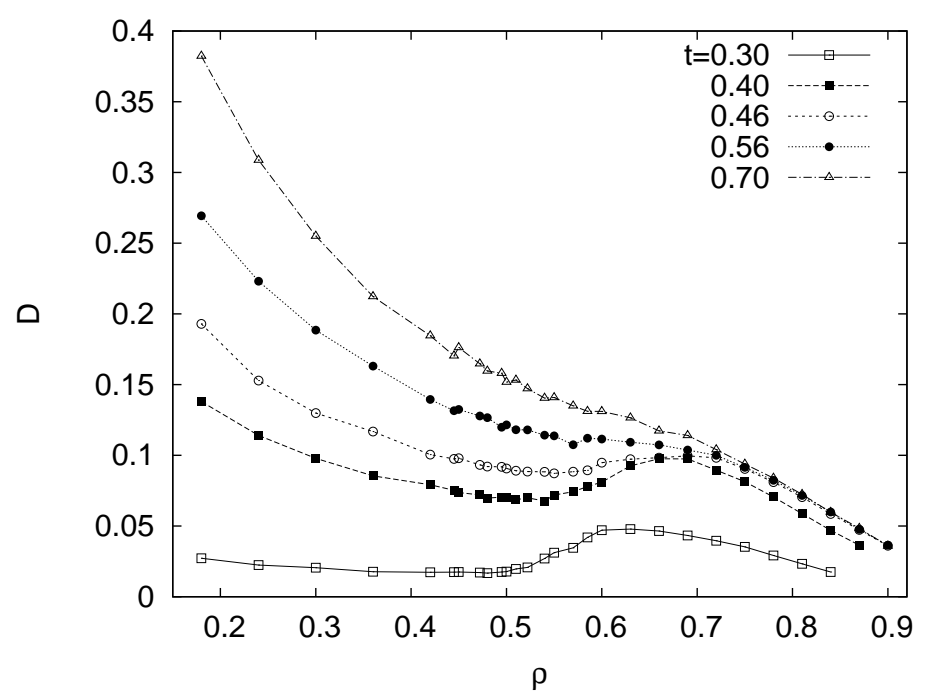

Figura 4.7: Difusão em função da densidade

a densidade é um dos comportamentos anômalos apresentado pela água [3]. Podemos notar que para temperaturas elevadas, $t=0.7$, a difusão decresce com o aumento da densidade como esperado em substâncias normais.

Para localizarmos os pontos de máximo e mínimo da difusão, $\left(D_{\max }\right),\left(D_{\min }\right)$ respectivamente, fizemos um fit usando o programa Gnuplot, utilizando a seguinte função:

$$
D(t, \rho)=\left(a \rho^{3}+b \rho^{2}+c \rho+d\right) \exp \left(e \rho^{2}+f \rho+g\right),
$$

onde $a, b, c, d, e, f$, e $g$ são parâmetros numéricos que ajustam a função aos resultados numéricos. Feito os ajustes e encontrado os valores dos parâmetros, nós podemos derivar a equação 4.20 para encontrar os valores de $\left(D_{\max }\right)$ e $\left(D_{\min }\right)$ para cada uma da cinco temperaturas mostradas na figura 4.7. Para realizarmos o ajuste da função nos usamos 10 pontos da curva em torno dos pontos de máximo e mínimo para temperaturas menores que $t=0.43$ e 17 pontos para temperaturas mais elevadas.

A anomalia na difusão já havia sido observada em modelos atômicos [67] e modelos de rede mais complexos, contudo esta é a primeira vez que este comportamento pode ser visto em um modelo unidimensional.

Na figura 4.8 comparamos os pontos de máximo e mínimo de difusão com linha de Temperatura de Máximo de Densidade (TMD), em um gráfico de densidade pela temperatura. Comparando esta figura com resultados similares obtidos por outros modelos 18, 19, embora seja visivel uma penetração da linha $D_{\max }$ na região cercada pela linha TMD, observamos uma tendência ao que chamamos de hierarquia de anomalias, 


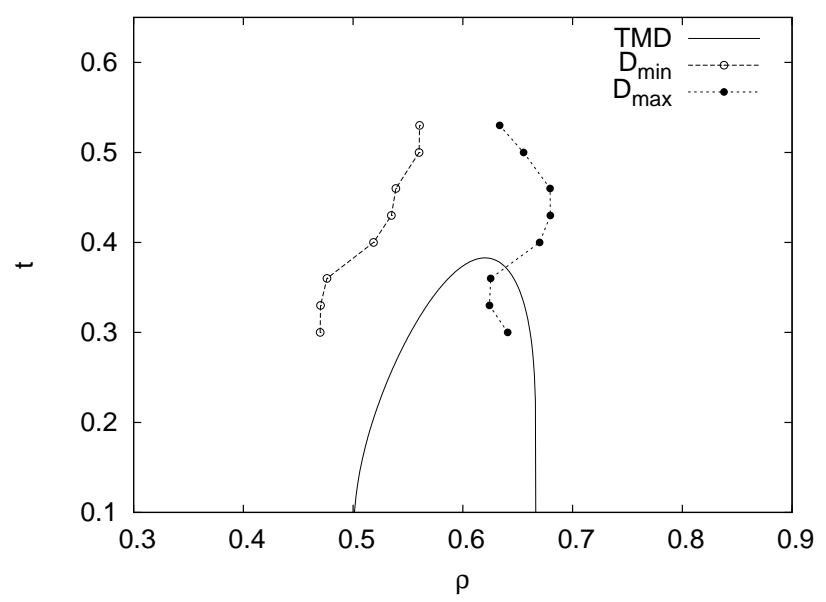

Figura 4.8: hierarquia de anomalias no diagrama de fase t vs $\mathrm{p}$.

conforme visto no capitulo de introdução, caracterizado pela seguinte ordem; a região de de anomalia termodinâmica, região interna da linha TMD, cercada pelas linhas de máximo $D_{\max }$ e mínimo $D_{\min }$ de difusão, região que acontece as anomalias dinâmicas [5].

\subsubsection{Conclusões}

Nesse modelo simples, foram encontradas anomalias na densidade e na difusão, também foi possível identificar duas estruturas líquidas as quais chamamos de fluido de baixa densidade (BF), onde temos maioria de ligações de hidrogênio (segundos vizinhos) e um fluido denso(DF), onde a atração de Van der Waals (primeiros vizinhos) é dominante. Investigando a compressibilidade isotérmica e o coeficiente de expansão térmica, identificamos a região onde ocorrem as anomalias termodinâmicas e verificamos que esta se encontra na vizinhança de transição DF-BF. Nessa região, com temperatura baixa, o coeficiente de expansão térmica apresenta um comportamento divergente quando aproximamos do ponto $P=P_{c}$ (figura 4.5), onde $P_{c}$ é a pressão crítica. A temperatura nula, identificamos o ponto onde ocorre a transição DF-BF como sendo o segundo ponto crítico.

Através desse modelo investigamos a relação existente entre as anomalias termodinâmicas e dinâmicas da água, que foram encontradas na região de transição entre as duas estruturas líquidas, contudo, ele não apresentou uma hierarquia de anomalias bem definida, pois a região de anomalia dinâmica penetra a região de anomalia termodinâmica em baixa temperatura, como pode ser visto na figura 4.8 .

Com sucesso obtido utilizando um modelo simples, fizemos a seguinte pergunta: é possível simplificar ainda mais a forma do potencial e ainda assim obter propriedades similares à água? A resposta para essa pergunta é sim conforme demostraremos na 
próxima seção.

\subsection{Modelo com interação repulsiva entre primeiros vi- zinho}

Nosso novo modelo é similar ao descrito na seção anterior, formado por uma rede linear de comprimento L dividida em $\mathrm{N}$ sítios idênticos, cada um podendo estar ocupado por uma partícula ou vazio (Figura 4.9] [68]. Como o número de moléculas distribuídas na rede é igual a $n$, a densidade é $\rho=\frac{n}{L}$. A grande diferença entre os dois modelos está no potencial de interação entre as moléculas.

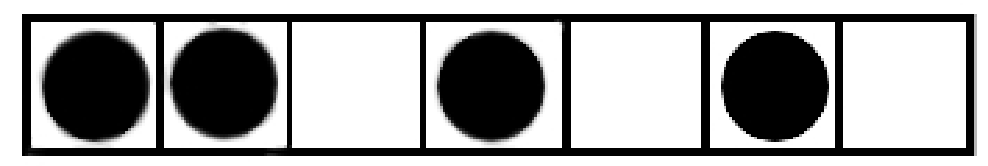

Figura 4.9: rede linear. As partículas são representadas por círculos pretos

Como anteriormente, definimos uma variável de ocupação $\eta_{k}$ que assume os valores 0 se o sítio estiver vazio ou 1 se ele estiver ocupado. A simplicidade do modelo, além do fato de ser em uma dimensão, está no seu potencial de interação (figura 4.10) que, ao contrário da maioria dos modelos em rede encontrados na literatura 42, 69, possui somente um "núcleo duro" e uma interação repulsiva entre primeiros vizinhos.

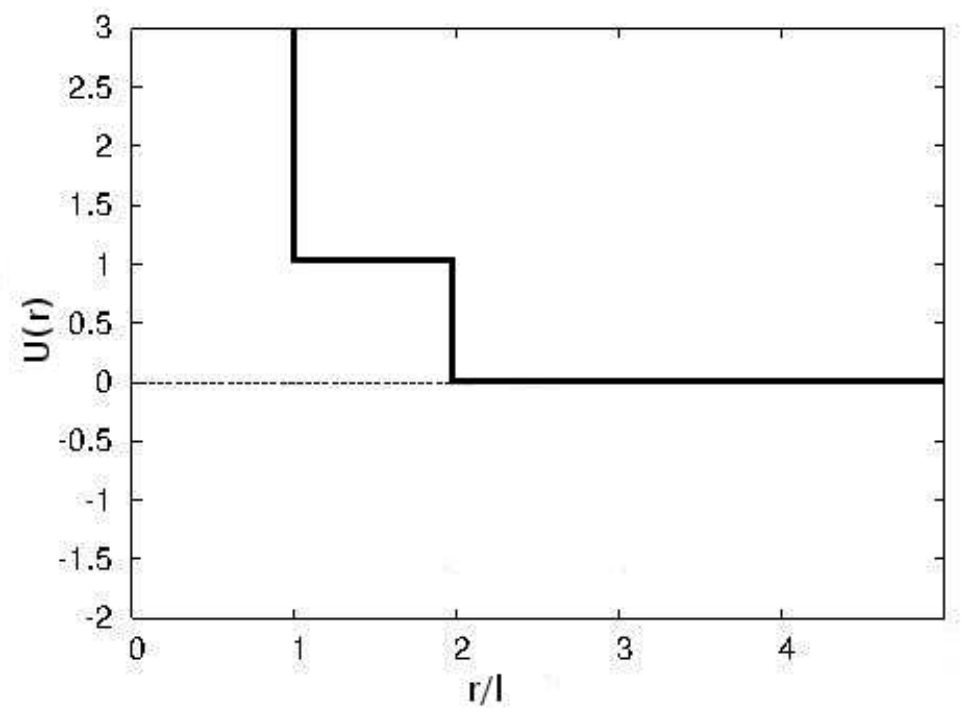

Figura 4.10: Representação do potencial de interação entre as moléculas da rede no modelo aqui investigado. 
A grande vantagem do nosso modelo é que podemos utilizar cálculos simples para obtermos as soluções exatas de todas as funções termodinâmicas e além disso, o desenvolvimento de códigos de Monte Carlo, para investigar a cinética, é bastante simples e não requer grandes recursos computacionais, que nos permite acessar regiões com temperaturas mais baixas. Para investigarmos o caso com interação atrativa basta uma troca de sinal na equação 4.22 .

\section{O Hamiltoniano}

O Hamiltoniano que representa a energia total do sistema, no caso do modelo proposto para calcularmos seu valor basta fazer uma contagem sobre todos o sítios da rede, contando as partículas e os contatos entre primeiros vizinhos, com o potencial de interação entre as moléculas dado por:

$$
U(R)= \begin{cases}\infty, & R \leq r_{1} \\ \epsilon, & r_{1}<R \leq r_{2} \quad . \\ 0, & R>r_{2}\end{cases}
$$

Onde $r_{1}$ e $r_{2}$ são as distâncias entre o primeiro e o segundo vizinho do sítio, respectivamente, $\operatorname{com} \epsilon>0$ a energia de ligação entre vizinhos.

Então, uma partícula que tem o sítio subsequente, ou seja, seu primeiro vizinho, ocupado por outra partícula, irá contribuir para energia total do sistema com uma energia de interação $\epsilon$, e seu potencial químico $\mu$. Se o vizinho estiver desocupado, a contribuição será somente do seu potêncial químico. A fim de obtermos a solução analítica do sistema, nos utilizaremos o ensemble grade canônico que é o mais apropriado para esse tipo de modelo, então, usando a variável de ocupação definida anteriormente obtemos o Hamiltoniano efetivo:

$$
\mathcal{H}=\epsilon \sum_{i=1}^{N+1} \eta_{i} \eta_{i+1}-\mu \sum_{i=1}^{N+1} \eta_{i}
$$

Nesse caso assumimos a condição períodica de contorno, ou seja $\eta_{N+1}=\eta_{1}$. $\mu$ é o potêncial químico.

Agora calculamos o peso de Boltzmann utilizando o hamiltoniano dado e a equação 4.22 e assim temos:

$$
Q_{n}=e^{-\beta \mathcal{H}}=\prod_{i} e^{-\beta\left(\epsilon \eta_{i} \eta_{i+1}-\mu \eta_{i}\right)}
$$

com isso calculamos a função de grande partição como: 


$$
\Xi(\mu, L, T)=\sum_{\{\eta\}} Q_{n}
$$

Substituindo 4.23 em 4.24 temos:

$$
\Xi(\mu, L, T)=\sum_{\{\eta\}} \prod_{i} e^{-\beta\left(\epsilon \eta_{i} \eta_{i+1}-\mu \eta_{i}\right)}
$$

Para calcularmos a solução exata desta função vamos usar à Técnica da Matriz de Transferência (TMT), apresentada anteriormente na seção (2.3). Em nosso modelo temos a função de Grande Partição dada pela equação 4.25), onde assumimos uma condição períodica de contorno. Definimos uma matriz $P\left(\eta_{i} \eta_{i+1}\right)$, tal que,

$$
P\left(\eta_{i} \eta_{i+1}\right)=e^{-\beta\left(\epsilon \eta_{i} \eta_{i+1}-\mu \eta_{i}\right)} .
$$

Como visto anteriormente, podemos escrever a equação 4.25 como o traço da matriz $P^{N} \operatorname{logo:}$

$$
\Xi(\mu, L, T)=\operatorname{Tr}\left(P^{N}\right)
$$

lembrando que a variável de ocupação $\eta$ assume os valores 0 ou 1, assim podemos ter as seguintes combinações: $\mathrm{P}(0,0) ; \mathrm{P}(0,1) ; \mathrm{P}(1,0)$ e $\mathrm{P}(1,1)$. Fazendo $a=e^{-\beta \epsilon}$ e $z=e^{\beta \mu}$ temos a partir da eq. 4.26 .

$$
\begin{gathered}
P(1,1)=a z ; \quad P(0,1)=1 \\
P(1,0)=z \quad ; \quad P(0,0)=1 .
\end{gathered}
$$

Então podemos montar nossa matriz na forma:

$$
P=\left(\begin{array}{cc}
a z & 1 \\
z & 1
\end{array}\right)
$$

Para encontrarmos uma solução não trivial é necessário que:

$$
\operatorname{Det}(P-I \lambda)=0
$$

que nos dá o polinômio característico, logo temos:

$$
\operatorname{Det}\left(\begin{array}{cc}
a z-\lambda & 1 \\
z & 1-\lambda
\end{array}\right)=0 .
$$


$\mathrm{ou}$

$$
(a z-\lambda)(1-\lambda)-z=0
$$

Colocando $z$ em função de $\lambda$ temos:

$$
z=\frac{\lambda(1-\lambda)}{a(1-\lambda)-1}
$$

Como no limite termodinâmico somente o maior autovalor tem uma contribuição significativa para a função de grande partição, a equação 4.25 é resulta em

$$
\Xi(\mu, L, T)=\lambda^{L}=e^{\beta P L} .
$$

Portanto, obtemos $\lambda=e^{\beta P}$. Com isso podemos encontrar a solução exata de todas as funções termodinâmicas indicadas na seção anterior.

\subsubsection{Pressão crítica e Densidade}

Seguindo a referência [45], calculamos a pressão crítica a partir da minimização da energia livre de Gibbs (eq. 2.8). Tomando o valor $T=0$, temos

$$
P_{c}=-\frac{\left(U_{a}-U_{d}\right)}{\left(r_{a}-r_{d}\right)}
$$

onde $U_{a}$ e $U_{d}$ são os valores da energia para uma estrutura aberta (baixa densidade) e outra fechada (alta densidade), respectivamente. Fazendo as substituições $U_{a}=0$, $U_{d}=\epsilon, r_{a}=l$ e $r_{b}=2 l$, de acordo com a representação do potencial na figura 4.10 , ficamos com

$$
P_{c}=\frac{\epsilon}{l}
$$

que é a pressão critica.

A densidade do modelo pode ser calculada em função de $\lambda$, partindo da equação (2.14) e realizando alguns cálculos chegamos a seguinte expressão:

$$
\rho=\frac{z}{L}\left(\frac{\partial \ln \Xi}{\partial z}\right)=\frac{z}{\lambda}\left[\left(\frac{\partial z}{\partial \lambda}\right)\right]^{-1},
$$

então substituindo o valor de $z$ dado pela equação 4.30, temos:

$$
\rho=\frac{(1-\lambda)[a(1-\lambda)-1]}{a(1-\lambda)^{2}-1+2 \lambda} .
$$


Um gráfico da densidade pela temperatura, com pressão constante, é mostrado na figura 4.11. Podemos observar um aumento na densidade com a temperatura, com $P<P_{c}$, até que seja alcançado um ponto de máximo, reproduzindo um comportamento anômalo da água, nessa região temos $\alpha<0$, indicando um aumento da densidade. Após o ponto máximo da densidade, esta começa a diminuir quando a temperatura aumenta, como esperado para fluidos "normais". Para esse caso temos, portanto, uma inversão no sinal do coeficiente de expansão térmica $\alpha$.

Quando $P>P_{c}$ não observamos a anomalia na densidade, assim independente da temperatura $\alpha$ é sempre positivo, visto que a pressão está fora da região onde ocorre o comportamento não usual das propriedades termodinâmicas da água.

Quando $P=P_{c}$ a curva de densidade é praticamente constante para uma faixa de baixa temperatura, nessa região temos $\alpha \approx 0$. Para temperaturas mais elevadas, a densidade se comporta como esperado em sistemas normais.

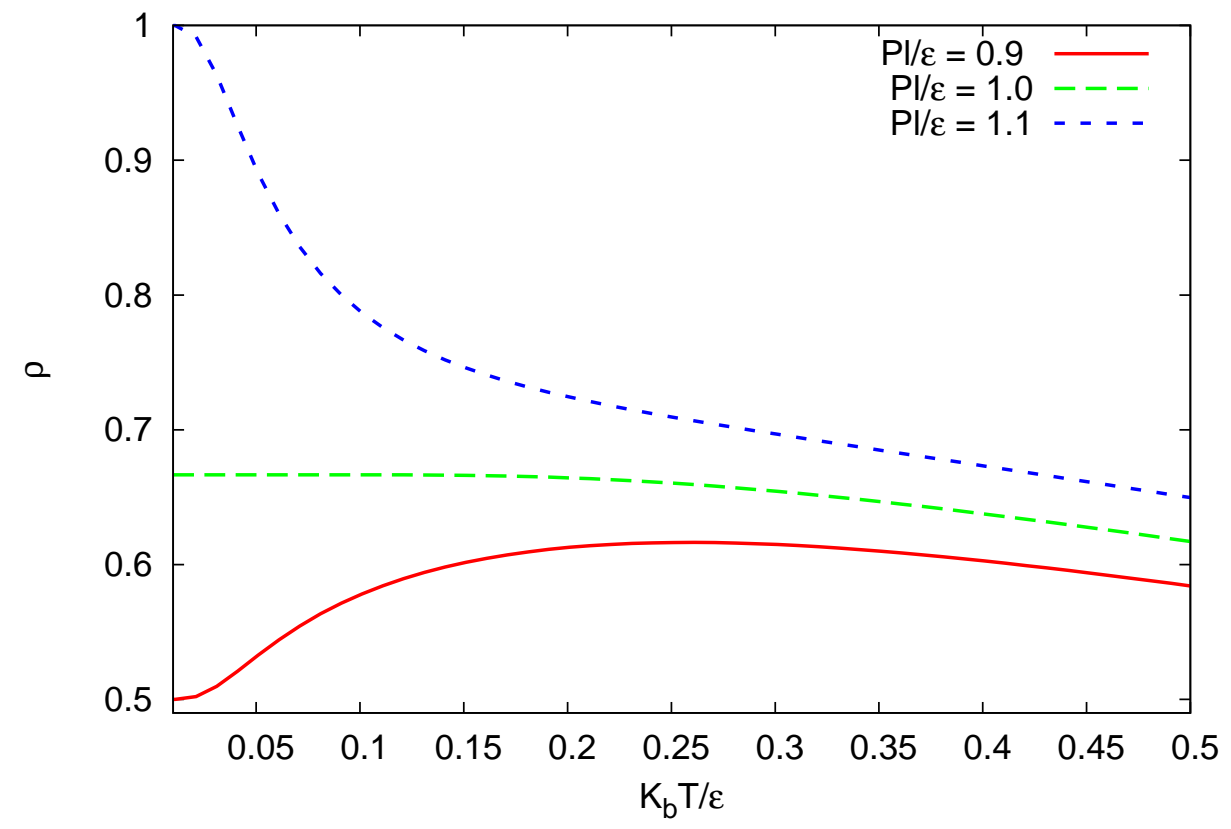

Figura 4.11: Densidade em função da temperatura para três pressões distintas. Para $\mathrm{P}=1.1$, observamos um comportamento de um fluido normal, com a densidade diminuindo com aumento da temperatura.

Este tipo de comportamento da densidade é geralmente relacionado às quebras das ligações de hidrogênio, que provoca a contração do volume molecular do sistema, visto que a distância entre as moléculas é maior nas ligações de hidrogênio que nas ligações de Van der Waals.

No caso do modelo em estudo, esse comportamento tem origem na variação do 
número de primeiros vizinhos. Quando aumentamos a temperatura ocorre um aumento da entropia, assim mantendo a pressão constante e abaixo da pressão crítica, pode ocorrer a penetração das partículas na região repulsiva do potencial, aumentando o número de primeiros vizinhos, ou seja, elas se ligam com outras partículas vizinhas formando uma estrutura fechada, mais densa. Ao continuarmos aumentando a temperatura, aumentamos a energia do sistema, que favorece o afastamento das partículas, diminuindo o número de primeiros vizinhos e portanto diminuindo a densidade.

\subsubsection{Cálculo da Entropia}

Nesta seção vamos encontrar, analiticamente, a entropia para o modelo proposto, e fazer uma comparação com a aproximação de dois estados, baseado na versão de rede do metodo de Takahashi que foi usado na referência [70].

Para o cálculo analítico da entropia iremos relacionar o comportamento anômalo da densidade. Como visto ela diminuí com a temperatura que implica em um $\alpha<0$, à um aumento anômalo da entropia, que pode ser explicado pelo consequente aumento de volume. Isto pode ser visto, observando que $(\partial V / \partial T)_{P}=-(\partial S / \partial P)_{T}$. Portanto se $\alpha=(\partial V / \partial T)_{P}$ for negativo, então

$$
\left(\frac{\partial S}{\partial P}\right)_{T}>0
$$

portanto, temos uma região onde acontece um aumento da entropia com a pressão, mantendo-se a temperatura fixa. Sabemos que a entropia pode ser expressa como

$$
s=-\left(\frac{\partial \mu}{\partial T}\right)_{P},
$$

sendo,

$$
\ln (z)=\beta \mu \quad \rightarrow \quad \mu=k_{B} T \ln (z)
$$

portanto temos:

$$
s=-\left(\frac{\partial\left[k_{B} T \ln (z)\right]}{\partial T}\right)_{P} .
$$

Usando $z$ dado pela equação 4.30, encontramos:

$$
s=-k_{B} \ln (z)+\frac{1}{T z}\left[P z-\frac{P \lambda^{2}}{a(1-\lambda)-1}+z \epsilon \frac{a(1-\lambda)+P \lambda}{a(1-\lambda)-1}\right] .
$$


Que é a entropia exata para nosso modelo.

Agora vamos usar o método de Takahashi, adaptado a modelos de rede [70], para fazer uma aproximação de dois estados na região do segundo ponto crítico, onde ocorre a transição entre os dois estados, o de líquido de baixa densidade e o de alta densidade. Para este modelo podemos escrever a energia livre de Gibbs aproximadamente como:

$$
G / N \approx h_{c}-k_{B} T \ln \left\{e^{-\beta\left(P-P_{c}\right) r_{A}}+e^{-\beta\left(P-P_{c}\right) r_{B}}\right\}
$$

onde $h_{c}$ é uma constante indêntica a entalpia local microscopia na transição de fase no estado fundamental [68]. Rescrevendo a equação $4.41 \mathrm{em}$ termos das unidades reduzidas, $t=k_{B} T / \epsilon, p=P l / \epsilon, g=G / N \epsilon, \rho=N / L l$ e $s=S / N k_{B}$, obtemos

$$
g=\frac{h_{c}}{\epsilon}+\frac{3}{2}(p-1)-t \ln \left[2 \cosh \left(\frac{(p-1)}{2 t}\right)\right] .
$$

Nesta equação já substituímos valor da pressão critica $p_{c}=1$.

Vimos que a entropia pode ser relacionada com a energia livre de Gibbs através da seguinte relação

$$
s=-\left(\frac{\partial g}{\partial t}\right)_{p}
$$

assim obtemos nossa aproximação para entropia do modelo dada por:

$$
s=\ln \left[2 \cosh \left(\frac{p-1}{2 t}\right)\right]-\left(\frac{p-1}{2 t}\right) \tanh \left(\frac{p-1}{2 t}\right) .
$$

Podemos ver da equação 4.43 que para o estado fundamental na região de transição liquido-liquido, ou seja, com $t \rightarrow 0, p=p_{c}=1$, o resultado sera $s \rightarrow \ln 2$, chamada de entropia residual.

Um gráfico da entropia pela pressão, mantendo a temperatura fixa, é mostrado na figura 4.12. Neste gráfico plotamos três valores distintos para temperatura, $t=0.2$, $t=0.4$ e $t=0.5$, com as curvas obtidas da função da entropia dado pela nossa solução exata (eq 4.40). Uma quarta curva é obtida pela aproximação dada pela equação 4.43 . formada por círculos no gráfico, com $t=0.5$. Podemos ver que a entropia apresenta um ponto de máximo e mínimo local, para $T=0.2$. Com $T=0.4$ a entropia comporta-se como um fluido normal, pois para essa temperatura já não observamos anomalias termodinâmicas, como pode ser visto no gráfico da densidade (fig. 4.11), onde o aumento da densidade com a temperatura vai até aproximadamente $t=0.25$, passando a se comportar como esperado. O ponto de máximo da entropia ocorre em $P=P_{c}$. Este comportamento para entropia é considerado anômalo, pois é natural que 


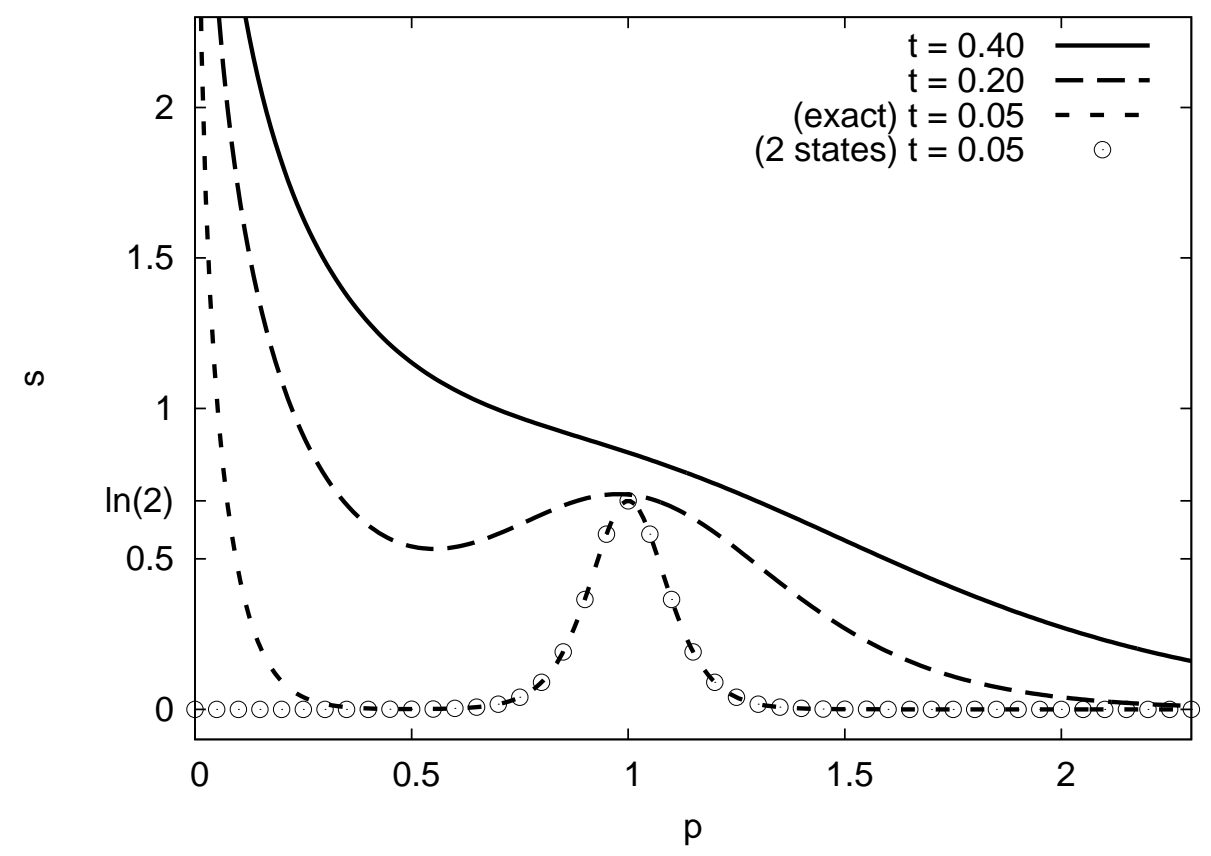

Figura 4.12: Entropia em função da pressão, com temperatura fixa, soluções exatas (linhas contínuas e tracejadas) e aproximação de dois estados (círculos). Note que a entropia apresenta um valor máximo a baixas temperaturas em $p=p_{c}=1$.

ao comprimirmos o sistema, mantendo sua temperatura constante, a entropia diminua. Comportamento que não acontece na água na região onde $P<P_{c}$.

Olhando ainda para fig. 4.12, é importante observar a precisão da aproximação de dois estados perto da transição. Essa precisão evidencia a relevância de uma entropia residual para o aparecimento de uma linha TMD, uma vez que uma região de aumento anômalo da entropia aparece em baixa temperatura na vizinhança da transição liquidoliquido. O que é interessante nesse comportamento é que a anomalia na entropia aparece naturalmente devido a entropia residual, cuja origem é a mistura de duas fases na transição no estado fundamental. Desta forma, o comportamento anômalo da entropia e da densidade está intrinsecamente associada à transição de nosso modelo unidimensional, uma vez que a mistura e o comportamento crítico não dissociada quando transições contínuas e descontínuas são colapsado no mesmo ponto.

A entropia residual também pode explicar o comportamento oscilatório observado no coeficiente de expansão térmica em função da pressão, 4.13 , perto do ponto de transição crítica. Esse comportamento já observado no modelo anterior pode ser relacionado com a anomalia da entropia de maneira simples: abaixo da pressão crítica, $\alpha$ deve ser negativo devido ao rápido aumento da entropia para o seu valor residual $\ln 2$, e acima da $p_{c}$, entropia deve diminuir rapidamente para um valor baixo, uma vez que seu valor 
deve ser nulo em $t=0$.

Vale ressaltar que a aproximação de dois estados também prediz um aumento na compressibilidade isotérmica a pressão constante enquanto se reduz a temperatura, para pressões próxima da pressão crítica. Ambos as funções de resposta devem apresentar valores máximos como função da temperatura para pressões próximas à crítica.

\subsubsection{Coeficiente de Expansão Térmica e Compressibilidade Iso- térmica}

Nesta sub-seção iremos analisar o comportamento do nosso modelo em rede para duas importantes funções resposta do sistema; o coeficiente de expansão térmica $\alpha$ e a compressibilidade isotérmica $K_{T}$. Mostraremos como esse comportamento pode ser relacionado com as anomalias dessas funções na água líquida.

\section{Coeficiente de Expansão Térmica}

O coeficiente de expansão térmica $(\alpha)$ a pressão constante, pode ser expresso em termos da densidade por

$$
\alpha=-\frac{1}{\rho}\left(\frac{\partial \rho}{\partial T}\right)_{P} .
$$

Ele mede a capacidade de um corpo aumentar o diminuir suas dimensões com a variação da temperatura, por isso também é conhecido como coeficiente de dilatação térmica. A sua unidade é o inverso da temperatura, no sistema internacional $\left(K^{-1}\right)$. Quanto maior for $\alpha$ maior será a variação do tamanho do sistema com a flutuação na temperatura. Para a maioria dos materiais, que são considerados "normais", o volume aumenta com aumento da temperatura, isso ocorre pois, ao ser aquecido os materiais absorvem energia na forma de calor, que resulta em um aumento da energia cinética dos átomos e consequentemente um maior afastamento entre eles.

No caso da água essa propriedade apresenta um comportamento diferente do usual, pois na região de 0 a $4{ }^{\circ} \mathrm{C}$ o volume da água diminui com aumento da temperatura, o que caracteriza um coeficiente de expansão negativo.

Podemos observar na figura 4.13 que assim como no modelo anterior com duas interações atrativas há uma divergência no comportamento do coeficiente de expansão térmica no gráfico em função da pressão, mantendo a temperatura fixa. Neste diagrama $\alpha$ apresenta uma variação abrupta na região de transição entre LDL-HDL e que o sinal de $\alpha$ depende de como nos aproximamos do ponto crítico $\left(T=0, P=P_{c}\right)$. Quando 


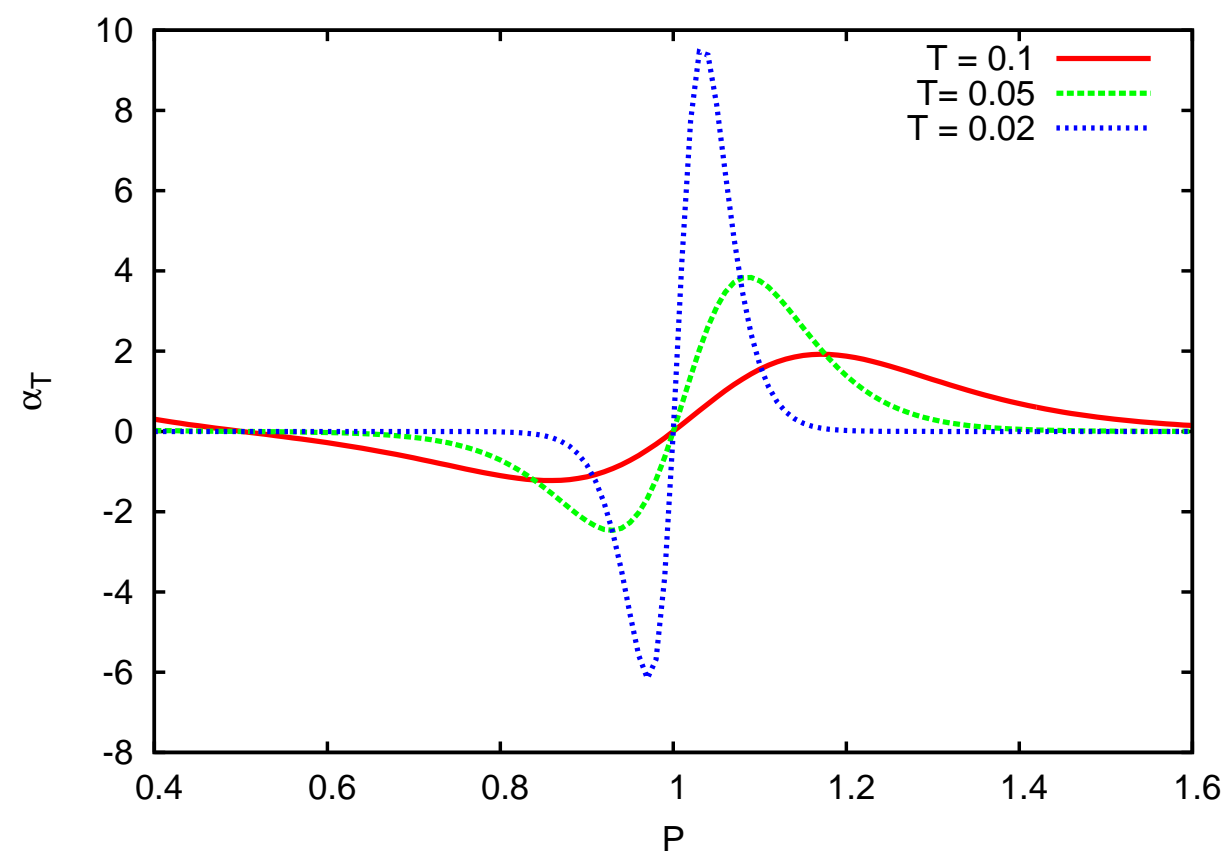

Figura 4.13: Coeficiente de expansão térmica em função da pressão com temperatura fixa.

tomamos o limite $T \rightarrow 0$, com $P \rightarrow P_{c}$ pela direita (altas pressões), temos

$$
\alpha \sim \frac{1}{T}
$$

Quando o limite é tomado com $P \rightarrow P_{c}$ pela esquerda (baixa pressões), temos

$$
\alpha \sim-\frac{1}{T}
$$

Este comportamento também foi obtido em um modelo com múltiplas transições liquidoliquido [70], onde esse comportamento divergente acontece em dois pontos de transição marcados pela pressão critica.

\section{Compressibilidade Isotérmica}

A compressibilidade isotérmica $\left(K_{T}\right)$, é a medida da variação do volume em resposta a uma variação na pressão, mantendo a temperatura constante. Em termos da densidade podemos expressar $K_{T}$ como,

$$
K_{T}=\frac{1}{\rho}\left(\frac{\partial \rho}{\partial P}\right)_{T}
$$




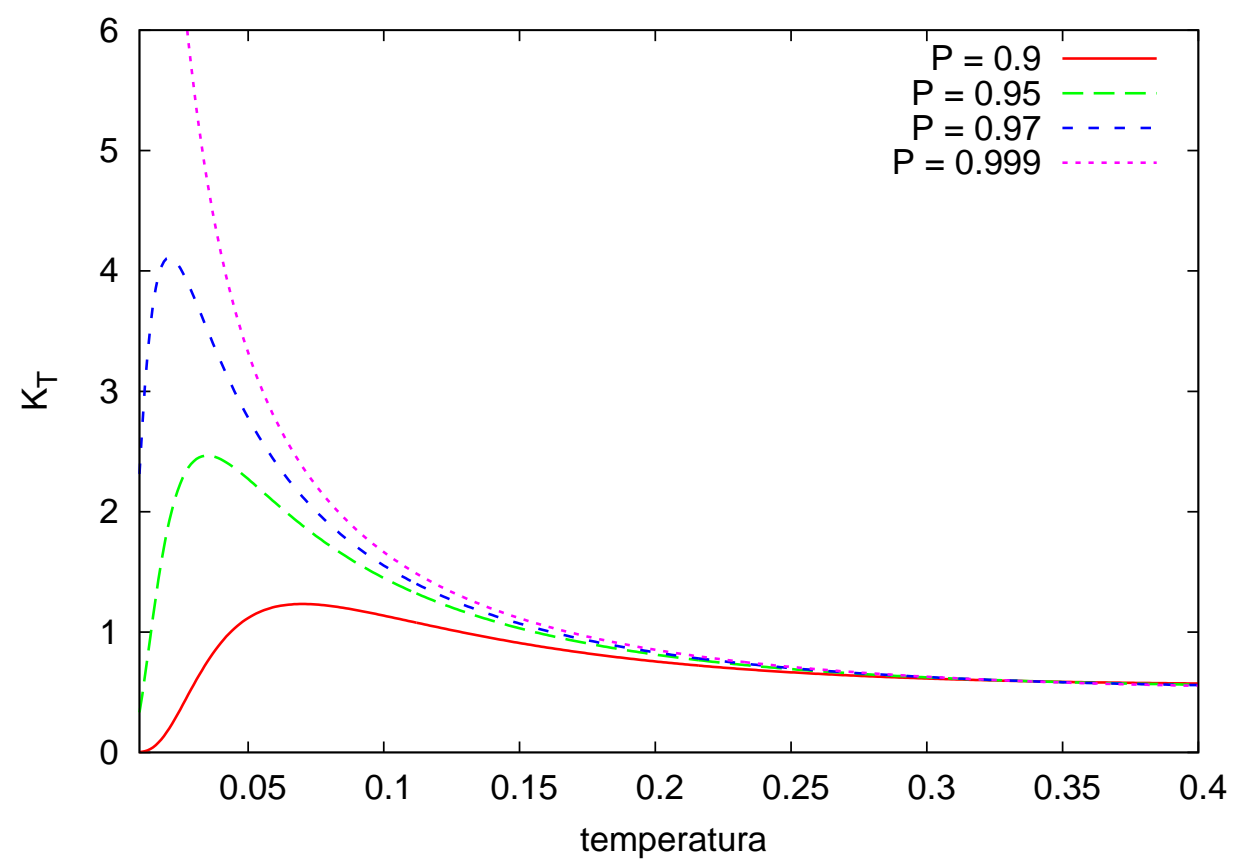

Figura 4.14: Compressibilidade isotérmica em função da temperatura

O comportamento esperado para a compressibilidade é a diminuição do volume com o aumento da pressão. Em todos os sistemas termodinâmicos estáveis temos $\left(\partial K_{T} / \partial T\right)_{P}>$ 0. Visto que, $K_{T} \propto<(\Delta V)^{2}>$, então, para esses sistemas temos uma diminuição da flutuação volumétrica quando abaixamos a temperatura. No caso da água, existe uma região onde a compressibilidade diminui com o aumento da temperatura, apresentando um ponto de mínimo. Para $P=1$ atm o mínimo acontece em torno de $T=46^{\circ} \mathrm{C}[65$.

Na figura 4.14 a compressibilidade isotérmica do nosso modelo é mostrada em função da temperatura para quatro valores de pressão distintos. Na vizinhança da região de transição entre as duas estruturas líquidas observa-se um aumento da compressibilidade quando a temperatura diminui, comportamento atípico, como encontrado em outros modelos em rede para água [45,61]. Pode-se notar ainda, que ao se aproximar da pressão crítica, a baixa temperatura, a compressibilidade apresenta uma divergência característica de um ponto crítico. Podemos observar que, quando $T \rightarrow 0 \operatorname{com} P=P_{c}$, temos

$$
K_{T} \sim \frac{1}{T}
$$

Tanto $K_{T}$ quanto $\alpha$, apresentam um comportamento anômalo, similar ao apresentado pela água líquida. Também esta presente uma linha de transição líquido-líquido, a qual termina em um ponto crítico, estando de acordo com a hipótese do segundo ponto 
crítico. Esse tipo de comportamento é bem conhecido na literatura, já sendo encontrado em outros modelos tipo água.

\subsubsection{Estrutura líquida}

Às anomalias na compressibilidade isotérmica e na expansão térmica podem ser relacionadas a uma existência de duas estruturas líquidas, HDL e LDL, como visto anteriormente. Na figura 4.15 apresentamos o diagrama de fase de pressão pela temperatura, onde é visto a linha de máximo de densidade (TMD). Essa linha tem início em $T=0$ e $P=P_{c}$, ponto onde ocorre a transição entre os dois fluidos, HDL-LDL, marcada com um triângulo.

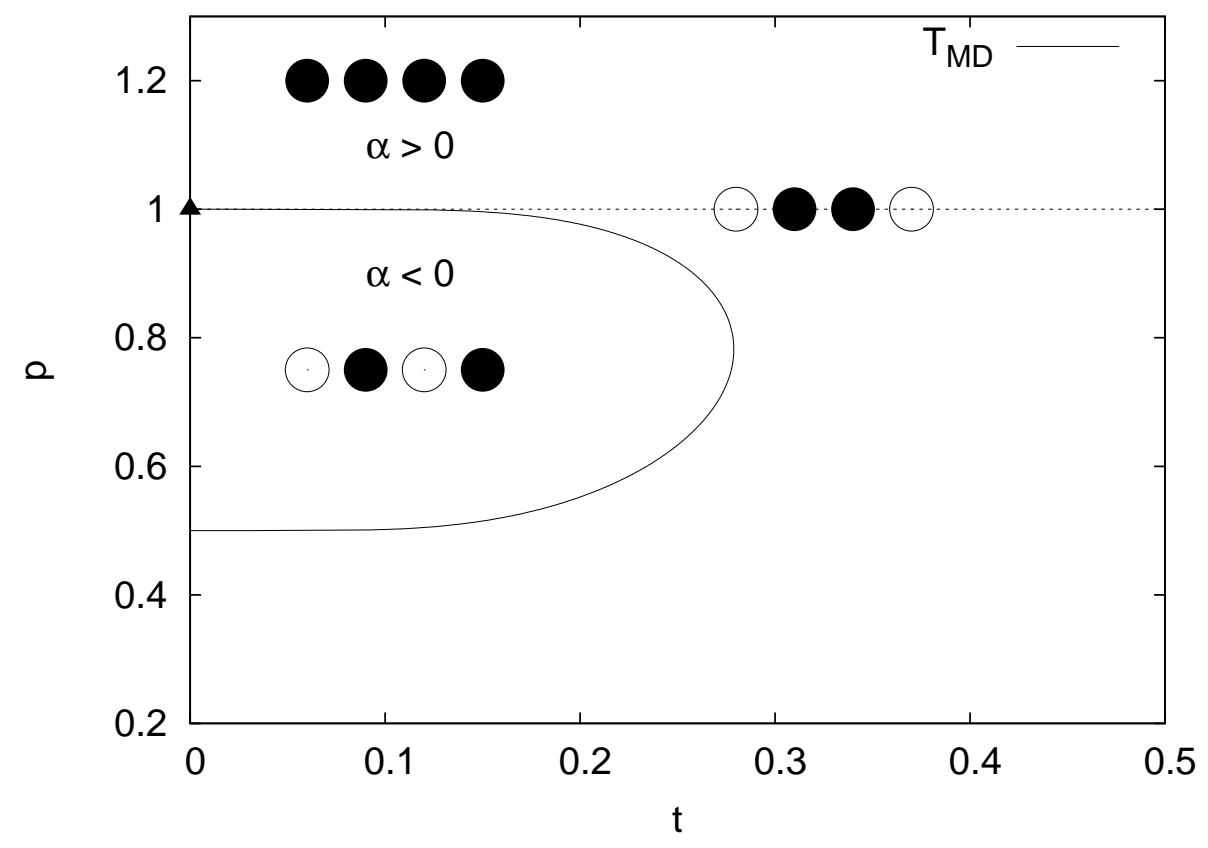

Figura 4.15: Temperatura de máximo de densidade TMD

Seguindo a referência [71, vamos relacionar as anomalias termodinâmicas da água à competição entre duas estruturas local, uma de baixa densidade LDL(segundos vizinhos) e outra de alta densidade(primeiros vizinhos) HDL. No ensemble de Gibbs as configurações são determinadas pela minimização do potencial de Gibbs (2.8). Na figura 4.16 é mostrado $G$ em função da distância entre as moléculas $l$, em uma dimensão e $T=0$, para dois valores de $P$, um valor acima e outro abaixo da pressão crítica. Note que assumimos que o sistema (no limite termodinâmico) será caracterizado pela repetição de uma célula unitária contendo uma única molécula posicionada no mesmo sítio. No equilíbrio a distância $l(P)$ é determinada pelo mínimo absoluto de $G$, quando 
a pressão está abaixo da pressão crítica, $P<P_{c}$, esse mínimo é localizado no segundo vizinho $l=2$ e para $P>P_{c}$ o mínimo se encontra no primeiro vizinho $l=1$.

Na figura 4.15 podemos notar também, as regiões onde o coeficiente de expansão térmica é positivo ou negativo, sendo separados por uma linha onde temos $\alpha=0$. Essa linha começa exatamente no ponto $\left(T=0, P=P_{c}\right)$ que é, também o inicio da linha TMD e marca a transição HDL-LDL.

A região onde temos $\alpha<0$, cercada pela linha TMD, é a região onde o modelo apresenta a anomalia na densidade. Fora dessa linha, onde $\alpha>0$, o comportamento da densidade do fluido é normal.

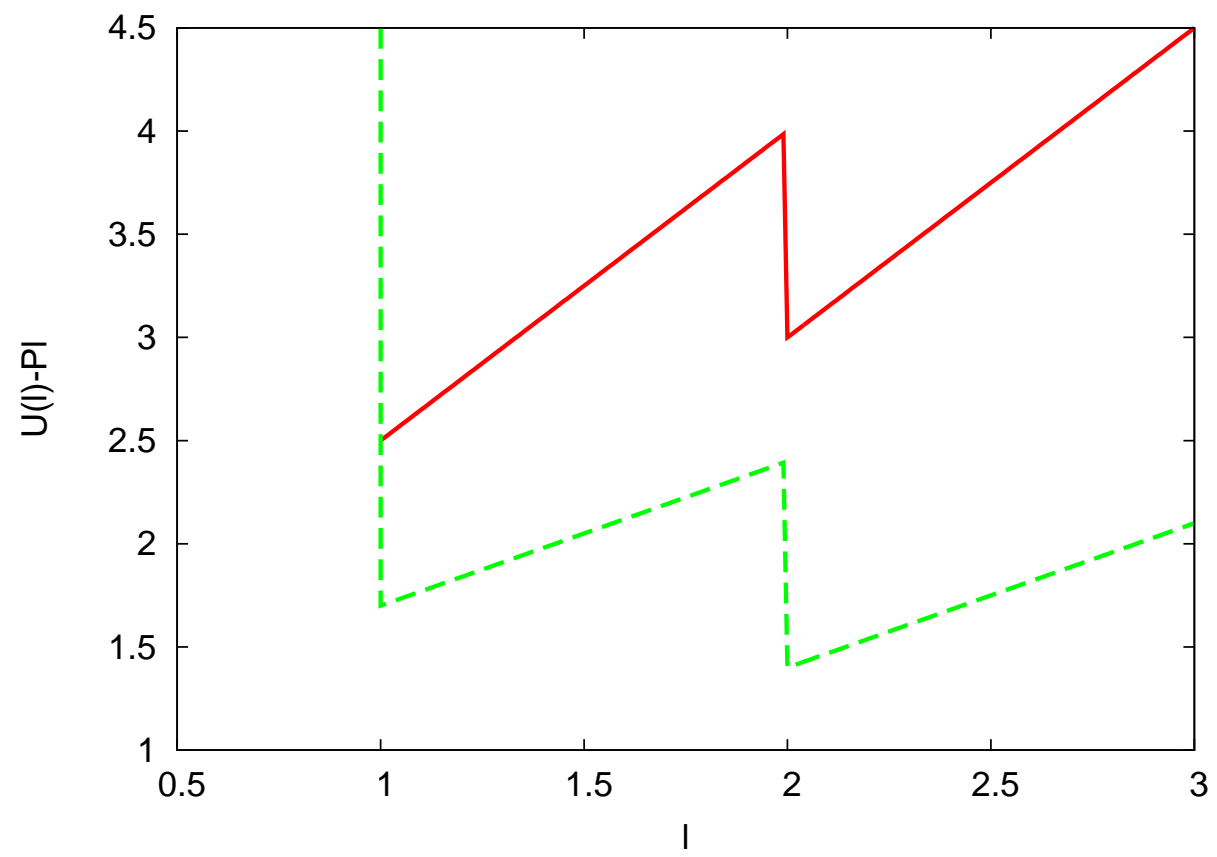

Figura 4.16: Potencial de Gibs em uma dimensão em função da distância entre as moléculas da rede com $\mathrm{T}=0$, com potencial de interação discreto dado por 4.21$)$. ( $\mathrm{P}=1.5$ Linha cheia , $\mathrm{P}=0.7$ linha tracejada)

\subsubsection{Dinâmica}

Nesta seção estudamos a dinâmica do nosso modelo e descrevemos o procedimento adotado para a obtenção dos dados, apresentando os resultados das simulações. As simulações computacionais nos permitem fazer uma conexão entre as propriedades macroscópicas e microscópicas do sistema e podem servir para calcular quantidades de sistemas físicos em regiões onde a obtenção experimental se torna muito complicada, como no caso da água super resfriada abaixo da temperatura de nucleação espontânea, onde o tempo de vida do líquido metastável vai a zero. 
Utilizando o Método de Monte Carlo, maiores detalhes no apêndice A, obtemos a parte da dinâmica do nosso modelo. Todas as simulações foram feitas no ensemble canônico, mantendo numero de partículas (N), volume (V) e temperatura (T) fixos. Iniciamos a simulação com uma configuração inicial gerada aleatoriamente distribuindose $\mathrm{N}$ partículas nos $\mathrm{V}$ sítios da rede, em nosso trabalho a rede é composta por $\mathrm{V}=1000$ sítios e condições de contorno periódicas.

Após a montagem da configuração inicial obtemos a cinética das partículas do fluido realizando os seguintes passos: uma partícula é escolhida aleatoriamente e em seguida ela realiza um salto que pode ser de um ou dois sítios à direita ou à esquerda em relação à posição atualmente ocupada. Assim como no modelo anterior quando o salto for de dois sítios a partícula ignora o sítio intermediário, que pode estar ocupado ou vazio, condição aplicada para que pudéssemos obter a difusão, visto que, para uma rede unidimensional as partículas ficariam sempre na mesma ordem inicialmente arranjadas se não houvesse a possibilidade de saltos através de outra partícula.

Atribuímos a um vetor $\vec{X}(0)$ a posição de cada uma das partículas. Em seguida escolhemos aleatoriamente uma delas para realizar um salto, então olhamos para posição para qual a partícula irá ser deslocada, caso esse sítio esteja ocupado ela não pode realizar o salto permanecendo na posição que ocupava originalmente, em seguida escolhemos outra partícula e testamos novamente a possibilidade de que seja realizado o salto. Quando uma partícula salta para um sítio vazio, usamos o algorítimo de Metropolis para testarmos se a nova configuração é aceita. Ao repetirmos esse procedimento N vezes obtemos um passo de Monte Carlo (PMC) [66] e ao final de cada PMC calculamos o deslocamento médio das partículas.

Quando é atingido um tempo de equilíbrio $\tau_{e q}$ estipulado inicialmente, passamos a calcular o deslocamento quadrado médio, que é salvo em um arquivo a cada $10^{3}$ PMC. Terminada a simulação, obtemos a constante de difusão interpolando a relação de Einstein, dado por:

$$
D(t, \rho)=\left\langle\frac{1}{2 N \tau} \sum_{j=1}^{N}\left[X_{j}(\tau)-X_{j}(0)\right]^{2}\right\rangle .
$$

onde t é a temperatura reduzida, $\rho$ é a densidade, $\mathrm{N}$ é o número de partículas e $\tau$ é o tempo de simulação.

Com o intuito de descobrir se nosso modelo apresentava também anomalia na difusão $D$, analisamos o comportamento da variação de $D$ em função da densidade $\rho$, com temperatura fixa. Para cada temperatura realizamos cinco simulações, partindo de configurações iniciais diferentes, sobre as quais tomamos a média. Com isso obtemos a média expressa na equação 4.49. Foram obtidos dados para temperaturas reduzidas 

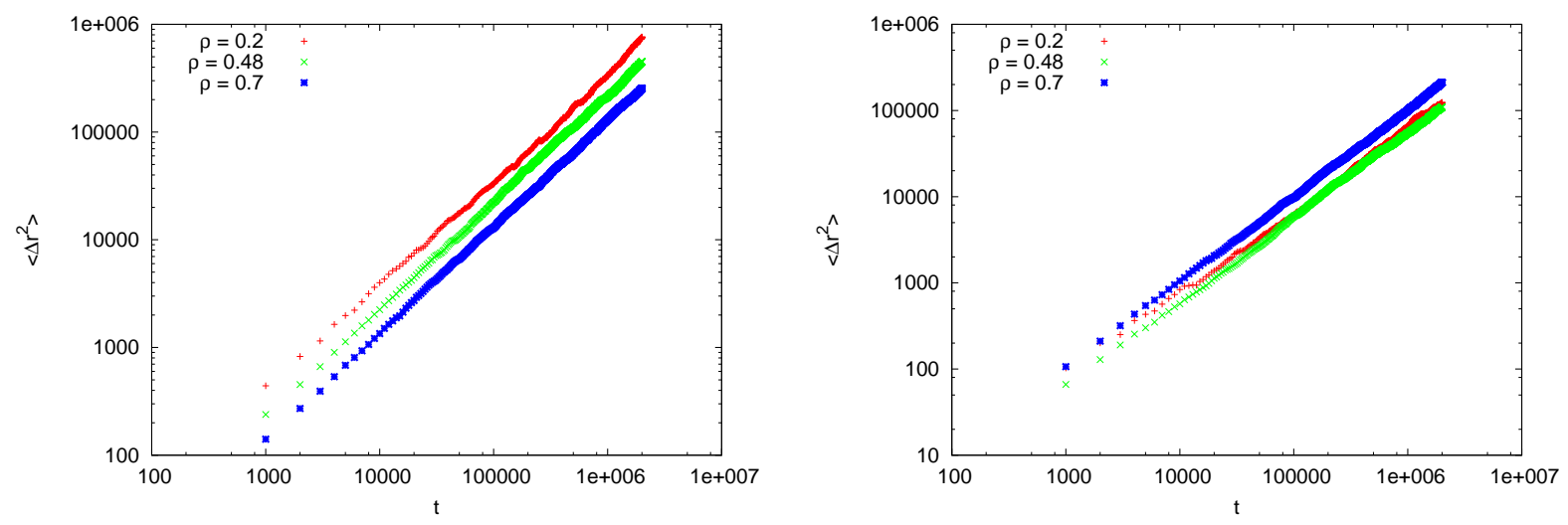

Figura 4.17: Deslocamento quadrado médio em função do tempo (passos de monte carlo) na escala logarítmica. Do lado direito a temperatura é igual 0.3 , do lado esquerdo a temperatura é igual a 0.8

entre 0.2 a 0.7 e densidades reduzidas de 0.15 até 0.85 . Em todos os casos o tempo para cada simulação, dado em passos de Monte Carlo, foi de $10^{6}$ PMC.

Na figura 4.17 apresentamos dois gráficos do deslocamento quadrado médio em função do tempo com a temperatura fixa. No lado esquerdo exibimos os valores para $T=0.8$. Nessa temperatura, que pode ser considerada elevada, observamos uma maior mobilidade das partículas quando reduzimos a densidade. Assim, o coeficiente de difusão, que é calculado usando a equação (4.49), onde $<\Delta r^{2}>$ é obtido via simulação, é reduzido com o aumento da densidade, como pode ser visto da figura 4.18. Esse é o comportamento esperado para fluidos simples. Para $T=0.3$ (figura 4.17 lado direito) podemos observar um comportamento diferente do deslocamento quadrado com a densidade. Para $\rho=0.7$ a mobilidade é maior que para $\rho=0.2$, indicando um aumento peculiar da difusão quando aumentamos a densidade.

Na figura 4.18 mostramos um gráfico da difusão em função da densidade para diversas temperaturas. Podemos ver que para temperaturas acima de 0.55 a difusão apresenta um comportamento esperado para líquidos normais, decrescendo quando há um aumento da densidade. Para $\mathrm{T}<0.46$ observamos uma região onde ocorre um máximo e um mínimo para difusão, caracterizando um comportamento anômalo, como apresentado em outros modelos de fluidos com propriedades similares à água [5, 19,72].

Essa anomalia na difusão, assim como a anomalia na densidade, pode ser explicada através da quebra de ligações de hidrogênio, causada pelo aumento de pressão. Como as ligações de hidrogênio apresentam uma interação de maior intensidade entre as partículas, quando elas são destruídas ocorre um aumento da mobilidade molecular, ocasionando então um aumento da difusão. Comportamento anômalo para a densidade e 


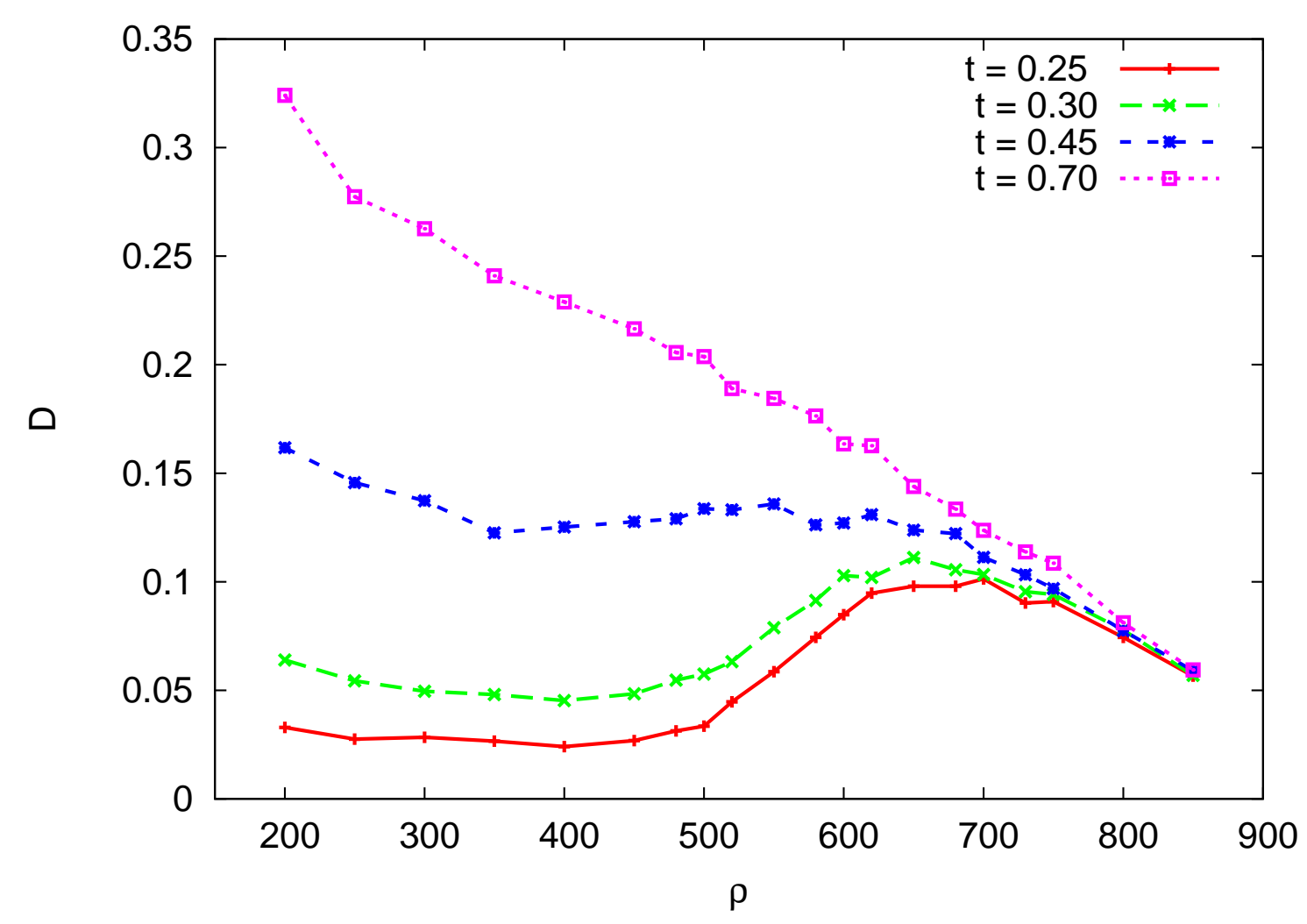

Figura 4.18: Difusão pela densidade, para modelo unidimensional com interação repulsiva entre primeiros vizinhos

difusão similares aos apresentados com nosso modelo também foi encontrado em um outro modelo com interação puramente repulsiva, proposto por Bertolazzo e Barbosa [73], porem neste caso o modelo proposto é formado por uma rede bidimensional triangular.

Outra interpretação dada por Scala e colaboradores [74], relaciona a difusão com o volume livre por partícula, e o volume livre é definido como:

$$
v_{l}=v-v_{e x}
$$

onde $v_{e x}$ é o volume excluído por partícula, que resulta do potencial de caroço duro. Quando aumentamos a pressão, podemos reduzir ou aumentar o valor de $v$, isso vai depender de qual termo será dominante, $\Delta v_{e x}$ ou $\Delta V$, visto que ambos decrescem com o aumento de $P$. Essa dominância pode ser relacionada a duas estrutura líquidas HDL e LDL e, quando ocorre a transição HDL-LDL ocorre também a troca do termo dominante.

Para investigarmos qual a relação existente entre as anomalias termodinâmica e dinâmica do nosso modelo construímos a figura 4.19, onde comparamos os pontos de máximo e mínimo de difusão com a linha TMD, no diagrama de fases temperatura vs densidade. Os pontos de máximo $D_{\max }$ e mínimo $D_{\min }$ de difusão foram obtidos fazendo 


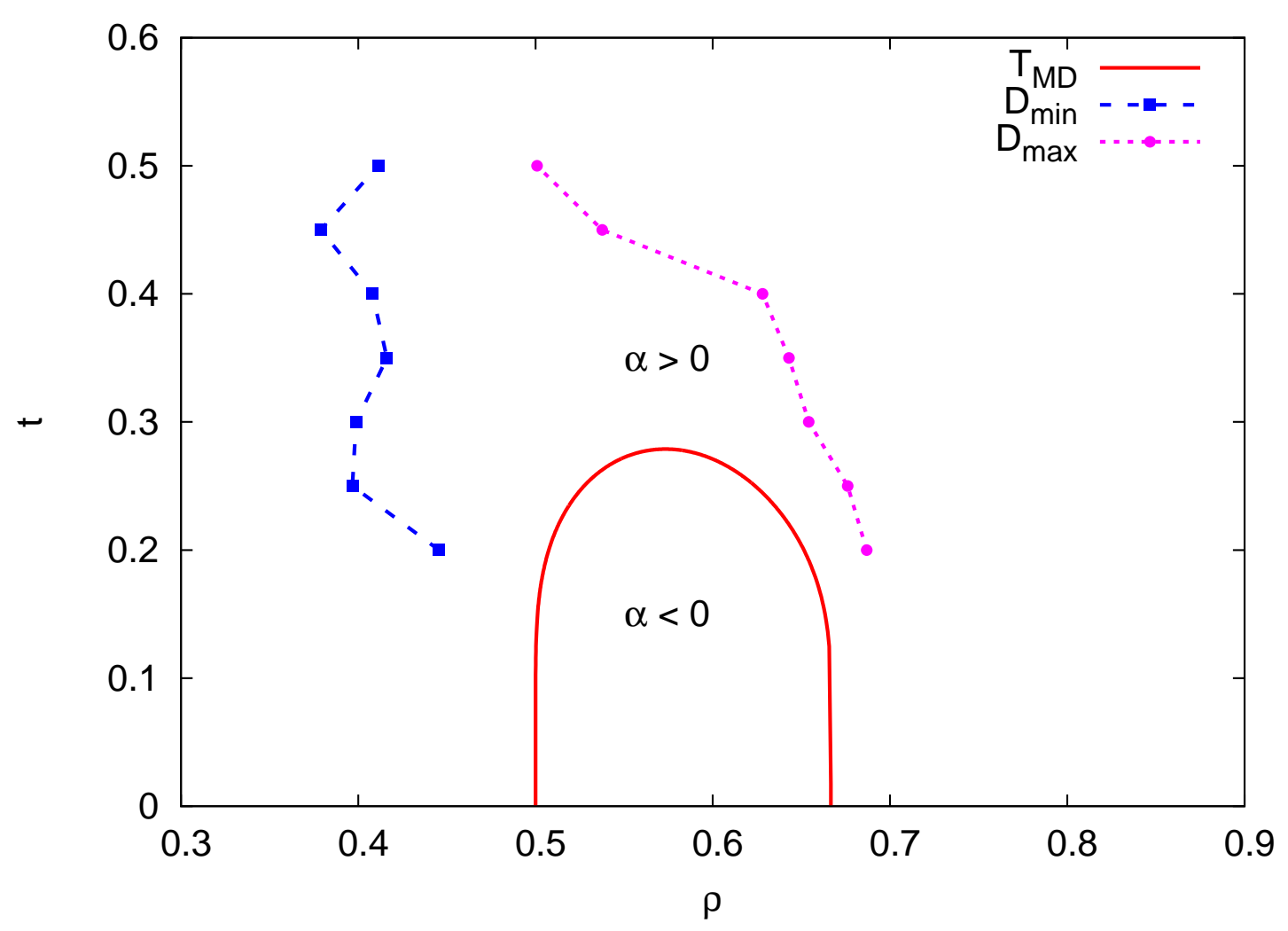

Figura 4.19: Hierarquia de anomalias no diagrama temperatura vs densidade. Máximo (círculos) e mínimo (quadrados) de difusão comparado com a TMD (linha contínua)

um ajuste na região de máximo e mínimo, respectivamente, usando a equação: $D(t, \rho)=a \rho^{4}+b \rho^{3}+c \rho^{2}+d \rho+e$, onde $a, b, c, d$ e $e$ são parâmetros de ajuste da curva, então, derivando esta equação obtemos os pontos $D_{\text {mim }}$ e $D_{\text {max }}$, que delimitam a região com anomalia na difusão.

A área cercada pela linha TMD é onde ocorrem a anomalia termodinâmica na densidade, que também é caracterizada por apresentar um coeficiente de expansão térmica negativo, $\alpha<0$. Ao longo da TMD $\alpha$ se anula, passando a ter um valor positivo, $\alpha>0$, fora da região envolvida pela TMD.

Podemos ver na fig. 4.19 que região onde ocorre a anomalia na difusão, entre $D_{\max }$ e mínimo $D_{\min }$, cerca externamente a região de anomalia na densidade, linha TMD.

Nosso modelo apresenta a região de anomalias dinâmicas envolvendo a região de anomalias termodinâmica, um fenômeno usualmente conhecido como hierarquia de anomalias. Tal hierarquia foi encontrada também em outros modelos de água com detalhes atômicos, discutidos na introdução, os quais apresentaram a mesma orden encontrada nesse modelo para as anomalias. Contudo, modelos de rede bidimensional apresentaram uma inversão nesse comportamento, sendo que a TMD envolvia a região de anomalia na 
difusão 16, 18. Além disso em nosso modelo anterior [61](anexo I) não observamos uma hierarquia de anomalias bem definida, pois naquele caso, a linha de extremos de difusão cruza a TMD entrando na região de anomalia na densidade,(seção 3.1).

Comparando o modelo aqui estudado com os outros apresentados nessa dissertação podemos concluir que a hierarquia de anomalias depende da forma do potencial de interação entre as partículas. Para modelos em rede além da dependência na forma do potencial, também existe uma dependência com a dimensionalidade do sistema.

\subsubsection{Conclusões}

Estudamos, por meio de simulação computacional, as anomalias apresentadas pela água onde procuramos por uma forma de simplificar ao máximo o potencial de interação molecular e, com essa forma de interação, reproduzir o comportamento anômalo da água.

Com isso em mente, propusemos um modelo simplificado de água em rede unidimensional com interação repulsiva entre primeiros vizinhos da rede. Com esse modelo reproduzimos as anomalias dinâmica e termodinâmica presentes na água. Assim como outros modelos 43,54 que utilizam formas de interação mais complexas, nosso modelo apresenta uma transição do tipo líquido-líquido em $\mathrm{T}=0$. Esse resultado está de acordo com a hipótese do segundo ponto crítico [28]. Em razão da simplicidade do modelo, calculamos todas as funções termodinâmicas analiticamente, utilizando a técnica da matriz de transferência. Mostramos o comportamento da densidade, que apresenta um aumento com a temperatura (figura 4.11) assim como acontece na água em temperaturas abaixo de $4{ }^{\circ} \mathrm{C}$ e em outros modelos que simulam o comportamento desse líquido.

Estudamos também, o comportamento da entropia do modelo proposto, que apresentou um comportamento atípico, se comparado com fluidos normais, onde podemos observar, no diagrama $S$ vs $P$ (figura 4.12), uma região onde ocorre um aumento da entropia com a pressão. Tal comportamento foi observado por outros modelos com interação tipo "core-softened" e é conhecido como anomalia na entropia. Termodinamicamente, a anomalia na entropia está relacionada à anomalia na densidade através de uma transformação de Maxwell (seção 2.1).

Para discutirmos a transição de fase entre duas estruturas líquidas, estudamos o comportamento da funções resposta $\alpha_{T}$ e $K_{T}$, notamos que ambas apresentaram uma divergência, tipica de uma transição. Quando tomamos o limite com $T=0$ e $P \rightarrow P_{c}$, observamos que tanto a compressibilidade, quanto o coeficiente de expansão térmica, divergem, indicando a presença de um ponto crítico. Tal ponto é previsto na hipótese do segundo ponto crítico, sendo localizado no final de uma linha de transição entre um 
líquido de baixa densidade e outro de alta densidade em sistemas com a dimensão maior que um.

Finalmente, usando o método de Monte Carlo, obtemos a dinâmica do modelo. Estudamos o comportamento da difusão e notamos que essa propriedade também apresenta um comportamento anômalo, como observado em outros modelos. Diferentemente do modelo investigado no anexo I, o modelo aqui estudado apresentou uma hierarquia de anomalias similar à de água, com a região anômala na difusão encobrindo a região anômala na densidade.

Podemos concluir que apesar do nosso modelo ter somente uma interação repulsiva entre primeiros vizinhos (o que representa uma simplificação dos modelos tipo "core-softened") ele pode ser usado para representar fluidos com características anômalas, com ênfase na água. Com ele conseguimos reproduzir as anomalias nas propriedades termodinâmicas e na dinâmica, que também está presente em outros modelos desenvolvidos para investigar as propriedades anômalas de água. 


\section{Capítulo 5}

\section{CONCLUSÕES}

Nesta tese estudamos dois modelos em rede unidimensional que, apesar da simplicidade, apresentam em suas propriedades termodinâmicas e dinâmicas comportamento tipico de água.

Em nosso primeiro modelo, com duas interações atrativas, pudemos observar o comportamento anômalo da densidade, da compressibilidade isotérmica, do coeficiente de expansão e da difusão. Esta foi a primeira vez que um modelo deste tipo foi usado para investigar a relação entre as anomalias dinâmica e termodinâmicas características da água 61.

Em nosso segundo modelo, com uma interação puramente repulsiva, observamos os mesmos comportamentos anômalos do primeiro, contudo, desta vez com um modelo extremamente simples [68], que permitiu acessar regiões de menores temperaturas.

Ambos os modelos apresentaram uma transição de fase líquido-líquido, caracterizado por uma mistura entre o líquido de baixa densidade (LDL) e de alta densidade(HDL). A principal consequência deste estado misto é uma entropia residual em um único ponto no diagrama de fase pressão vs. temperatura. Usando relações termodinâmicas, argumentou-se que a presença de uma entropia residual em um único ponto é consistente com uma linha de temperatura de máxima densidade, TMD, $(\alpha=0)$ que emana da transição de fase no estado fundamental . Considerando isso, é possível afirmar que as transições de fase do estado fundamental, entropia residual e anomalias de densidade são propriedades termodinâmicas de nosso modelo que estão intrinsecamente relacionadas e não podem ser dissociadas uma da outra. Discussão adicional sobre as transições de fase do estado fundamental em modelos unidimensionais é relevante neste ponto. Em primeiro lugar, as duas transições observadas em nossos modelos podem ser vistas como remanescentes de transições de fase em sistemas com dimensões superiores que se desmoronam para $t \longrightarrow 0$ quando a dimensionalidade é reduzida a $D \longrightarrow 1$. Este 
colapso também é evidente na análise da solução de um gás de rede dentro da rede Bethe: neste caso, enquanto reduz continuamente o número de coordenação a transição de fase líquido-gás encolhe continuamente para $t \longrightarrow 0$ [75,76. Esta é uma questão relevante para sistemas unidimensionais porque as transições de fase no estado fundamental observadas incorporam elementos de transições de fase contínuas e descontínuas, enquanto normalmente uma transição descontínua permite quaisquer misturas entre duas fases coexistentes, quando uma transição contínua é colapsada sobre ele, qualquer mistura, exceto para maximizar a entropia é proibida. Assim, para a transição líquido-líquido a entropia é maximizada para uma distribuição igual de uma mistura aleatória de interações compatíveis entre o HDL e LDL resultando em uma entropia por partícula $s=S / N=K_{b} \ln 2$ (como em um lance de moeda no jogo).

A viabilidade de usar uma aproximação simples de dois estados para descrever com precisão o sistema na vizinhança da transição de fase do estado fundamental é outra questão que merece atenção, uma vez que há uma longa tradição em usar dois modelos de estado para descrever a água líquida $77-79]$. Recentemente, um modelo modificado de solução regular dentro de uma abordagem com dois solventes foi ajustado para dados de simulação computacional do modelo ST2, sendo usados com precisão para dados acima do segundo ponto crítico, em uma região chamada linha de Widom [80]. Isso levanta a possibilidade de conectar a abordagem atual a sistemas mais complexos. No entanto, deve-se enfatizar que o caráter dos dois estados de aproximação empregada aqui é conceitualmente distinta daquelas implementadas em Ref. [80], onde dois estados se referem a dois estados com energias livres distintas. Nessa abordagem a aproximação é no sentido de dois estados que são estados microscópicos localizados com energias e entropias locais bem definidas, que são úteis para truncar a função de partição em algum tipo de expansão. Certamente deve ser interessante para vincular essas diferentes visões, mas isso está fora do escopo do trabalho atual.

Nossos resultados mostram que a região das anomalias termodinâmicas está localizada na vizinhança da transição entre dois fluidos estruturados: um líquido de baixa densidade(LDL) E um líquido de alta densidade(HDL). Nos dois modelos encontramos um comportamento oscilatório no coeficiente de expansão térmica associado à anomalia de densidade e à transição de fase do estado fundamental. Mais recentemente, este efeito mostrou ser geral sendo uma característica de qualquer transição de fase de estado fundamental entre diferentes estruturas de fluidos em modelos unidimensionais com interações restritas ao primeiro vizinho inspiradas por esses modelos, foi possível desenhar um sistema tridimensional esfericamente simétricos com duas transições de fase líquido-líquido, ambos associada à temperatura das linhas de densidade máxima [70].

Por fim concluímos que o comportamento oscilatório do coeficiente de expansão 
térmica $\alpha$, bem como o comportamento anômalo da compressibilidade isotérmica a pressão constante e da capacidade térmica, pode ser explicados em termos de uma entropia residual usando termodinâmica e argumentos estatísticos.

Cabe ressaltar que a simplicidade dos modelos apresentados aqui os torna protótipo ideal para investigações mais detalhadas sobre as inter-relações entre anomalias termodinâmicas e dinâmicas de água. 


\section{Apêndice A}

\section{Método de Monte Carlo}

O Método de Monte Carlo(MMC) é um método estocástico, que permite a simulação de problemas envolvendo um número muito grande de variáveis aleátorias. Esse método foi batizado por Ulam e Von Neumann [81], durante o Projeto Manhattan na Segunda Guerra Mundial, por ser muito similar a jogos de azar: eles fizeram uma referência à Monte Carlo, distrito de Mônaco, que é famoso por ter grandes cassinos.

O MMC é alimentado por um gerador de números aleatórios (algoritmo matemático que gera um número randomico) e, junto com uma função densidade de probabilidade que caracteriza o processo, fornece uma maneira direta de simular processos físicos sem a necessidade de explicitar todas as equações matemáticas envolvidas para descrever o comportamento do sistema em estudo. Portanto, podemos dizer que o MMC utiliza uma simulação estocástica para escolher os estados que participam na distribuição de probabilidade do sistema.

A probabilidade que caracteriza um sistema físico em equilíbrio é definida de acordo com o ensemble adotado, por exemplo o micro-canônico, canônico ou grandecanônico. Obviamente essa técnica pode ser usada em outros sistemas, não somente sistemas físicos, bastando que as quantidades de interesse sejam ponderadas por uma distribuição de probabilidade bem definida.

Na mecânica estatística,a média de uma determinada grandeza é calculada definindo-se inicialmente o ensemble apropriado para melhor descrever o sistema no estado de equilíbrio. Então, se $f(x)$ for uma função de estado no ensemble canônico sua média será dada por

$$
\langle f(x)\rangle=\frac{\int f(x) e^{-\beta H(x)} d x}{\int e^{-\beta H(x)} d x}
$$

onde o termo $e^{-\beta H x}$, é o peso de Boltzmann. 
O método de Monte Carlo consiste em resolver a integral acima transformando-a em uma soma discreta, o que pode ser feito levando em consideração a probabilidade $P(x)$ de cada estado do sistema. Assim podemos escrever a média de $f(x)$ como

$$
\langle f(x)\rangle=\frac{\sum_{x} f(x) e^{-\beta H(x)}}{Z}
$$

onde

$$
Z=\sum_{x} e^{-\beta H(x)}
$$

é função de partição do sistema.

A probabilidade $P(\mathrm{x})$ do sistema ser encontrado em um estado microscópico $x$ é, portanto,

$$
P(x)=\frac{1}{Z} e^{-\beta H(x)}
$$

Essa expressão, conhecida como distribuição de Boltzmann, estabelece uma relação entre a termodinâmica e a estatística de um sistema termodinâmico em equilíbrio.

Para calcular a média da função $f(x)$ devemos imaginar um certo número $N$ de estados que seja gerado de acordo com a probabilidade $P(\mathrm{x})$. Assim, a média aritmética de $f(x)$,

$$
F_{N}=\frac{1}{N} \sum_{i=1}^{N} f\left(x_{i}\right)
$$

será uma estimativa para o valor da grandeza física em questão. Quanto maior for $N$ melhor será essa estimativa para essa função.

Para encontramos o valor de $f(x)$ no equilíbrio termodinâmico, podemos simular computacionalmente um sistema físico que tenha $\mathrm{N}$ partículas distribuídas em um volume $\mathrm{V}$ com temperatura fixa $\mathrm{T}$ e um conjunto de estados $x$ usando o MMC, que pode ser resumido nos seguintes passos:

1. Distribua aleatoriamente as $\mathrm{N}$ partículas no volume $\mathrm{V}$.

2. Escolha aleatoriamente uma partícula, que pode assumir uma nova posição no sistema.

3. Usando uma taxa de transição definida testar se o novo estado é aceito.

4. Repetir os passos 2 e $3 \mathrm{~N}$ vezes, isso corresponde a 1 passo de Monte Carlo (PMC). No fim de cada passo calcular a quantidade física desejada. 
5. Depois de um numero de PMC t escolhido inicialmente, essa escolha deve ser suficientemente grande para o sistema entre em equilíbrio termodinâmico, obtemos todos os dados de interesse físico.

Em seguida apresentamos o algoritmo de Metropolis, o qual usamos para definir a taxa transição do nosso modelo.

\section{A.1 Algoritmo de Metropolis}

O algoritmo de Metropolis é um dos métodos muito utilizado dentro do Método de Monte Carlo. Ele define como o sistema evolui no tempo através das mudanças de energia causadas por uma nova configuração que define um novo estado, e assim definindo se o estado permanece inalterado ou passa para o novo (passo 3 do esquema de monte carlo apresentado acima). Para realizar esse procedimento, o algoritmo de Metropolis gera variáveis aleatórias seguindo uma taxa de transição $W\left(x_{i} \rightarrow x_{j}\right)$, que segue um processo de Markov [82]. A probabilidade de mudança de estado pode ser definida escolhendo-se uma variável para de distribuição $P(\mathrm{x})$, que no caso é a distribuição de Boltzmann, dada em A.4. Além disso, temos que garantir que o processo para gerar números aleatórios seja descorrelacionado, ou seja, que as variáveis aleatórias geradas não tenha memória. Essa condição é satisfeita desde que

$$
P\left(x_{i}\right) W\left(x_{i} \rightarrow x_{j}\right)=P\left(x_{j}\right) W\left(x_{j} \rightarrow x_{i}\right) .
$$

Essa condição é conhecida como balanceamento detalhado, a taxa de transição $W\left(x_{i} \rightarrow x_{j}\right)$ é pode ser definida da seguinte forma: se a variação de energia $\Delta E=$ $E\left(x_{j}\right)-E\left(x_{i}\right)$ for menor que 0 , o novo estado é aceito automaticamente, é a energia da nova configuração e é a energia da configuração antiga. Caso contrário para que o novo estado seja aceito faz-se o seguinte, sorteamos aleatoriamente um numero entre 0 e 1, caso esse numero seja menor que, conhecido como peso de Boltzmann, a nova configuração é aceita, se não o sistema volta para configuração original. Esta taxa de transição garante que uma cadeia de Markov irá gerar um distribuição de probabilidades única, para tempos suficientemente longos, que corresponde à condição de equilíbrio estacionária.

Podemos dizer que o Algoritmo de Metropolis leva o sistema para um estado de menor energia livre, permitindo que os estados mais prováveis tenham maior chance de ocorrer. O funcionamento do algoritmo de Metropolis pode ser representado no seguinte esquema: 
1. Dada uma nova configuração do sistema(passo 2 do equema de Monte Carlo), calcular a variação de energia. $\Delta E=E\left(x_{j}\right)-E\left(x_{i}\right)$

2. Se $\Delta E<0$, então a nova configuração é aceita automaticamente.

3. Se $\Delta E>0$, sorteia-se um número $A$ aleatoriamente no intervalo [0,1], caso seja $A<$ $e^{-\beta \Delta E}$, o sistema permace na nova configuração, caso contrario o sistema retorna a configuração anterior.

Esse esquema para o algoritmo de Metropolis é substituído no passo 3 no esquema de Monte Carlo. Para mais detalhes sobre o MMC e o Algoritmo de Metropolis, é recomendado a leitura de livros textos na área de simulação computacional. 


\section{Referências Bibliográficas}

[1] Chaplin, M. (http://www.lsbu.ac.uk/water/phase.html). [Online; acessado em 20 de janeiro de 2013].

[2] (http://ntevaiaescolaestadualazevedofernandes.blogspot.com.br/2008/12/pesquisasobre-ligaes-qumicas-inica-e.html). [Online; acessado em 08 de janeiro de 2013].

[3] Debenedetti, P. G. Journal of Physics: Condensed Matter 15(45), R1669 (2003).

[4] Angell, C. a. The Journal of Chemical Physics 65(8), 3063 (1976).

[5] Errington, J. R. and Debenedetti, P. G. Nature 409(6818), 318-21 January (2001).

[6] Franzese, G. and Stanley, H. E. Journal of Physics: Condensed Matter 14(9), 2201-2209 March (2002).

[7] Peter H. Poole, Francesco Sciortino, U. E. . H. E. S. Nature 360(25), 324-328 (1992).

[8] Jones, D. Nature 409(January), 300-301 (2001).

[9] Yan, Z., Buldyrev, S. V., Kumar, P., Giovambattista, N., Debenedetti, P., and Stanley, H. Physical Review E 76(5), 051201 November (2007).

[10] Clavio, A. S. G. . E. Propriedades Físico-Químicas da Água. Universidade Federal Fluminense Departamento de Biologia Marinha, (2005).

[11] Zhao, H.-X., Kong, X.-J., Li, H., Jin, Y.-C., Long, L.-S., Zeng, X. C., Huang, R.-B., and Zheng, L.-S. Proceedings of the National Academy of Sciences of the United States of America 108(9), 3481-6 March (2011).

[12] Cho, C., Singh, S., and Robinson, G. Physical review letters 76(10), 1651-1654 March (1996).

[13] Vilaseca, P. and Franzese, G. The Journal of chemical physics 133(8), 084507 (2010). 
[14] Netz, P. a., Starr, F. W., Stanley, H. E., and Barbosa, M. C. The Journal of Chemical Physics 115(1), 344 (2001).

[15] Kumar, P., Buldyrev, S., Starr, F., Giovambattista, N., and Stanley, H. Physical Review E 72(5), 051503 November (2005).

[16] Szortyka, M. M., Fiore, C. E., Henriques, V. B., and Barbosa, M. C. The Journal of chemical physics 133(10), 104904 September (2010).

[17] Netz, P. A., Starr, F. W., Barbosa, M. C., and Stanley, H. E. Physica A 314, 470-476 (2002).

[18] Szortyka, M. M. and Barbosa, M. C. Physica A: Statistical Mechanics and its Applications 380, 27-35 July (2007).

[19] Girardi, M., Szortyka, M., and Barbosa, M. C. Physica A: Statistical Mechanics and its Applications 386(2), 692-697 December (2007).

[20] Stanley, H., Kumar, P., Xu, L., Yan, Z., Mazza, M., Buldyrev, S., Chen, S.-H., and Mallamace, F. Physica A: Statistical Mechanics and its Applications 386(2), 729-743 December (2007).

[21] Stanley, H. E. and Teixeira, J. The Journal of Chemical Physics 73(7), 3404 (1980).

[22] Bellissent-Funel, M. C., Bosio, L., Hallbrucker, a., Mayer, E., and Sridi-Dorbez, R. The Journal of Chemical Physics 97(2), 1282 (1992).

[23] Mishima, O. and Stanley, H. E. Nature 396(6709), 329-335 (1998).

[24] Stanley, H. E. Pramana 53(1), 53-83 July (1999).

[25] Rebelo, L. P. N., Debenedetti, P. G., and Sastry, S. The Journal of chemical physics $\mathbf{1 0 9}(2)$, 626-633 (1998).

[26] Salcedo, E., de Oliveira, A. B., Barraz, N. M., Chakravarty, C., and Barbosa, M. C. The Journal of Chemical Physics 135(4), 044517 July (2011).

[27] Bellissent-Funel, M.-C. EPL (Europhysics Letters) 42(2), 161 (1998).

[28] O. Mishima and H. E. Stanley. Nature, 164-168 (1998).

[29] Brovchenko, I., Geiger, A., and Oleinikova, A. The Journal of chemical physics 123(4), 044515 July (2005). 
[30] Jorgensen, W. L., Chandrasekhar, J., Madura, J. D., Impey, R. W., and Klein, M. L. The Journal of Chemical Physics 79(2), 926 (1983).

[31] Berendsen, H. J., Postma, J. v., van Gunsteren, W. F., DiNola, A., and Haak, J. The Journal of chemical physics 81(8), 3684-3690 (1984).

[32] Soper, A. and Ricci, M. Physical Review Letters 84(13), 2881-4 March (2000).

[33] Andersson, J.-O. Calphad 9(no 1), 153-276 July (1987).

[34] Debenedetti, P. G., Raghavan, V., and Borick, S. S. The Journal of Physical Chemistry 95(11), 4540-4551 (1991).

[35] Lu, J., Chakravarty, C., and Molinero, V. The Journal of Chemical Physics 144(23), 234507 (2016).

[36] Tanaka, H. The Journal of Chemical Physics 111(7), 3163 (1999).

[37] Barraz, N. M., Salcedo, E., and Barbosa, M. C. The Journal of chemical physics 131(9), 094504 September (2009).

[38] de Oliveira, A. B., Netz, P. a., Colla, T., and Barbosa, M. C. The Journal of chemical physics 124(8), 084505 February (2006).

[39] Sharma, R., Chakraborty, S. N., and Chakravarty, C. The Journal of chemical physics 125(20), 204501 November (2006).

[40] Agarwal, M. and Chakravarty, C. Physical Review E 79(3), 030202 March (2009).

[41] Sastry, S. and Austen Angell, C. Nature materials 2(11), 739-43 November (2003).

[42] Bell, G. M. Journal of Mathematical Physics 10(9), 1753 (1969).

[43] Ben-Naim, A. The Journal of Chemical Physics 128(2), 024505 January (2008).

[44] Ben-Naim, A. The Journal of chemical physics 128(2), 024506 January (2008).

[45] Sadr-Lahijany, M. R., Scala, a., Buldyrev, S. V., and Stanley, H. E. Physical review. E, Statistical physics, plasmas, fluids, and related interdisciplinary topics $\mathbf{6 0}(6 \mathrm{Pt}$ A), 6714-21 December (1999).

[46] Buldyrev, S., Franzese, G., Giovambattista, N., Malescio, G., Sadr-Lahijany, M., Scala, a., Skibinsky, a., and Stanley, H. Physica A: Statistical Mechanics and its Applications 304(1-2), 23-42 February (2002). 
[47] Yan, Z., Buldyrev, S. V., Kumar, P., Giovambattista, N., Debenedetti, P. G., and Stanley, H. E. Phys. Rev. E 76, 051201 Nov (2007).

[48] Salinas, S. Introdução à física estatística. Edusp, (1997).

[49] Dasgupta, C. and Halperin, B. I. Phys. Rev. Lett. 47, 1556-1560 Nov (1981).

[50] Abkevich, V., Gutin, A., and Shakhnovich, E. Biochemistry 33(33), 10026-10036 (1994).

[51] Vaia, R. and Giannelis, E. Macromolecules 30(25), 7990-7999 (1997).

[52] Baxter, R. J. Physical Review Letters 26(14), 832 (1971).

[53] Andrews, G. E., Baxter, R. J., and Forrester, P. J. Journal of Statistical Physics 35(3-4), 193-266 (1984).

[54] Mahoney, M. W. and Jorgensen, W. L. The Journal of Chemical Physics 112(20), 8910 (2000).

[55] Cho, C. H., Singh, S., and Robinson, G. W. Phys. Rev. Lett. 76, 1651-1654 Mar (1996).

[56] and G., P. C. H. and Stell. (1970).

[57] Stell, G. and Hemmer, P. The Journal of Chemical Physics 56(9), 4274-4286 (1972).

[58] Stillinger, F. H., Head-gordon, T., Laboratories, T. B., and Hill, M. Physical Review E 47(4), 2484-2490 (1993).

[59] Head-Gordon, T. and Stillinger, F. H. The Journal of Chemical Physics 98(4), 3313 (1993).

[60] Debnetletti, P. G., Raghavan, V. S., and Borick, S. S. The Journal of Chemical Physics (1), 4540-4551 (1991).

[61] Barbosa, M. A. a., Barbosa, F. V., and Oliveira, F. A. The Journal of chemical physics 134(2), 024511 January (2011).

[62] Singh, R. S., Biddle, J. W., Debenedetti, P. G., and Anisimov, M. A. The Journal of chemical physics 144(14), 144504 (2016).

[63] Yagasaki, T., Matsumoto, M., and Tanaka, H. Physical Review E 89(2), 020301 (2014). 
[64] Smallenburg, F. and Sciortino, F. Physical review letters 115(1), 015701 (2015).

[65] Debenedetti, P. G. Metastable liquids: concepts and principles. Princeton University Press, (1996).

[66] Chubynsky, M. and Slater, G. Physical Review E 85(1), 016709 January (2012).

[67] Errington, J. R., Truskett, T. M., and Mittal, J. The Journal of chemical physics 125(24), 244502 (2006).

[68] da Silva, F. B. V., Oliveira, F. A., and Barbosa, M. A. A. The Journal of chemical physics 142(14), 144506 (2015).

[69] Roberts, C., Panagiotopoulos, A., and Debenedetti, P. Physical review letters 77(21), 4386-4389 November (1996).

[70] Barbosa, M. A. A., Salcedo, E., and Barbosa, M. C. Physical Review E 87(3), 032303 (2013).

[71] Sadr-Lahijany, M., Scala, A., Buldyrev, S., and Stanley, H. Physical Review Letters 81(22), 4895-4898 November (1998).

[72] Campo, M. G. Papers in Physics 2(December 2009), 1-7 (2010).

[73] Bertolazzo, A. A. and Barbosa, M. C. Physica A: Statistical Mechanics and its Applications 404, 150-157 (2014).

[74] Scala, A., Sadr-lahijany, M. R., Giovambattista, N., Buldyrev, S. V., and Stanley, H. E. Physical Review E 63(October 2000), 1-8 (2001).

[75] Hu, C.-K. and Izmailian, N. S. Physical Review E 58(2), 1644 (1998).

[76] Barbosa, M. A. and Widom, B. The Journal of chemical physics 132(21), 214506 (2010).

[77] Malenkov, G. Journal of Physics: Condensed Matter 21(28), 283101 (2009).

[78] Sánchez, G., Costas, M. E., and Varea, C. The Journal of chemical physics 86(5), 2966-2968 (1987).

[79] Russo, J. and Tanaka, H. Nature communications 5 (2014).

[80] Cuthbertson, M. J. and Poole, P. H. Physical review letters 106(11), 115706 (2011). 
[81] Eckhardt, R. Stan Ulam, John Von Neumann and the Monte Carlo Method. Los Alamos Science Special, (1987).

[82] Landau, D. and Binder, K. A guide to Monte Carlo simulations in statistical physics. Cambridge university press, (2005). 